\title{
European Stroke Organisation (ESO) - European Society for Minimally Invasive Neurological Therapy (ESMINT) Guidelines on Mechanical Thrombectomy in Acute Ischemic Stroke
}

\author{
Guillaume Turc, ${ }^{\bullet 1,2,3,4}$ Pervinder Bhogal, ${ }^{\oplus 5}$ Urs Fischer, $^{6}$ Pooja Khatri, ${ }^{7}$ \\ Kyriakos Lobotesis, ${ }^{8}$ Mikaël Mazighi, ${ }^{3,9,10,11}$ Peter D. Schellinger, ${ }^{12}$ Danilo Toni, ${ }^{13}$ \\ Joost de Vries, ${ }^{14}$ Philip White, ${ }^{15}$ Jens Fiehler ${ }^{16}$
}

- Additional material is published online only. To view please visit the journal online (http://dx.doi.org/10.1136/ neurintsurg-2018-014569).

For numbered affiliations see end of article.

Correspondence to Dr Guillaume Turc, Neurology Department, GHU Paris Psychiatrie et Neurosciences, Sainte-Anne Hospital, Paris, 75014, France; g.turc@ghuparis.fr

Endorsed by Stroke Alliance for Europe (SAFE).

This article is co-published in the European Stroke Journal February 2019

Received 7 November 2018 Revised 5 December 2018 Accepted 5 December 2018

Check for updates

(c) Author(s) (or their employer(s)) 2019. No commercial re-use. See right and permissions. Published by BMJ.

To cite: Turc $G$, Bhogal $P$ Fischer $U$, et al.

J Neurolntervent Surg Epub ahead of print: [please include Day Month Year]. doi:10.1136/

neurintsurg-2018-014569

\begin{abstract}
Background Mechanical thrombectomy (MT) has become the cornerstone of acute ischemic stroke management in patients with large vessel occlusion (LVO).
\end{abstract}

Objective To assist physicians in their clinical decisions with regard toMT.

Methods These guidelines were developed based on the standard operating procedure of the European Stroke Organisation and followed the Grading of Recommendations, Assessment, Development, and Evaluation (GRADE) approach. An interdisciplinary working group identified 15 relevant questions, performed systematic reviews and meta-analyses of the literature, assessed the quality of the available evidence, and wrote evidence-based recommendations. Expert opinion was provided if not enough evidence was available to provide recommendations based on the GRADE approach.

Results We found high-quality evidence to recommend MT plus best medical management (BMM, including intravenous thrombolysis whenever indicated) to improve functional outcome in patients with LVO-related acute ischemic stroke within 6 hours after symptom onset. We found moderate quality of evidence to recommend MT plus BMM in the 6-24h time window in patients meeting the eligibility criteria of published randomized trials. These guidelinesdetails aspects of prehospital management, patient selection based on clinical and imaging characteristics, and treatment modalities. Conclusions MT is the standard of care in patients with LVO-related acute stroke. Appropriate patient selection and timely reperfusion are crucial. Further randomized trials are needed to inform clinical decisionmaking with regard tothe mothership and drip-and-ship approaches, anesthaesia modalities during MT, and to determine whether MT is beneficial in patients with low stroke severity or large infarct volume.

\section{INTRODUCTION}

Mechanical thrombectomy (MT) in addition to best medical management (BMM) has become the standard of care for patients with acute ischemic stroke with large vessel occlusion (LVO) since the publication in 2015 of five pivotal trials using modern endovascular devices. ${ }^{1-5}$ Those trials demonstrated major benefits for patients randomized to MT plus
$\mathrm{BMM}$ versus $\mathrm{BMM}$ alone, with numbers needed to treat of 3 and 5 to achieve any better functional outcome and functional independence, respectively. ${ }^{6}$ Major scientific advances have been made since the publication of the 2014/2015 consensus statement by the ESO-Karolinska Stroke Update and the 2016 European Recommendations on Organisation of Interventional Care in Acute Stroke (EROICAS), ${ }^{78}$ notably in the treatment of patients in late time windows. ${ }^{9}{ }^{10}$ The European Stroke Organisation (ESO) and the European Society for Minimally Invasive Neurological Therapy (ESMINT) decided to update those recommendations and provide guidelines based on a systematic literature review and on the Grading of Recommendations, Assessment, Development, and Evaluation (GRADE) system. The aim of this guideline is to assist physicians treating patients with acute ischemic stroke in their clinical decisions with regard to MT.

\section{METHODS}

These joint ESO-ESMINT guidelines were initiated by the ESO. A module working group (MWG) was formed, composed of five ESO representatives (GT: co-chair, UF, MM, PDS, DT), five ESMINT representatives (JF: co-chair, $\mathrm{PB}, \mathrm{JdV}, \mathrm{KL}, \mathrm{PW}$ ), and 1 US expert (PK). The MWG consisted of six neurointerventionalists (five radiologists and one neurologist) and five vascular neurologists. Based on the review of the intellectual and financial disclosures of all MWG members (online supplemental table 1 ), the composition of the group was approved by the ESO guidelines board, the ESMINT guidelines committee, and the executive committees of ESO and ESMINT.

These guidelines were prepared following the GRADE methodology and the ESO standard operating procedure. ${ }^{1112}$

The steps undertaken by the working group are summarized below:

1. A list of topics of clinical interest for guidelines users was produced and agreed by all MWG members.

2. A list of relevant outcomes was produced and rated according to GRADE definitions as critical, important, or of limited importance. ${ }^{11} 12$ Functional outcome and survival were the only outcomes rated as of critical importance. As a 
consequence, the 3-month modified Rankin Scale (mRS), which encompasses functional outcome and vital status, was considered to be the most important parameter to be extracted from studies of interest. Functional independence was defined as an mRS score 0-2, while any better functional outcome corresponded to ordinal shift analysis of the mRS. Time to reperfusion, symptomatic intracerebral hemorrhage (sICH), and final infarct volume were considered to be important outcomes.

3. The MWG formulated 15 Population, Intervention, Comparator, Outcome (PICO) questions, which were reviewed and subsequently approved by the ESO guidelines board, the ESMINT guidelines committee, and the executive committees of ESO and ESMINT.

4. For each PICO question, a systematic review of three major bibliographic databases (PubMed, EMBASE, and the Cochrane Library) was conducted with the help of the ESO guidelines methodologist, Avtar Lal (AL). AL, GT, and JF agreed on the search terms for each PICO question (online supplementary appendix). The literature search was conducted from the inception of each database to February 2018 and subsequently updated with the results of the DAWN and DEFUSE-3 trials.

5. Two authors (GT and JF) independently screened the titles and abstracts of the publications identified by the electronic search and assessed the full text of potentially relevant studies. Only those studies in which modern thrombectomy devices were predominantly used (stent retrievers or contact aspiration devices) were considered to be eligible.

6. For each PICO question, a PICO group consisting of three MWG members was formed. The members of each PICO group confirmed that, to the best of their knowledge, no randomized trial or systematic review had been omitted in the systematic literature search. Whenever no randomized trial or systematic review was identified, the PICO group confirmed that no key observational study was omitted in the literature search.

7. The risk of selection, performance, detection, attrition, and reporting biases in each randomized trial was assessed using the Cochrane Collaboration's tool. ${ }^{13}$

8. Random-effects meta-analyses of the impact of therapeutic interventions on functional independence, defined as 3 -month mRS score $\leq 2$, were conducted using Stata software version 11.0 (Statacorp). Results were summarized as odds ratios (ORs), risk ratios (RRs), and their 95\% confidence intervals (CIs). Heterogeneity across studies was assessed using Cochran's Q (reported as a p value) and $\mathrm{I}^{2}$ statistics. Heterogeneity was classified as moderate $\left(\mathrm{I}^{2} \geq 30 \%\right)$, substantial $\left(\mathrm{I}^{2} \geq 50 \%\right)$, or considerable $\left(\mathrm{I}^{2} \geq 75 \%\right) .{ }^{14}$ Publication bias was assessed with the help of funnel plots.

9. The results of data analysis were imported into the GRADEpro Guideline Development Tool (McMaster University, 2015; developed by Evidence Prime, Inc). For each PICO question and each outcome, the quality of evidence was rated as high, moderate, low, or very low based on the type of available evidence (randomized or observational studies) and considerations of inconsistency of results, indirectness of evidence, imprecision of results, and risk of bias. ${ }^{12}$ GRADE evidence profiles/summary of findings tables were generated using GRADEPro.

10. Each PICO group addressed their respective PICO question by writing up to three distinct paragraphs. First, a paragraph named 'Analysis of current evidence and evidence-based recommendation', in which the results of the dedicated randomized trials were summarized and briefly discussed. Whenever no randomized trial was available, this paragraph described results of systematic reviews of non-randomized trials. At the end of the first paragraph, an evidence-based recommendation was provided, based on the GRADE methodology. The direction, the strength, and the formulation of the recommendation were determined according to the GRADE evidence profiles and the ESO standard operating procedure. Second, an 'Additional information' paragraph could be added to provide more details on randomized trials mentioned in the first paragraph, to summarize results of observational studies, or to provide information on ongoing or future trials. Third, according to the first addendum to the ESO standard operating procedure, an 'Expert opinion' paragraph was added whenever the PICO group considered that insufficient evidence was available to provide evidencebased recommendations for situations in which practical guidance is needed for the everyday clinical practice. In that particular case, a pragmatic suggestion was provided, with the results of the votes of all $11 \mathrm{MWG}$ members on this proposal. Importantly, the suggestions provided in this paragraph should not be mistaken as evidence-based recommendations. They reflect only the opinion of the MWG.

11. The guideline document was subsequently reviewed several times by all MWGs and modified until a consensus was reached according to the Delphi method.

12. Finally, the guideline document was reviewed and approved by six external reviewers, the ESO Guidelines board, the ESMINT Guidelines committee, and the ESO and ESMINT executive committees.

\section{PICO 1: FOR ADULTS WITH LARGE VESSEL OCCLUSION- RELATED ACUTE ISCHEMIC STROKE WITHIN 6 HOURS OF SYMPTOM ONSET, DOES MECHANICAL THROMBECTOMY PLUS BEST MEDICAL MANAGEMENT COMPARED WITH BEST MEDICAL MANAGEMENT ALONE IMPROVE FUNCTIONAL OUTCOME?}

Analysis of current evidence and evidence-based recommendation

A total of nine randomized controlled trials (RCTs) of MT were included in the analysis: MR CLEAN, ${ }^{1}$ EXTEND IA, ${ }^{2}$ ESCAPE, ${ }^{3}$ SWIFT PRIME, ${ }^{4}$ REVASCAT,${ }^{5}$ THRACE, ${ }^{15}$ THERAPY, ${ }^{16}$ PISTE, ${ }^{17}$ and EASI. ${ }^{18}$ All these trials recruited patients with acute stroke and proven LVO (internal carotid artery, M1, M2) with or without tandem stenosis/occlusion within a 6-hour time window from stroke onset, and two of these trials up to $8^{5}$ and 12 hours, ${ }^{3}$ respectively. Patients were randomized to $\mathrm{MT}$ plus BMM versus BMM alone including, whenever indicated, intravenous thrombolysis (IVT) in both arms. We intentionally excluded three previous trials which used older thrombectomy devices. ${ }^{19-21}$ In all trials, there was no blinding of patient or staff for the treatment arm. However, the primary endpoint ( $\mathrm{mRS}$ score at 90 days) was assessed in a blinded fashion in all trials except THRACE and EASI (figure 1). Other risk of bias for the EASI trial included the enrollment of patients without proven occlusion, the fact that 10/40 patients randomized to MT did not receive MT and that $8 \%$ of patients from BMM crossed over to MT. A total of 1906 patients (951 MT plus BMM versus 955 BMM alone) were entered into the meta-analysis, which showed a statistically significant difference in rates of functional independence $(\mathrm{mRS}$ score $\leq 2)$ at day 90 in favor of MT plus BMM (453/951; 


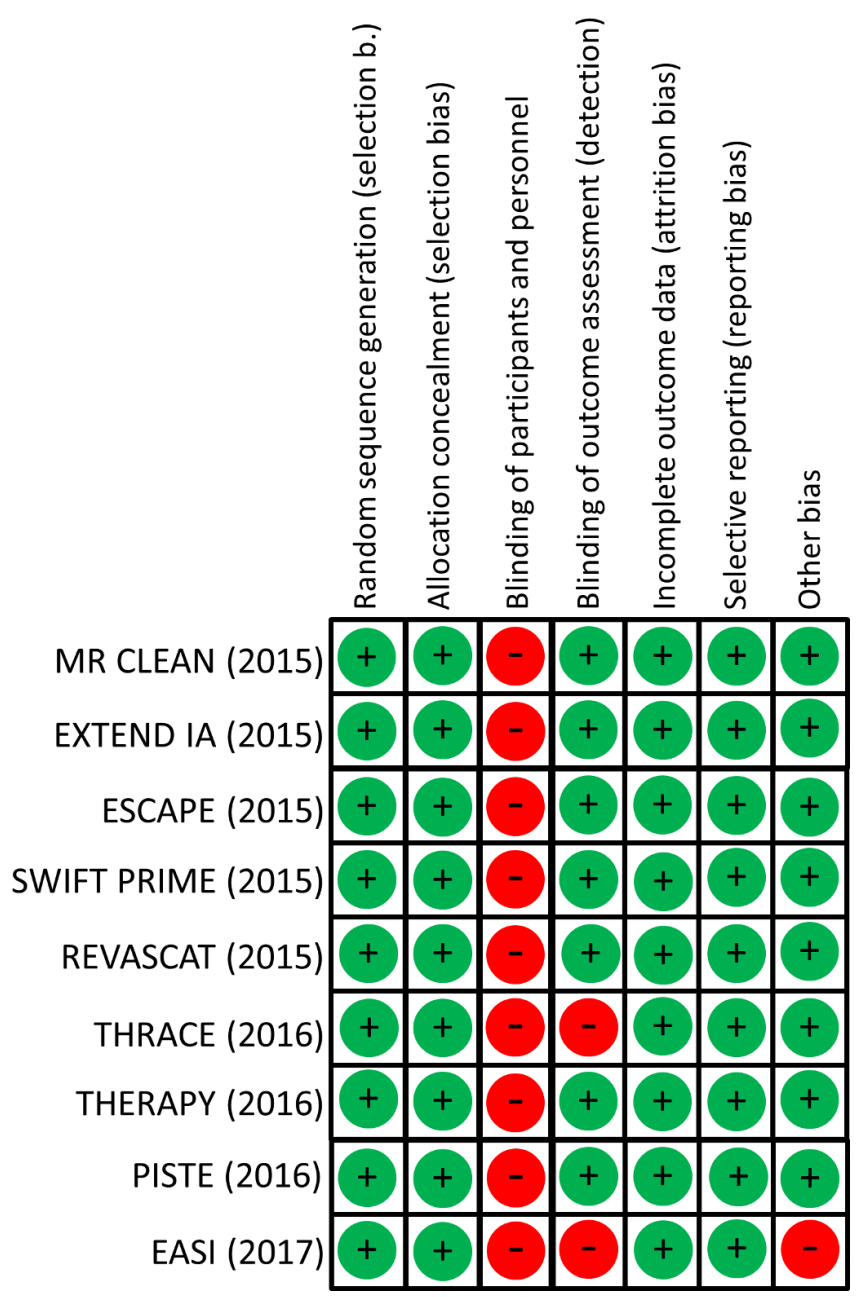

Figure 1 Risk of bias in each trial.

47.6\%) versus BMM alone (295/955; 30.9\%): $\mathrm{OR}=2.03$ (95\% CI 1.68 to $2.46, \mathrm{p}<0.0001 ; \mathrm{I}^{2}=0 \%$; figure 2 ); $\mathrm{RR}=1.50$ (95\% CI 1.34 to $1.68, \mathrm{p}<0.0001 ; \mathrm{I}^{2}=0 \%$; figure 3 ).

The absolute effect was 154 additional independent patients for 1000 patients treated (95\% CI 105 to 210). There was no sign of statistical heterogeneity across trials. The overall quality of evidence was rated as high with no serious risk of bias, inconsistency, indirectness, or imprecision (table 1).

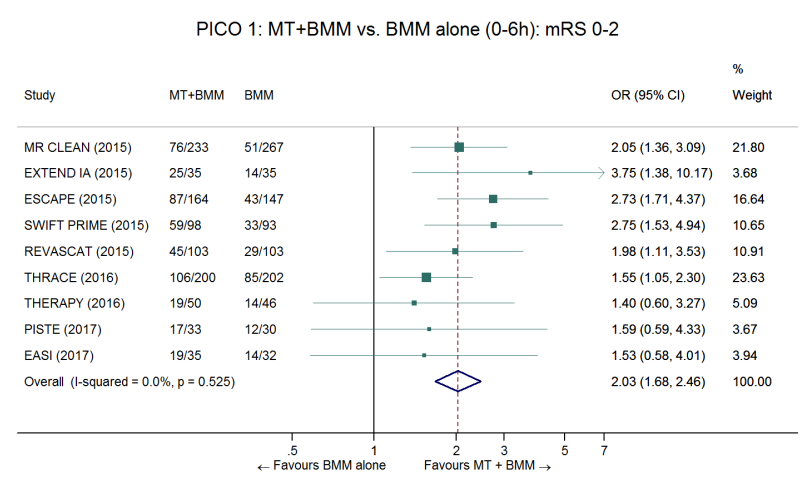

Figure 2 Pooled OR for functional independence in patients treated with $\mathrm{MT}+\mathrm{BMM}$ versus BMM alone in the $0-6$ hour time window. Random-effects meta-analysis. BMM, best medical management; MT, mechanical thrombectomy.

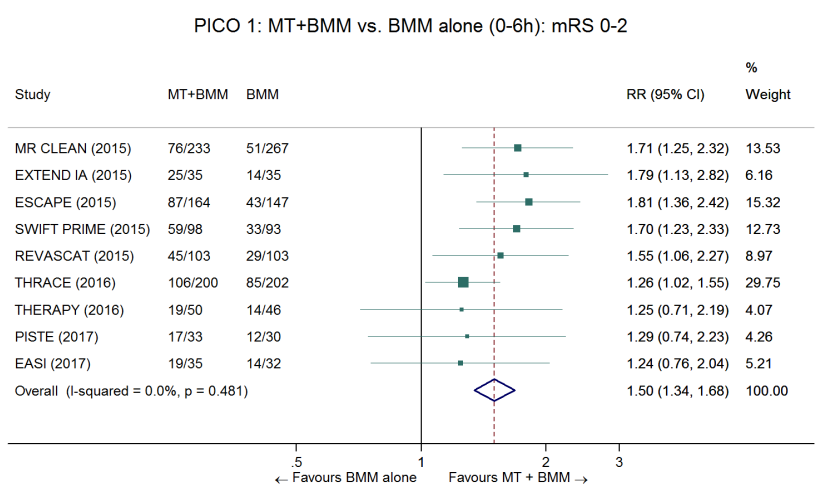

Figure 3 Pooled risk ratio for functional independence in patients treated with $\mathrm{MT}+\mathrm{BMM}$ versus BMM alone in the $0-6$ hour time window. Random-effects meta-analysis. BMM, best medical management; MT, mechanical thrombectomy.

\section{Recommendation}

In adults with anterior circulation large vessel occlusion-related acute ischemic stroke presenting within 6 hours after symptom onset, we recommend mechanical thrombectomy plus best medical management-including intravenous thrombolysis whenever indicated-over best medical management alone to improve functional outcome.

Quality of evidence: High $\oplus \oplus \oplus \bigoplus$; strength of recommendation: Strong $\uparrow \uparrow$

\section{Additional information}

From EASI, only the anterior circulation strokes were included in the analysis. For THRACE, the four patients with basilar artery occlusion could not be extracted from the meta-analysis. For PISTE the denominator was changed from 32 to 30 patients in the BMM only group because of missing mRS scores at day 90.

The primary results of the randomized Basilar Artery Occlusion Chinese Endovascular Trial (BEST, NCT02737189) have been presented at the World Stroke Congress 2018, suggesting that patients treated with MT plus BMM achieved significantly better outcomes than patients treated with BMM alone. However, these results have not yet been published.

The present analysis does not differentiate patients pretreated with IVT $(85 \%$ according to the HERMES collaboration individual patient data meta-analysis of the first five trials ${ }^{6}$ ) versus primary MT $(8.4 \%$ of the whole population in the HERMES collaboration), and trials with additional imaging selection criteria and narrower versus broader imaging inclusion criteria. Those topics will be considered further with PICO questions 3, 8 , and 9 .

It is worth mentioning that many of the included RCTs closed to recruitment early and in some instances before a prespecified sample size was reached. Such premature trial termination will, on average, lead to overestimation of the treatment effect. ${ }^{22}$ Nonetheless, since RCTs showed consistent benefit of MT over BMM alone, and a dose-effect relation (reperfusion rates vs clinical outcome), the benefit of MT is considered established. 


\section{Expert opinion}

A major point of debate is the effect of MT in patients with M2 occlusions. Some trials did (MR CLEAN, ${ }^{1}$ EXTEND IA, ${ }^{2}$ PISTE, ${ }^{17}$ EASI, ${ }^{18}$ THERAPY ${ }^{16}$ ) while others did not (ESCAPE, ${ }^{3}$ SWIFT PRIME, ${ }^{4}$ REVASCAT, 5 THRACE ${ }^{15}$ ) allow recruitment of these patients (table 2). In the HERMES collaboration subgroup analysis, the number of patients with an M2 occlusion was $67 / 818(8 \%)$ in the MT plus BMM and $64 / 828(8 \%)$ in the BMM arms, respectively. ${ }^{6}$ The common adjusted OR for better functional outcome was 1.68 (95\% CI 0.90 to 3.14 ) in this subgroup. This result did not reach statistical significance, but there was no evidence for heterogeneity of treatment effect across occlusion sites ( $\mathrm{p}_{\text {interac. }}$ tion $=0.32) .{ }^{23}$ Of note, MT was significantly associated with functional independence in the subgroup of patients with M2 occlusion (adjusted OR=2.35, 95\% CI 1.07 to 5.14). No patient with M2 occlusion experienced sICH after MT. Despite these results, we believe that data is insufficient to give a specific evidence-based recommendation for or against MT plus BMM in patients with M2 occlusions, especially as some patients probably were misclassified as M1 occlusions and then adjudicated as proximal M2 occlusions. ${ }^{24}$

\section{Expert opinion on mechanical thrombectomy for M2} occlusion

There is a consensus among the guideline group (11/11 votes) that patients with $\mathrm{M} 2$ occlusion fulfilled the inclusion criteria in most randomized trials and therefore mechanical thrombectomy is reasonable in this situation.

For basilar artery stroke there are no published randomized trial results. An international prospective registry of patients with basilar artery occlusion did not suggest the superiority of intra-arterial therapy over intravenous thrombolysis. ${ }^{25}$ However, this study was observational and the intra-arterial therapy group did not correspond only to patients treated with MT, but also to patients treated with intra-arterial thrombolysis or stenting. Furthermore, older-generation MT devices were used in most instances.

Table 2 Number of patients with M2 occlusion in each randomized trial

\begin{tabular}{lcc}
\hline Trial & $\begin{array}{l}\text { M2 occlusions, MT } \\
\text { arm, } \%\end{array}$ & $\begin{array}{l}\text { M2 occlusions, BMM } \\
\text { arm, } \%\end{array}$ \\
\hline MR CLEAN & $18 / 233(7.7)$ & $21 / 266(7.9)$ \\
\hline EXTEND IA & $6 / 35(17.1)$ & $4 / 35(11.4)$ \\
\hline ESCAPE* & $6 / 163(3.7)$ & $3 / 147(2.0)$ \\
\hline SWIFT PRIME* $^{*}$ & $6 / 94(6.4)$ & $13 / 93(14.0)$ \\
REVASCAT $^{*}$ & $10 / 102(9.8)$ & $8 / 101(7.9)$ \\
\hline THRACE* & $2 / 208(1.0)$ & $0 / 204(0)$ \\
\hline PISTE & $5 / 32(15.6)$ & $3 / 33(9.1)$ \\
\hline THERAPY & $6 / 55(10.9)$ & $5 / 53(9.4)$ \\
\hline EASI & $12 / 40(30.0)$ & $6 / 37(16.2)$ \\
\hline TOTAL & $71 / 962(7.4)$ & $63 / 969(6.5)$ \\
\hline
\end{tabular}

${ }^{*} \mathrm{M} 2$ inclusion not allowed.

BMM, best medical management; MT, mechanical thrombectomy. 
We recommend enrollment of patients with basilar artery occlusion into RCTs whenever and wherever possible (Basilar Artery International Cooperation Study trial [BASICS]: NCT01717755, ${ }^{26}$ ). If inclusion in a dedicated RCT is not possible, the decision for or against MT plus BMM vs BMM alone should be based on institutional guidelines, standard operating procedures and individual patient characteristics.

Expert opinion on mechanical thrombectomy for basilar artery occlusion

There is a consensus among the panel (11/11 votes) that in analogy to anterior circulation large vessel occlusion and with regard to the grim natural course of basilar artery occlusions, the therapeutic approach with intravenous thrombolysis plus mechanical thrombectomy should strongly be considered.

Finally, in addition to active trials, future registry data may shed more light on the effect of MT in addition to BMM including IVT.

\section{PICO 2: FOR ADULTS WITH LARGE VESSEL OCCLUSION- RELATED ACUTE ISCHEMIC STROKE 6-24 HOURS FROM TIME LAST KNOWN WELL, DOES MECHANICAL THROMBECTOMY PLUS BEST MEDICAL MANAGEMENT COMPARED WITH BEST MEDICAL MANAGEMENT ALONE IMPROVE FUNCTIONAL OUTCOME? \\ Analysis of current evidence and evidence-based recommendation}

Two RCTs of endovascular therapy recruited highly selected patients from six up to 16 (DEFUSE- $3^{10}: n=182$ ) or 24 hours $\left(\mathrm{DAWN}{ }^{9}: \mathrm{n}=206\right)$ after symptom onset or last seen normal.

\begin{tabular}{|c|c|c|}
\hline Inclusion criteria & DEFUSE- $3^{10}$ & DAWN $^{9}$ \\
\hline Time window & $\begin{array}{l}6-16 \text { hours since time } \\
\text { last known well }\end{array}$ & $\begin{array}{l}6-24 \text { hours since time } \\
\text { last known well }\end{array}$ \\
\hline Age & 18-90years & $\geq 18$ years \\
\hline $\begin{array}{l}\text { mRS score before qualifying } \\
\text { stroke }\end{array}$ & $\begin{array}{l}\leq 2 ; \text { life } \\
\text { expectancy } \geq 6 \text { months }\end{array}$ & $\begin{array}{l}\leq 1 \text {; life } \\
\text { expectancy } \geq 6 \text { months }\end{array}$ \\
\hline NIHSS score & $\geq 6$ & $\geq 10$ (see below) \\
\hline Arterial occlusion & ICA and/or $\mathrm{M} 1$ * & ICA and/or M1 \\
\hline Mismatch definition & $\begin{array}{l}\text { Target mismatch profile } \\
\text { on CT or MR perfusion } \\
\text { imaging, as determined } \\
\text { by an automated image } \\
\text { postprocessing system: } \\
\text { Infarct core } \\
\text { volume }<70 \mathrm{~mL} \dagger \\
\text { AND mismatch } \\
\text { volume }>15 \mathrm{~mL} \\
\text { (Tmax }>6 \mathrm{~s} \ddagger \text { ) } \\
\text { AND mismatch ratio } \\
\text { (penumbra/core) } \\
>1.8\end{array}$ & $\begin{array}{l}\text { Clinical-imaging } \\
\text { mismatch } \\
\text { Age }<80 \text { years and } \\
\text { NIHSS score } \geq 10 \text { and } \\
\text { infarct core } 0-30 \mathrm{~mL} \\
\text { OR age }<80 \text { years and } \\
\text { NIHSS score } \geq 20 \text { and } \\
\text { infarct core } 31-51 \mathrm{~mL} \\
\text { OR age } \geq 80 \text { years and } \\
\text { NIHSS score } \geq 10 \text { and } \\
\text { infarct core } 0-20 \mathrm{~mL}\end{array}$ \\
\hline
\end{tabular}

\footnotetext{
${ }^{*}$ Carotid occlusions could be cervical or intracranial, with or without tandem MCA lesions in DEFUSE-3.

†Based on CT perfusion or MRI diffusion.

$¥$ The size of the penumbra was estimated from the volume of tissue for which there was delayed arrival of an injected tracer agent (time to maximum of the residue function (Tmax) exceeding $6 \mathrm{~s}$. $^{148}$

ICA, internal cerebral artery; MCA, middle cerebral artery; mRS, modified Rankin Scale; NIHSS, National Institutes of Health Stroke Scale.
}

The inclusion of patients with stroke on awakening, if otherwise fitting the inclusion criteria, was encouraged. A small number of patients were recruited beyond 6 hours in REVASCAT (up to 8 hours, $\mathrm{n}=21$ ) $^{5}$ and ESCAPE (up to 12 hours, $n=49){ }^{3}$ Inclusion criteria varied between the trials (table 3). DAWN used a stratification by age and National Institutes of Health Stroke Scale (NIHSS) score, leading to differing maximum infarct core cut-off volumes measured by imaging software in an automated fashion ( $>80$ years, infarct core up to $20 \mathrm{~mL} ;<80$ years and NIHSS score $0-19$, infarct core up to $30 \mathrm{~mL} ;<80$ years and NIHSS score $\geq 20$, infarct core up to $51 \mathrm{~mL}$ ). DEFUSE-3 allowed a larger core volume (up to $70 \mathrm{~mL}$ ) but required a perfusion mismatch measured by perfusion CT or MRI of $>1.8$ (ratio) and a penumbra volume $\geq 15 \mathrm{~mL}$ (table 3 ), again measured by imaging software in an automated fashion. The median infarct core volume was 8 (75 th centile: $20 \mathrm{~mL}$ ) and $10 \mathrm{~mL}$ (75thcentile: $25 \mathrm{~mL}$ ) in DAWN and DEFUSE-3, respectively. A large majority of patients enrolled in DAWN or DEFUSE-3 had an unknown time of stroke onset (stroke on awakening or unwitnessed stroke): $88 \%$ in DAWN and 64\% in DEFUSE-3. It is possible that many of those patients had an actual stroke onset-totreatment time within the 6-hour time window. The total numbers of IVT patients and M2 occlusions were negligible.

There was no blinding of patient or staff for the treatment arm in DAWN and DEFUSE-3. However, the primary endpoint (mRS score at 90 days) was assessed in a blinded fashion. Each trial was considered to be at low risk of bias (figure 4).

An individual patient data meta-analysis of DAWN, DEFUSE-3 and patients recruited beyond 6 hours in ESCAPE and REVASCAT (AURORA collaboration) was presented at the 2018 European Stroke Organization Conference. A total of 459 patients were

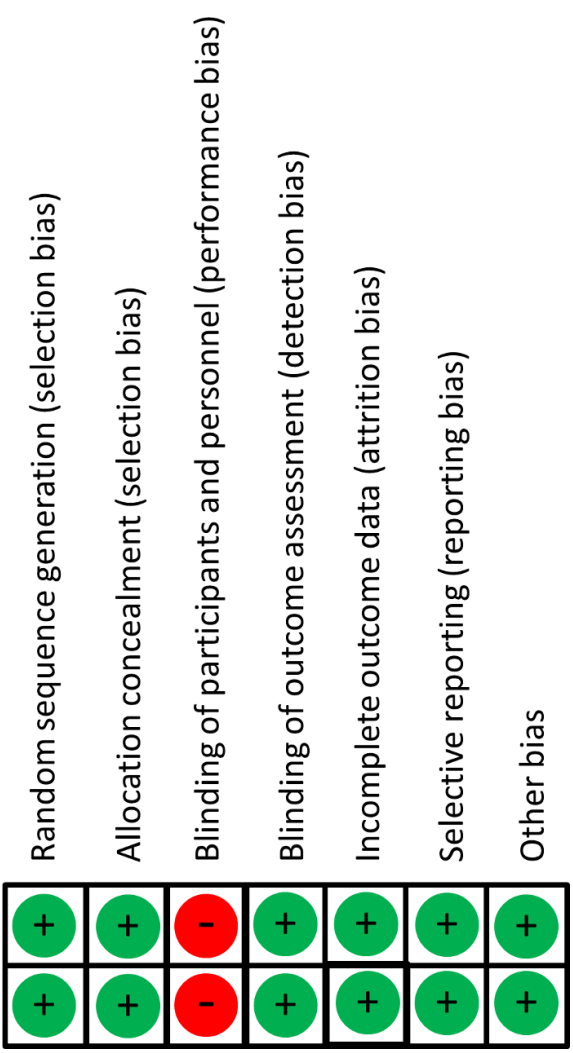

Figure 4 Risk of bias in each trial. 
included in this meta-analysis. Compared with BMM alone, MT plus BMM was strongly associated with better functional outcome (adjusted common OR=2.77, 95\% CI 1.95 to 3.94, $\mathrm{p}<0.001$ ) and functional independence at 3 months ( $\mathrm{mRS}$ score $\leq 2$ ): $46.7 \%$ vs $16.7 \%$, adjusted $\mathrm{OR}=4.65$ (95\% CI 2.02 to $10.72, \mathrm{p}<0.001)$. It should be borne in mind that the vast majority $(84.5 \%)$ of patients included in the analysis of the AURORA collaboration were included in DAWN and DEFUSE-3. Therefore, the evidencebased recommendations presented for the 6-24 hour time window are based only on the results of these two trials.

Despite a low risk of bias in each trial (figure 4), the overall quality of evidence (QoE) to provide recommendations for the 6-24 hour time window was rated as moderate (see table 4 for details).

\section{Recommendation}

In adults with anterior circulation large vessel occlusion-related acute ischemic stroke presenting between 6 and 24 hours from time last known well and fulfilling the selection criteria of DEFUSE- ${ }^{*}$ or DAWN ${ }^{* *}$, we recommend mechanical thrombectomy plus best medical management over best medical management alone to improve functional outcome.

Quality of evidence: Moderate $\oplus \bigoplus \bigoplus$; strength of recommendation: Strong $\uparrow \uparrow$

(see below and table 3 regarding patient selection)

${ }^{*} 6$ to 16 hours since time last known well:

- Age $\leq 80$ years and NIHSS $\geq 6$ : infarct core volume $<70 \mathrm{~mL}$ and penumbra volume $>15 \mathrm{~mL}$ and penumbra volume/core volume $>1.8$.

**6 to 24 hours since time last known well:

- Age $<80$ years: infarct core $\leq 30 \mathrm{~mL}$ if NIHSS $\geq 10$; infarct core $\leq 51 \mathrm{~mL}$ if NIHSS $\geq 20$.

- Age $\geq 80$ years: infarct core $\leq 20 \mathrm{~mL}$ and NIHSS $\geq 10$.

See table 3 for details.

\section{Additional information}

The DAWN and DEFUSE-3 trials selected patients in the late time window of up to 24 hours after unwitnessed (last known well) or witnessed stroke onset. Both trials have a very narrow set of inclusion criteria (table 3), including volumetric quantification of the infarct core and penumbra using specific imaging analysis software. In addition, the 2018 ASA/AHA guidelines do give a stepwise recommendation: I-A for selected patients within 6-16 hours fulfilling DEFUSE-3 or DAWN eligibility criteria and IIa-BR within 16-24 hours for patients for patients fulfilling DAWN criteria. $^{27}$

Recently, the WAKE-UP trial of intravenous alteplase alone versus placebo in patients with unknown time of onset and for whom MT was not planned has been reported. Patients were selected based on mismatch between diffusion-weighted imaging and fluid-attenuated inversion recovery (FLAIR) on MRI, and showed a considerable therapy effect (adjusted OR for mRS score $\leq 1: 1.61,95 \%$ CI 1.09 to $2.36, \mathrm{p}=0.02$; adjusted common OR for better functional outcome: $1.62,95 \%$ CI 1.17 to 2.23 , $\mathrm{p}=0.003){ }^{28}$ A subgroup analysis for differential efficacy in different occlusion sites, among those enrolled, is under way and might further inform decision-making.

According to a recent publication, about $2.7 \%$ of patients with acute ischemic stroke presenting to a comprehensive stroke center within 24 hours after stroke onset meet the DEFUSE-3 and/or DAWN criteria. ${ }^{29}$ According to the same study, about $9 \%$ of all patients with acute ischemic stroke presenting in the

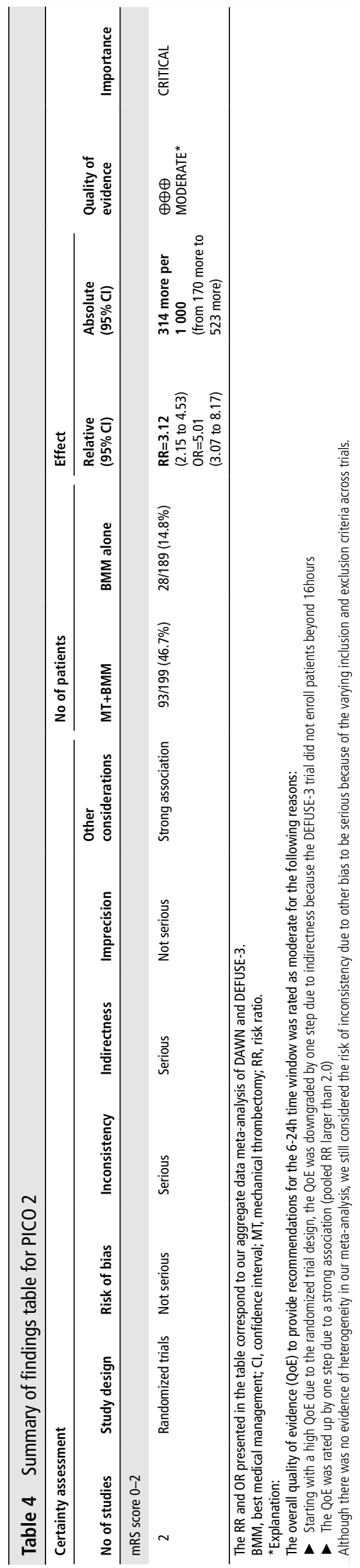


6-24hours time window meet the DEFUSE-3 and/or DAWN inclusion criteria.

In ESCAPE $(n=49)$ and REVASCAT $(n=21)$ patients were recruited beyond 6 hours. These patients represent an unaccounted $17.8 \%$ of patients relevant for PICO question 2 . ESCAPE used imaging inclusion criteria of Alberta Stroke Program Early CT Score (ASPECTS) $\geq 6$ plus good/intermediate collaterals on CT angiography (CTA) collateral scoring (assessed on multiphase CTA) up to 12 hours. In the REVASCAT trial, patients with CTA/MR angiography obtained within 4.5-8 hours after stroke onset had to have a good ASPECTS $(\geq 7)$ and eligibility confirmed by advanced brain imaging (CT perfusion [CTP], DWI, or CTA-source images analysis). Data from the HERMES collaboration suggest a therapy effect of MT up to 7 hours 18 min. ${ }^{30}$

\section{Expert opinion}

The stratified core volume approach as well as the need for perfusion imaging compatible hardware and software restrict the application of DAWN/DEFUSE-3 criteria for patient selection, making generalizability and implementation of late time window MT according to the published evidence difficult at best. ${ }^{29}$

Because the DAWN and DEFUSE-3 inclusion criteria correspond only to a low proportion of patients seen within the 6-24hour time window, the guidelines group make the two following expert-opinion based recommendations:

\section{Expert opinion on $\mathrm{m}$ in late time windows}

Patients should be treated with mechanical thrombectomy plus best medical management up to approximately 7 hours 18 min after stroke onset, without the need for perfusion imaging-based selection. ${ }^{30}$

10/11 Experts agree that patients can be treated in the 6-12 hour time window if they fulfill the ESCAPE criteria, notably ASPECTS $\geq 6$ and moderate-to-good collateral circulation. However, such patients should preferably be treated in the context of clinical studies. Also, concurrent software applications using similar perfusion algorithms and rendering equivalent volumetry results as those used in the DAWN and DEFUSE-3 trials may be options, as well as simple volumetry on a highquality DWI scan for core volume when applying DAWN criteria. Therefore we advocate further research, inclusion of patients in late window trials, and implementation of institutional imaging standard operating procedures.

If patients are treated without strict DAWN/DEFUSE-3 criteria, centres are encouraged to collect their data and compare their outcomes with those treated with the more stringent DAWN/ DEFUSE imaging criteria.

\section{PICO 3: FOR ADULTS WITH LARGE VESSEL OCCLUSION- RELATED ACUTE ISCHEMIC STROKE, DOES INTRAVENOUS THROMBOLYSIS PLUS MECHANICAL THROMBECTOMY COMPARED WITH MECHANICAL THROMBECTOMY ALONE IMPROVE FUNCTIONAL OUTCOME?}

Analysis of current evidence and evidence-based recommendation

MT plus IVT versus MT alone

The literature search did not identify any RCT directly addressing this PICO question.
In the pivotal RCTs demonstrating the benefit of endovascular therapy, the experimental treatment arm comprised MT and also BMM, including IVT with alteplase in $83 \%$ of patients. ${ }^{6}$ Therefore, the current standard of care for adults with LVO-related acute ischaemic stroke is MT plus IVT (bridging therapy), if the patient has no contraindications for IVT. The HERMES collaboration individual patient data meta-analysis of the first five RCTs (MR CLEAN, Extend IA, ESCAPE, SWIFT PRIME, REVASCAT) reported a common OR for a better functional outcome of 2.45 (95\% CI 1.68 to 3.57) in patients receiving IVT and MT versus 2.43 (95\% CI 1.30 to 4.55 ) in those receiving MT alone, ${ }^{6}$ apparently not suggesting a higher benefit of MT in patients treated with versus without IVT. This result might be explained by a selection bias, as good responders to IVT might have been less likely to be enrolled in REVASCAT, in which the response to IVT had to be evaluated after $30 \mathrm{~min},{ }^{5}$ and in MR CLEAN, in which the median time between IVT and randomization was 2 hours. ${ }^{1}$

A systematic review and meta-analysis of 13 studies allowing the non-randomized comparison of MT plus IVTversus MT alone in adults with anterior circulation LVO-related acute ischemic stroke suggested a superiority of MT+IVT for functional independence ( $\mathrm{mRS}$ score $\leq 2$ : $\mathrm{OR}=1.27,95 \% \mathrm{CI} 1.05$ to 1.55 ; $\left.\mathrm{I}^{2}=17 \%\right) \cdot{ }^{31}$ However, this analysis is limited by potential selection bias, confounding by indication and indirectness. Therefore, the quality of evidence was downgraded as very low (table 5). Another meta-analysis did not suggest the superiority of MT+IVTversus MT alone in the subgroup of patients eligible for IVT (mRS score $\leq 2$ : OR $=0.93,95 \% \mathrm{CI} 0.57$ to $\left.1.49 ; \mathrm{I}^{2}=41 \%\right) .{ }^{32}$

\section{MT alone in patients not eligible for IVT}

The above-mentioned results of the individual patient data meta-analysis of the five first RCTs suggest that in the subgroup of patients not receiving IVT $(n=180)$, MT was effective as standalone therapy as compared with BMM without IVT (OR for functional independence $2.43,95 \% \mathrm{CI} 1.30$ to 4.55$).{ }^{6}$ However, this subgroup analysis suffers from very serious indirectness, because the five above-mentioned RCTs were not designed to deal with the question of the effectiveness and safety of MT in patients with a contraindication to IVT. The reasons for non-eligibility to IVT were probably heterogeneous, including patients with a contraindication to IVT (eg, oral anticoagulation) but also mostly patients outside the 4.5 hour time window.

\section{Recommendations}

- In patients with large vessel occlusion-related ischemic stroke eligible for both treatments, we recommend intravenous thrombolysis plus mechanical thrombectomy over mechanical thrombectomy alone. Both treatments should be performed as early as possible after hospital arrival. Mechanical thrombectomy should not prevent the initiation of intravenous thrombolysis, and intravenous thrombolysis should not delay mechanical thrombectomy. Quality of evidence: Very low $\oplus$; strength of recommendation: Strong $\uparrow \uparrow$

- In patients with large vessel occlusion-related ischemic stroke not eligible for intravenous thrombolysis, we recommend mechanical thrombectomy as stand-alone treatment.

Quality of evidence: Low $\oplus \oplus$; strength of recommendation: Strong $\uparrow \uparrow$ 
Additional information

Ongoing trials comparing MT alone with MT plus IVT

Several dedicated RCTs comparing MT alone with MTplus IVT in mothership patients with LVO are currently ongoing (Bridging Thrombolysis Versus Direct Mechanical Thrombectomy in Acute Ischemic Stroke [SWIFT DIRECT]: NCT03192332; MR CLEAN No IV: NL58320.078.17; A Randomized Controlled Trial of DIRECT Endovascular Clot Retrieval Versus Standard Bridging Thrombolysis With Endovascular Clot Retrieval [DIRECT-SAFE]: NCT03494920).

\section{IVT with alteplase or tenecteplase before MT}

EXTEND IA TNK is a recently published phase II RCT designed to assess the non-inferiority of IV tenecteplase $(0.25 \mathrm{mg} / \mathrm{kg})$ over IV alteplase $(0.9 \mathrm{mg} / \mathrm{kg})$ in patients with LVO-related acute ischemic stroke eligible for IVT and for whom MT was planned. ${ }^{33}$ CT-perfusion mismatch was originally required for patient enrollment in EXTEND IA TNK, but that criterion was removed after the inclusion of the first 80 patients, leaving 122 patients enrolled based on non-contrast CT plus CTA. The primary outcome-successful reperfusion at the time of the initial angiographic assessment (Thrombolysis in Cerebral Infarction [TICI] score $\geq 2 \mathrm{~b}$ )-occurred in $22 \%$ of the patients treated with tenecteplase versus $10 \%$ of those treated with alteplase (absolute difference 12\%, 95\% CI 2\% to $21 \% ; \mathrm{p}=0.002$ for non-inferiority; $\mathrm{p}=0.03$ for superiority). Tenecteplase notably resulted in a better 90 -day functional outcome than alteplase (common $\mathrm{OR}=1.7,95 \% \mathrm{CI} 1.0$ to $2.8 ; \mathrm{p}=0.04$ ), but the trend in favor of a higher rate of functional independence ( $\mathrm{mRS}$ score $\leq 2$ ) failed to reach statistical significance (adjusted $\mathrm{OR}=1.8$, $95 \%$ CI 1.0 to $3.4, \mathrm{p}=0.06$ ).

The median time from stroke onset to successful reperfusion (mTICI score $2 \mathrm{~b} / 3$ ) or completion of the procedure was 203 (175-255) $\mathrm{min}$ in the tenecteplase group, versus 232 (185-268) min in the alteplase group $(\mathrm{p}=0.07)$.

The optimal tenecteplase dose for acute ischemic stroke is currently uncertain. ${ }^{33} 34$ A clinical trial comparing two different doses of tenecteplase $(0.25 \mathrm{mg} / \mathrm{kg}$ vs $0.4 \mathrm{mg} / \mathrm{kg})$ in patients eligible for IVT and MT is currently ongoing (Determining the Optimal Dose of Tenecteplase Before Endovascular Therapy for Ischaemic Stroke [EXTEND-IA TNK Part 2]: NCT03340493).

\section{Expert opinion}

Several important limitations need to be taken into account concerning the use of tenecteplase versus alteplase:

- The superiority of tenecteplase over alteplase in patients eligible for MT has been shown only in a single phase II randomized controlled trial (EXTEND IA TNK), ${ }^{33}$ in which functional outcome was a prespecified secondary outcome. The superiority of tenecteplase was shown for better functional outcome (ordinal analysis over the whole range of the mRS), but failed to reach statistical significance for functional independence (mRS score $\leq 2$ ) and excellent outcome (mRS score $\leq 1$ ).

- The non-inferiority of tenecteplase compared with alteplase has not been established in other situations. ${ }^{34-38}$

- Neither vascular imaging nor advanced imaging is needed to make a therapeutic decision about IVT. ${ }^{27}$ IVT should be started without delay. ${ }^{39}$

- Whether the results of EXTEND IA TNK may be generalized to all patients with LVO-related acute ischemic stroke or only to those patients with both LVO and CT-perfusion mismatch is uncertain.

- Several randomized trials evaluating tenecteplase for acute ischemic stroke are ongoing (Alteplase-Tenecteplase Trial Evaluation for Stroke Thrombolysis [ATTEST 2]: NCT02814409; 
A Randomized Controlled Trial of TNK-tPA versus Standard of Care for Minor Ischemic Stroke With Proven Occlusion [TEMPO-2]: NCT02398656; Tenecteplase in Wake-up Ischaemic Stroke Trial [TWIST]: NCT03181360; Tenecteplase versus Alteplase for Stroke Thrombolysis Evaluation [TASTE]: NCT01472926; Determining the Optimal Dose of Tenecteplase Before Endovascular Therapy for Ischaemic Stroke [EXTEND-IA TNK Part 2]: NCT03340493).

Expert opinion on tenecteplase in patients eligible for thrombectomy

In patients with large vessel occlusion-related ischemic stroke eligible for intravenous thrombolysis before mechanical thrombectomy, $7 / 11$ experts suggest the use of tenecteplase $(0.25 \mathrm{mg} / \mathrm{kg})$ over alteplase $(0.9 \mathrm{mg} / \mathrm{kg})$ if the decision on intravenous thrombolysis is made after vessel occlusion status is known.

\section{PICO 4: FOR ADULTS WITH SUSPECTED ACUTE STROKE, DOES THE USE OF A PREHOSPITAL SCALE COMPARED WITH NO PREHOSPITAL SCALE: (A) IMPROVE IDENTIFICATION OF PATIENTS ELIGIBLE FOR MECHANICAL THROMBECTOMY?(B) REDUCE TIME TO REPERFUSION?}

\section{Analysis of current evidence and evidence-based recommendation}

The literature search did not identify RCTs or observational studies directly comparing the use of a prehospital scale versus no prehospital scale to identify patients with LVO. However, two before-and-after studies allowed such a comparison.

In the study by Zaidi et $a l^{40}$ emergency medical services personnel underwent training in the Rapid Arterial oCclusion Evaluation (RACE) score, a clinical scale designed for prehospital identification of patients with LVO. ${ }^{41}$ All patients with a RACE score $\geq 5$ (range $0-9$ ) were taken to a facility with interventional capability. The authors used a historical control group to compare patients triaged before or after the implementation of the RACE scale. Patients assessed by the RACE score were more likely to have a discharge diagnosis of acute ischemic stroke than those without RACE assessment ( $52.3 \%$ vs $31 \%)$. There was an increase in the rate of MT $(20.1 \%$ vs $7.7 \%, p=0.03)$ and improvement in the treatment times (median arrival-to-recanalization times: 101 vs $205 \mathrm{~min}, \mathrm{p}=0.001)$. No statistically significant difference was found in the rate of functional independence (90-day mRS score $\leq 2$ : $50 \%$ vs $36.4 \%, \mathrm{p}=0.3$ ).

A similar study conducted by Mohamad et $a l^{42}$ following the implementation of four-item screening showed the median system delay for MT fell from $234 \mathrm{~min}$ (IQR 184-282) to $185 \mathrm{~min}$ (IQR 141-226), corresponding to an adjusted relative delay of 0.79 (95\% CI 0.67 to 0.93$)$. The reduction in the delay occurred in both the prehospital phase (adjusted relative delay $0.86,95 \%$ CI 0.71 to 1.04 ) and in the in-hospital phase (adjusted relative delay $0.76,95 \%$ CI 0.62 to 0.94 ) but did not reach statistical significance in the prehospital phase. There was significantly higher chance of functional independence at 90 days among the patients treated with MT in the postinterventional period than among the preinterventional patients with a total of $62 \%(40 / 65)$ vs $43 \%(15 / 35)$ achieving functional independence $(\mathrm{OR}=3.08$, 95\% CI 1.08 to 8.78$)$.

The results of these studies suggest that the use of a prehospital scale may reduce the time to reperfusion. However, both studies had serious limitations, notably the use of a historical cohort as control group, the important risk of residual confounding, and the lack of assessment of the impact of misclassification. As such, we believe that the associated level of evidence is too low to provide evidence-based recommendation on the use of such scales.

\section{Recommendation}

In patients with suspected stroke, we cannot make a recommendation on the use of a prehospital scale for improving identification of patients eligible for mechanical thrombectomy. We suggest enrolling patients in a dedicated randomized controlled trial, whenever possible.

Quality of evidence: Very low $\bigoplus$; strength of recommendation: -

\section{Additional information}

A consensus statement and practical guidance for prehospital management of stroke has been published by the European Academy of Neurology (EAN) and the ESO in $2018 .{ }^{43}$

A randomized controlled trial comparing the mothership with the the drip-and-ship approach (see PICO question 5) in patients with suspected LVO based on the RACE score is currently ongoing (Direct Transfer to an Endovascular Center Compared with Transfer to the Closest Stroke Center in Acute Stroke Patients With Suspected Large Vessel Occlusion [RACECAT]: NCT02795962). Another randomized trial using the Prehospital Acute Stroke Severity (PASS) score ${ }^{44}$ is also currently ongoing (TReatment Strategy In Acute Ischemic larGE Vessel STROKE: Prioritize Thrombolysis or Endovascular Treatment [TRIAGE]: NCT035421880.

Numerous clinical scales have been proposed for the identification of patients with LVO-related acute ischemic stroke. ${ }^{4144-48}$ However, the vast majority of them have been derived in a population of patients with confirmed acute ischemic strokes and very few scales have been validated in patients suspected to have a stroke in the prehospital field. ${ }^{49}$ Furthermore, there is heterogeneity across studies regarding who conducted the clinical assessment. Most of the studies did not use paramedics as the primary assessor with only the RACE score assessed by trained emergency medical technicians. ${ }^{41}$ A further study assessed the utility of the Cincinnati Stroke Triage Assessment tool, performed by personnel of the Cincinnati fire department, in comparison with FAST; results were comparable between the two scoring systems despite no formal training for the assessors. ${ }^{50}$ More recently, LAMS has been validated in field by paramedics, ${ }^{51}$ as has the ACT-FAST system. ${ }^{52}$

In a recent systematic review, Vidale et al compared the predictive values of 19 prehospital scales used to identify LVO. ${ }^{45}$ Most of the considered scales were assessed by neurologists, while only four scales were applied by paramedics. The authors observed a substantial and considerable heterogeneity of sensitivity and specificity between studies, which they mainly attributed to methodology and cut-off levels for detecting large vessel occlusion. They conclude that the scales with the highest predictive power to detect LVO were VAN, ${ }^{53}$ LAMS, ${ }^{54}$ and the NIHSS ${ }^{55}$ By contrast, scales with a lower predictive power were LVOS, ${ }^{56}$ CPSS $^{57}$ and 3I-SS. ${ }^{58}$ However, it is important to keep in mind that these scales were compared across different populations. The authors did not observe a significant difference in the overall accuracy between scoring systems that contained a gaze assessment or not. However, the presence of hemi-neglect did increase precision. 
Several of the studies have included patients with basilar artery and/or M2 4146475859 occlusions and although these are amenable to MT, there are very limited or no RCT data as of yet to confirm MT in such situations (see PICO question 1). ${ }^{6}$ The recent publication of the DAWN ${ }^{9}$ and DEFUSE- $3^{10}$ trials has resulted in extension of the time window in which to perform MT. Importantly, the sensitivity of clinical scales to identify LVO markedly decreases with time. ${ }^{60}$

\section{Expert opinion}

There is no convincing evidence that a particular scoring system is superior to any of the others. Although several clinical scales show a good accuracy to predict LVO, at least $20 \%$ of patients with LVO would be missed when applying published cut-offs. ${ }^{5961}$ Therefore, systems that use LVO prediction instruments for triage will miss milder stroke with LVO, who may benefit from MT, even though there is very limited evidence of the potential benefits of MT in patients with low NIHSS scores (see PICO question 7). ${ }^{62-65}$

The question of how well the scoring systems work when administered by paramedics has been poorly dealt with. Many scales were derived or evaluated in patients with a diagnosis of ischemic stroke. Their diagnostic performances are likely to be lower in an unselected prehospital population of patients with suspected stroke. ${ }^{59}$ Prospective studies are needed to assess the accuracy of LVO prediction instruments in the prehospital setting in all patients with suspected stroke, including those with hemorrhagic stroke and stroke mimics.

Expert opinion on using prehospital scales to identify patients with large vessel occlusion

- 11/11 experts concluded that there is insufficient evidence to use a clinical scale in routine care to help triage potential thrombectomy candidates in the prehospital field.

- All patients suspected of having an acute stroke, irrespective of the time of onset, should undergo emergency imaging of the brain, including vascular imaging.

\section{PICO 5: FOR ADULTS IDENTIFIED AS POTENTIAL CANDIDATES FOR MECHANICAL THROMBECTOMY IN THE PREHOSPITAL FIELD, DOES THE MOTHERSHIP MODEL, COMPARED WITH THE DRIP-AND-SHIP MODEL, IMPROVE FUNCTIONAL OUTCOME?}

Different organizational models are used for patients with acute ischaemic stroke who are potential candidates for MT. The most widely used are the mothership and the dripand-ship models. ${ }^{66}$ Briefly, the mothership model transports patients directly to a comprehensive stroke center (CSC) to minimize time to MT. In the drip-and-ship model patients are transported to the nearest primary stroke center (PSC) to have rapid diagnostic imaging and administration of IVT followed by transport to the comprehensive stroke center in case additional MT is indicated. ${ }^{67}$

\section{Analysis of current evidence and evidence-based recommendation}

The literature search did not identify any completed RCTs comparing the different models.

In one large-scale observational study, including 1000 patients with severe stroke and treated with MT within 8 hours, clinical outcomes were better in the mothership model with $60.0 \%$
(299/498) achieving functional independence compared with $52.2 \%(213 / 408)$ in the drip-and-ship model $(\mathrm{OR}=1.38,95 \%$ CI 1.06 to $1.79, \mathrm{p}=0.02) .{ }^{68}$ Hypothetical bypass modeling for all transferred patients suggested that IVT would be delayed by $12 \mathrm{~min}$, but MT would be performed $91 \mathrm{~min}$ sooner if patients were routed directly to endovascular-capable centers.

In six further observational studies ${ }^{69-75}$ and one RCT of mechanical thrombectomy, ${ }^{4}$ functional outcomes in the mothership and in the drip-and-ship model were not significantly different.

In five of the above mentioned studies, onset-to-groin puncture times in the mothership model were significantly shorter than in the drip-and-ship model (range 23-120 min faster, $\mathrm{p}<0001$ in all studies). ${ }^{69-73}$ One observational study documented a significantly shorter onset-to-revascularization time in the mothership model (277 vs $420 \mathrm{~min}$; $\mathrm{p}<0.001)^{75}$

In a HERMES collaboration meta-analysis, onset-to-reperfusion times were significantly shorter in the mothership group than in the drip-and-ship group (median 251 vs $345 \mathrm{~min}$, $\mathrm{p}<0.001){ }^{30}$ Rates of functional independence at 3 months declined with delay in onset-to-reperfusion time.

\section{Recommendation}

We cannot make recommendations on whether for adults identified as potential candidates for mechanical thrombectomy in the prehospital field, the mothership or the drip-and-ship model should be applied to improve functional outcome.

Quality of evidence: Very low $\oplus$; strength of recommendation: -

\section{Additional information}

A consensus statement and practical guidance for prehospital management of stroke has been published by EAN and ESO in 2018. . $^{2}$

We identified two other less widely used organizational models: the drip-and-drive (also called: trip-and-treat, or mobile interventional stroke team) and mobile stroke unit model. In the drip-and-drive model, an interventional stroke team travels from the central CSC to the PSC with MT capacity to perform MT. ${ }^{76}$ In the mobile stroke unit model patients are managed in a mobile stroke unit ambulance, in which the patient can be given IVT, and then can be transported to the CSC in cases of LVO diagnosed with on-board CT angiography. ${ }^{77} 78$

In one study short-term clinical outcome in the drip-anddrive and drip-and-ship models was compared. ${ }^{79}$ There was a trend in favor of improved admission-to-discharge change in NIHSS score for drip-and-drive compared with drip-and-ship $(\mathrm{p}=0.07)$.

Controlled trials assessing the interest of mobile stroke units in the era of MT are ongoing (Berlin PRehospital Or Usual Delivery of Acute Stroke Care [B_PROUD]: NCT02869386; BEnefits of Stroke Treatment Delivered Using a Mobile Stroke Unit [BEST-MSU]: NCT02190500; 'Mobile Stroke Unit'-Concept for Delivery of Specialized Acute Stroke Care to Patients in Remote Areas: NCT02465346). ${ }^{80}$

\section{Expert opinion}

As treatment delays lower the chance of functional outcome, time-lag to clinical assessment, imaging and intervention should be minimized. ${ }^{303981}$ 
Expert opinion on prehospital organizational models

- As there is lack of strong evidence for superiority of one organizational model, the choice of model should depend on local and regional service organization and patient characteristics (vote: 11/11 experts agree).

- The mothership model might be favored in metropolitan areas, with transportation time to a comprehensive stroke center of less than $30-45 \mathrm{~min}$ and the use of the drip-andship model when transportation times are longer (vote: 11/11 experts agree).

- As there is limited experience with the other two models (drip-and-drive and mobile stroke unit), no expert opinion can be provided for when to use these models (vote: 11/11 experts agree).

RCTs are needed to prospectively compare different models. Two RCTs examining the dilemma of whether to use the mothership or the drip-and-ship model are ongoing (RACECAT: NCT02795962 and TRIAGE: NCT03542188).

\section{PICO 6: FOR PATIENTS AGED $\geq 80$ YEARS WITH LARGE VESSEL OCCLUSION-RELATED ACUTE ISCHEMIC STROKE, DOES MECHANICAL THROMBECTOMY PLUS BEST MEDICAL MANAGEMENT COMPARED WITH BEST MEDICAL MANAGEMENT ALONE IMPROVE FUNCTIONAL OUTCOME? Analysis of current evidence and evidence-based recommendation}

0-6hour time window

Patients aged $\geq 80$ years were enrolled in seven RCTs of MT plus BMM versus BMM alone, ${ }^{1-35}$ 16-18 $^{-18}$ but with an upper age limit of 85 years in both REVASCAT and THERAPY. ${ }^{516}$ In an individual patient meta-analysis of five RCTs (HERMES Collaboration ${ }^{6}$ ), $198 / 1278$ (15.5\%) patients were aged $\geq 80$ years. A clear benefit of MT was seen for those patients, with an adjusted common OR for a better functional outcome of 3.68 (95\% CI 1.95 to 6.92) and a risk ratio for functional independence ( $\mathrm{mRS}$ score $\leq 2$ ) of 2.09 (95\% CI 1.03 to 4.25 ). There was no evidence of a lower benefit of MT in patients aged $\geq 80$ years compared with younger patients. On the basis of improved functional outcome, we rated the quality of evidence as high. However, the quality of evidence was downgraded to moderate for the outcome of functional independence, owing to imprecision.

\section{Later time windows}

One out of four patients enrolled in DAWN (6 to 24 hours from time last known well) and DEFUSE-3 (6 to 16 hours from time last known well) were aged $\geq 80$ years. ${ }^{9} 10$ In DAWN, there was no evidence of a lower benefit of MT in patients aged $\geq 80$ years $(n=54)$ compared with younger patients. However, the inclusion criteria for patients aged $\geq 80$ years were more stringent (infarct volume of $<21 \mathrm{~mL}$ and no pre-stroke disability [mRS score $\leq 1$ ]). In that group, the crude OR for functional independence with MT was 13.2 (95\% CI 1.51 to 114.8$){ }^{9}{ }^{9}$ In DEFUSE-3, the upper age limit for inclusion was set at 90 years (with no pre-stroke dependence [mRS score $\leq 2]$ ). There was no evidence of a lower benefit of MT in patients aged $\geq 70$ years compared with younger patients, but no interaction analysis was reported using 80 years as a threshold. Patients aged $\geq 80$ years $(n=46)$ treated with MT had an unadjusted OR of 2.86 (95\% CI 0.72 to 11.37 ) for functional independence. ${ }^{10}$ We conducted a meta-analysis of DAWN and DEFUSE-3, in which MT was significantly associated with functional independence in patients aged $\geq 80$ years $(\mathrm{OR}=4.87,95 \%$ CI 1.15 to 20.71 , $\mathrm{I}^{2}=29 \%$; figure 5 ), but this association failed to reach statistical significance when risk ratio was used as summary measure instead of odds ratio (figure 6; table 6). The quality of evidence was downgraded to low owing to very serious imprecision, for the following reasons: (a) clinical recommendation (MT or no MT) would differ if the upper versus the lower boundary of the $95 \% \mathrm{CI}$ of the RR represents the truth; (b) the absolute number of patients over 80 years in DAWN and DEFUSE-3 was small $(n=100)$ and the number of qualifying events (moved from dependence to independence) was much lower still.

\section{Recommendations}

- We recommend that patients aged $\geq 80$ years with large vessel occlusion-related acute ischemic stroke within 6 hours of symptom onset should be treated with mechanical thrombectomy plus best medical management, including intravenous thrombolysis whenever indicated. Application of an upper age limit for mechanical thrombectomy is not justified.

Quality of evidence: Moderate $\bigoplus \bigoplus \bigoplus$; strength of recommendation: Strong $\uparrow \uparrow$

- We suggest that patients aged $\geq 80$ years with large vessel occlusion-related acute ischemic stroke between 6 and 24 hours from time last known well should be treated with mechanical thrombectomy plus best medical management if they meet the eligibility criteria of the DEFUSE-3* or DAWN** trials.

Quality of evidence: Low $\bigoplus \bigoplus$; strength of recommendation: Weak $\uparrow$ ?

*6-16hours since time last known well:

- Age $\leq 90$ years and NIHSS score $\geq 6$ : infarct core volume $<70 \mathrm{~mL}$ and penumbra volume $>15 \mathrm{~mL}$ and penumbra volume/core vol $>1.8$.

${ }^{*}$ *6-24 hours since time last known well:

- Age $\geq 80$ years: infarct core $\leq 20 \mathrm{~mL}$ and NIHSS score $\geq 10$.

See table 3 for details.

\section{Additional information}

Elderly patients enrolled in RCTs of MT were functionally independent before the qualifying stroke. Whether patients over 80 years with significant pre-stroke disability may benefit from MT is currently uncertain.

Excessive vessel tortuosity, which is more common in the elderly, was an exclusion criterion in SWIFT PRIME and REVASCAT. ${ }^{45}$ In ESCAPE, the enrollment of patients with vessel tortuosity was not recommended if the investigator

PICO 6: MT+BMM vs. BMM alone (6-24h) in patients aged 80 or more: mRS 0-2

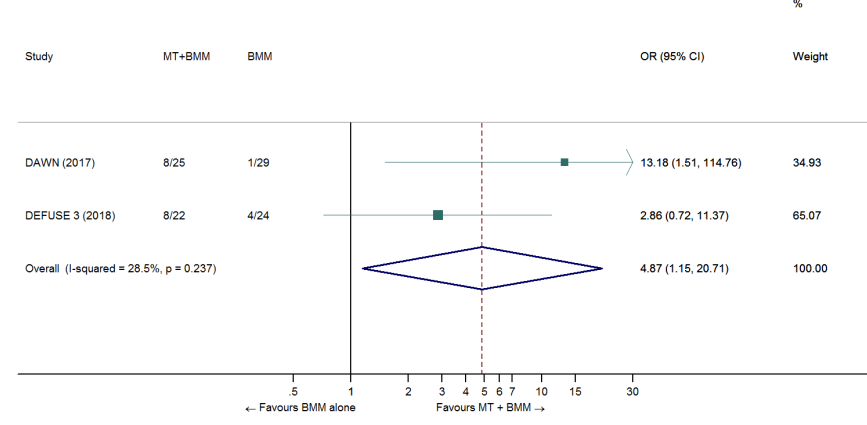

Figure 5 Pooled OR for functional independence in elderly patients treated with MT plus BMM versus BMM alone in the 6-24hours time window. Random-effects meta-analysis. BMM, best medical management; MT, mechanical thrombectomy. 


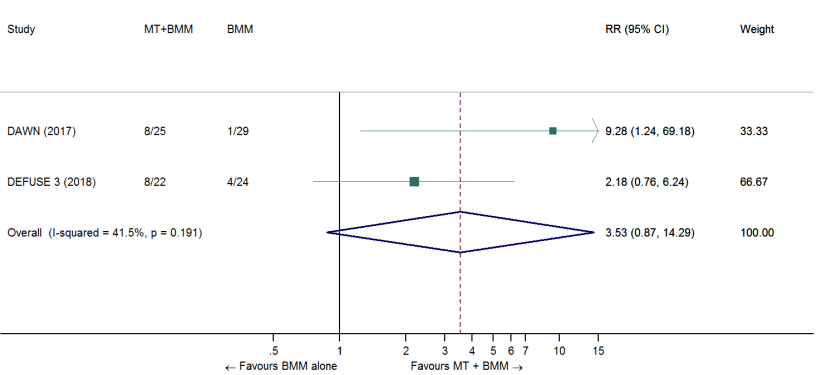

Figure 6 Pooled risk ratio for functional independence in elderly patients treated with MT+BMM vs. BMM alone in the $6-24$ hours time window. Random-effects meta-analysis. BMM, best medical management; MT, mechanical thrombectomy.

considered that this anatomical singularity would prevent meeting recommended time targets. ${ }^{3}$ In PISTE, vascular access contraindications included proximal vascular anatomy likely to render endovascular catheterization difficult (but this was left to operator judgment). ${ }^{17}$ It was also one of many exclusion criteria in DAWN. ${ }^{9}$

Elderly patients were eligible for enrollment beyond the 6-hour time window in REVASCAT (up to 8 hours; upper age limit 85 years $^{5}$ ) and ESCAPE (up to 12 hours $^{3}$ ), but data for this age subgroup were not available for inclusion in our meta-analysis. Regardless of age, only 20 patients were enrolled in the 6-8 hour time window in REVASCAT, and 49 patients were enrolled in the 6-12 hour time window in ESCAPE. The fact that no effect modification by age was demonstrated in the whole ESCAPE cohort is too indirect evidence to make recommendations based on that study about elderly patients in the 6-12 hour time window.

\section{PICO 7: FOR ADULTS WITH LARGE VESSEL OCCLUSION- RELATED ACUTE ISCHEMIC STROKE, DOES SELECTION OF MECHANICAL THROMBECTOMY CANDIDATES BASED ON A PARTICULAR NIHSS SCORE THRESHOLD COMPARED WITH NO SPECIFIC THRESHOLD IMPROVE FUNCTIONAL OUTCOME?}

\section{Analysis of current evidence and evidence-based} recommendation

High NIHSS score $(>20)$

Patients with high stroke severity (NIHSS score >20) were enrolled in all nine RCTs testing MT within 6hours, ${ }^{1-5}$ 15-18 although upper limits were required in SWIFT PRIME $(\leq 30)$ and
THRACE $(\leq 25) .{ }^{415}$ A patient level pooled analysis $(n=1278)$ of the five RCTs conducted by the HERMES collaboration showed no evidence of heterogeneity of treatment effect among severe strokes, as compared with other subgroups that were enrolled (NIHSS $>20$ [ $\mathrm{n}=321]$ : adjusted common OR for better functional outcome: $2.52,95 \%$ CI 1.40 to $\left.4.54 ; \mathrm{p}_{\text {interaction }}=0.45\right) .{ }^{6}$ The adjusted risk ratio for functional independence (mRS score $\leq 2$ ) in patients with NIHSS >20 was 1.80 (95\% CI 1.09 to 2.96). There are limited data on patients with a NIHSS score $>25$ ( $n=66$ in the first five RCTs). In two trials testing MT beyond 6 hours (DAWN and DEFUSE-3), there was also no evidence of modification of treatment effect by higher stroke severity. ${ }^{9} 10$

Low NIHSS score (0-5)

Patients with low stroke severity (NIHSS 0-5) could be enrolled in two RCTS of MT plus BMM versus BMM alone within 6 hours of symptom onset. MR CLEAN allowed an NIHSS score as low as 2 if there was sufficient uncertainty of MT benefit. ${ }^{1}$ EXTEND IA allowed enrollment of patients regardless of NIHSS score if the clinical decision was made to administer IVT. ${ }^{2}$ The remaining seven RCTs had lower NIHSS score limits, ranging from 6 to $10 .^{3-515-18}$ Of the 1916 randomized patients, only $14(0.7 \%)$ had an NIHSS score of $0-5$, a number too small to draw any conclusion about this subgroup. Furthermore, no patients with NIHSS score 0-5 were enrolled in any RCT testing MT beyond 6 hours (DAWN, DEFUSE-3, ESCAPE, REVASCAT). ${ }^{35910}$

\section{Recommendations}

- We do not recommend an upper NIHSS score limit for decision-making on mechanical thrombectomy. We recommend that patients with high stroke severity and large vessel occlusion-related acute ischemic stroke be treated with mechanical thrombectomy plus best medical management, including intravenous thrombolysis whenever indicated. These recommendations also apply for patients in the 6-24 hour time window, provided that they meet the inclusion criteria for the DAWN or DEFUSE-3 studies (see table 3).

Quality of evidence: High $\oplus \bigoplus \bigoplus \bigoplus$; strength of recommendation:

Strong $\uparrow \uparrow$

- We recommend that patients with low stroke severity (NIHSS score $0-5$ ) and large vessel occlusion-related acute ischemic stroke within 24 hours from time last known well be included in randomized controlled trials comparing mechanical thrombectomy plus best medical management versus best medical management alone. Quality of evidence: Very Low $\bigoplus$; strength of recommendation:

Table 6 Summary of findings table for PICO 6

\begin{tabular}{|c|c|c|c|c|c|c|c|c|c|c|c|c|}
\hline \multicolumn{7}{|c|}{ Certainty assessment } & \multicolumn{2}{|c|}{ № of patients } & \multicolumn{2}{|l|}{ Effect } & \multirow[b]{2}{*}{$\begin{array}{l}\text { Quality of } \\
\text { evidence }\end{array}$} & \multirow[b]{2}{*}{ Importance } \\
\hline $\begin{array}{l}\text { № of } \\
\text { studies }\end{array}$ & Study design & Risk of bias & Inconsistency & Indirectness & Imprecision & $\begin{array}{l}\text { Other } \\
\text { considerations }\end{array}$ & MT+BMM & $\begin{array}{l}\text { BMM } \\
\text { alone }\end{array}$ & $\begin{array}{l}\text { Relative } \\
(95 \% \mathrm{Cl})\end{array}$ & $\begin{array}{l}\text { Absolute } \\
(95 \% \mathrm{CI})\end{array}$ & & \\
\hline \multicolumn{13}{|c|}{ 0-6 hour time window: $\mathrm{mRS}$ score $0-2$} \\
\hline 4 & $\begin{array}{l}\text { Randomized } \\
\text { trials }\end{array}$ & Not serious & Not serious & Not serious & Serious* & None & & & $\begin{array}{l}\mathbf{R R}=\mathbf{2 . 0 9} \\
(1.03 \text { to } 4.25)\end{array}$ & & $\begin{array}{l}\oplus \oplus \oplus \bigcirc \\
\text { MODERATE }\end{array}$ & CRITICAL \\
\hline \multicolumn{13}{|c|}{ 6-24hour time window: $m R S$ score $0-2$} \\
\hline 2 & $\begin{array}{l}\text { Randomized } \\
\text { trials }\end{array}$ & Not serious & Not serious & Not serious & Very serious ${ }^{*} \dagger$ & None & $\begin{array}{l}16 / 47 \\
(34.0 \%)\end{array}$ & $\begin{array}{l}5 / 53 \\
(9.4 \%)\end{array}$ & $\begin{array}{l}\mathbf{R R}=3.53 \\
(0.87 \text { to } 14.29) \\
\text { OR=4.87 } \\
(1.15 \text { to } 20.71)\end{array}$ & $\begin{array}{l}239 \text { more per } \\
1000 \\
\text { (from } 12 \text { fewer } \\
\text { to } 1000 \text { more) }\end{array}$ & $\begin{array}{l}\oplus \oplus \bigcirc \bigcirc \\
\text { LOW }\end{array}$ & CRITICAL \\
\hline
\end{tabular}

* Clinical action (MT or no MT) would differ if the upper versus the lower boundary of the $\mathrm{Cl}$ represented the truth.

†The absolute number of patients over 80 years in DAWN and DEFUSE-3 was small $(n=100)$ and the number of qualifying events (moved from dependence to independence) was much lower still. $\mathrm{BMM}$, best medical management; $\mathrm{Cl}$, confidence interval; $\mathrm{MT}$, mechanical thrombectomy; RR, risk ratio 


\section{Additional information}

Randomized controlled trials that include patients with low NIHSS scores are in preparation or under way (ENDO-LOW, In Extremis/MOSTE).

Several observational studies have focused on the effect of MT in patients with low NIHSS scores. Haussen et al reported 32 patients with a baseline NIHSS score $\leq 5$ and confirmed LVO who were either treated with IVT alone (69\% of patients at admission) or MT (31\% at admission). ${ }^{82}$ Of those treated with IVT, 41\% deteriorated and required MT despite the fact that the median NIHSS score for patients in the medical treatment group was only 2 . The median time to deterioration was 5.2 hours (range $2-25$ hours). This group also showed a phase shift in mRS score of -2.5 points in favour of MT. Dargazanli et al published the results of prospectively collected consecutive patient data from four French registries. ${ }^{65}$ The inclusion criteria were confirmed acute ischaemic stroke with proximal large vessel occlusion and NIHSS score $<8$ at admission. Patients were subdivided into two groups: those who went directly to MT in addition to BMM and those who were treated with BMM and only proceeded to MT in the event of clinical deterioration. Three hundred and one patients met the inclusion criteria, 170 in the MT group and 131 in the group corresponding to BMM as first-line treatment. Overall, $64.5 \%$ of patients achieved an excellent outcome ( $\mathrm{mRS}$ score $\leq 1$ ) at 90 days with no significant difference between the two groups. Of those with an NIHSS score $<6$ at admission, $80 \%$ achieved functional independence ( $\mathrm{mRS}$ score $\leq 2$ ). A larger number of patients in the MT group achieved a perfect outcome ( $\mathrm{mRS}$ score $=0$ ) than those in the BMM group (47.2\% vs $34.7 \%)$. Of note $18.3 \%$ of patients in the BMM group had clinical deterioration and therefore went on to MT. This study, together with others, ${ }^{62638384}$ suggests that MT might be of benefit to patients presenting with mild symptoms. ${ }^{85}$ However, owing to a high risk of confounding by indication in those observational studies, we recommend enrolling patients in dedicated RCTs.

\section{Expert opinion}

Expert opinion on mechanical thrombectomy in patients with low NIHSS scores

In patients with a low NIHSS score $(\leq 5)$ who are not eligible for a dedicated randomized controlled trial, we suggest that treatment with mechanical thrombectomy in addition to intravenous thrombolysis (or alone in cases of contraindication to intravenous thrombolysis) may be reasonable:

- in patients with deficits that appear disabling (eg, significant motor deficit or aphasia or hemianopia) at presentation (vote: 9/11 experts)

- in the case of clinical worsening despite intravenous thrombolysis (vote: 9/11 experts).

- we did not reach majority vote to suggest mechanical thrombectomy in patients with deficits that appear nondisabling (eg, mild hypoesthesia ${ }^{149}$ ) at presentation (vote: 5/11 experts).
PICO 8: FOR ADULTS WITH LARGE VESSEL OCCLUSIONRELATED ACUTE ISCHEMIC STROKE, DOES SELECTION OF MECHANICAL THROMBECTOMY CANDIDATES BASED ON A PARTICULAR ASPECTS OR INFARCT CORE VOLUME THRESHOLD COMPARED WITH NO SPECIFIC THRESHOLD: (A) IMPROVE IDENTIFICATION OF PATIENTS WITH A THERAPY EFFECT OF MECHANICAL THROMBECTOMY ON FUNCTIONAL OUTCOME? (B) DECREASE THE RISK OF SYMPTOMATIC INTRACEREBRAL HEMORRHAGE?

Analysis of current evidence and evidence-based recommendation

Of the nine RCTs evaluating MT plus BMMversus BMM within 6 hours of anterior circulation stroke onset, only two large trials (MR CLEAN ${ }^{1}$ and THRACE ${ }^{15}$ ) allowed the enrollment of patients without restrictions for infarct volume or ASPECTS (table 7). CT/CTA was the preferred pretreatment choice in the vast majority of patients, except in the THRACE trial, where MRI was first-line imaging in $73 \%$ of patients.

\section{ASPECTS}

In the HERMES collaboration individual patient data meta-analysis of seven RCTs (MR CLEAN, EXTEND IA, ESCAPE, SWIFT PRIME, REVASCAT, THRACE, and PISTE), ${ }^{23}$ the median ASPECTS was 8 (IQR 7-9) in the patients treated with MT.

Table 7 Exclusion criteria based on ASPECTS or infarct volume in RCTs of MT+BMM versus MT

\begin{tabular}{|c|c|c|}
\hline Trial & Exclusion criteria & $\begin{array}{l}\text { Median (IQR) ASPECTS } \\
\text { or infarct volume }(\mathrm{mL}) \text { of } \\
\text { enrolled patients }\end{array}$ \\
\hline MR CLEAN & None & $\begin{array}{l}\text { MT+BMM: ASPECTS } 9(7-10) \\
\text { BMM: ASPECTS } 9(8-10)\end{array}$ \\
\hline Extend IA & Infarct core $\geq 70 \mathrm{~mL}$ & $\begin{array}{l}\text { MT+BMM: } 12 \mathrm{~mL}(4-32) \\
\text { BMM: } 18 \mathrm{~mL}(4-29)\end{array}$ \\
\hline ESCAPE & ASPECTS $\leq 5$ & $\begin{array}{l}\text { MT+BMM: ASPECTS } 9(8-10) \\
\text { BMM: ASPECTS } 9(8-10)\end{array}$ \\
\hline SWIFT PRIME & ASPECTS $\leq 5$ & $\begin{array}{l}\text { MT+BMM: ASPECTS } 9(7-10) \\
\text { BMM: ASPECTS } 9(8-10)\end{array}$ \\
\hline REVASCAT & $\begin{array}{l}\text { ASPECTS } \leq 6(\mathrm{CT}) \\
\text { ASPECTS } \leq 5(\mathrm{MRI})\end{array}$ & $\begin{array}{l}\text { MT+BMM: ASPECTS } 7 \text { (6-9) } \\
\text { BMM:ASPECTS } 8 \text { (6-9) }\end{array}$ \\
\hline THRACE & None & $\begin{array}{l}\text { DWI lesion volume: } 17 \mathrm{~mL} \\
(9.2-51.8)^{*}\end{array}$ \\
\hline PISTE & $\begin{array}{l}\text { Hypodensity }>1 / 3 \text { of the } \\
\text { MCA territory }\end{array}$ & $\begin{array}{l}\text { MT+BMM: ASPECTS } 9(4-10) \\
\text { BMM: ASPECTS } 9(2-10)\end{array}$ \\
\hline THERAPY & $\begin{array}{l}\text { Hypodensity }>1 / 3 \text { of the } \\
\text { MCA territory }\end{array}$ & $\begin{array}{l}\text { MT+BMM: ASPECTS } 7.5 \\
(6-9) \\
\text { BMM: ASPECTS } 8 \text { (7-9) }\end{array}$ \\
\hline EASI & None & $\begin{array}{l}\text { MT+BMM: ASPECTS } 8 \text { (7-9) } \\
\text { BMM: ASPECTS } 9 \text { (8-9) }\end{array}$ \\
\hline DAWN & Infarct core $\geq 51 \mathrm{~mL}$ & $\begin{array}{l}\text { MT+BMM: } 7.6 \mathrm{~mL}(2.0-18.0) \\
\text { BMM: } 8.9 \mathrm{~mL}(3.0-18.1)\end{array}$ \\
\hline DEFUSE-3 & Infarct core $\geq 70 \mathrm{~mL}$ & $\begin{array}{l}\text { MT+BMM: } 9.4 \mathrm{~mL}(2.3-25.6) \\
\text { ASPECTS } 8 \text { (7-9) } \dagger \\
\text { BMM: } 10.1 \mathrm{~mL}(2.1-24.3) \\
\text { ASPECTS } 8 \text { (7-9) } \dagger\end{array}$ \\
\hline
\end{tabular}

*Patients in whom the qualifying imaging study was MRI. tPatients in whom the qualifying imaging study was $C T$. ASPECTS, Alberta Stroke Program Early CT Score; BMM, best medical management; MCA, middle cerebral artery; MT, mechanical thrombectomy; RCT, randomized controlled trial 
MT was significantly associated with better functional outcome in patients with ASPECTS 8-10 ( $\mathrm{n}=975$; common adjusted $\mathrm{OR}=2.36,95 \%$ CI 1.88 to 2.98$)$, with ASPECTS 5-7 $(\mathrm{n}=617$; common adjusted $\mathrm{OR}=1.58,95 \% \mathrm{CI} 1.19$ to 2.11 ), and also in those with ASPECTS $0-4(n=126$; common adjusted $\mathrm{OR}=2.15$, $95 \%$ CI 1.06 to $\left.4.37, \mathrm{p}_{\text {interaction }}=0.054\right)$. However, the numbers of patients with ASPECTS 0-4 were relatively small-namely, 57/856 (7\%) in the MT plus BMMarm and 69/862 (8\%) in the BMM arm. In this subgroup, MT was not significantly associated with functional independence (adjusted $\mathrm{OR}=2.72$, $95 \%$ CI 0.89 to 8.33 ). Of 11 patients with ASPECTS $0-2$ in the MTplus BMM arm, none achieved functional independence.

There was evidence for heterogeneity across ASPECTS subgroups in the risk of sICH associated with MT ( $\mathrm{p}_{\text {inte }}$ $=0.025)$. In the ASPECTS 0-4 subgroup, the rate of sICH was $10 / 52(19 \%)$ in the MT plus + BMMarm, compared with 3/66 $(5 \%)$ in $\mathrm{BMM}$ arm (unadjusted $\mathrm{p}=0.016$; adjusted $\mathrm{OR}=3.94$, $95 \%$ CI 0.94 to 16.49$)$.

All those results are based on a central reading of ASPECTS by a core laboratory. The applicability of using a specific ASPECTS threshold for treatment decision-making in clinical practice may be challenging because interobserver agreement for non-contrast CT ASPECTS is only moderate in the hyperacute stroke setting. ${ }^{86}$ Furthermore, ASPECTS, which was designed for non-contrast CT, and its MRI counterpart (DWI-ASPECTS) are not equivalent, owing to the higher sensitivity of diffusion MRI to diagnose acute ischemia. It has been reported that for a given patient, the DWI-ASPECTS is generally one point lower that (CT-)ASPECTS. ${ }^{87}$ Accordingly, the ASPECTS threshold for eligibility to participate in the REVASCAT trial was $\geq 7$ and $\geq 6$ in patients imaged by CT and MRI, respectively.

\section{Infarct volume}

The HERMES collaboration recently led to a patient-level pooled analysis of CTP or MRI DWI-based infarct core volume in seven RCTs, which has been recently published. ${ }^{88}$ Pretreatment CTP was available in a total of 591 (34\%) patients and the volume of infarct core, defined as relative cerebral blood flow $<30 \%$ of normal brain, was estimated with automated software. DWI-MRI was available for 309 (18\%) patients and the volume of infarct core was defined as an apparent diffusion coefficient of $<620 \mu \mathrm{m}^{2} / \mathrm{s}$. Median CTP-estimated infarct core volume was $10 \mathrm{~mL}$ (IQR 3-28 mL) and median DWI-estimated infarct core volume was $21 \mathrm{~mL}$ (IQR $10-52 \mathrm{~mL}$ ). Increasing infarct core volume was associated with a reduced likelihood of functional independence (mRS score 0-2): CTP OR $=0.77$ (95\% CI 0.69 to 0.86 ) per $10 \mathrm{~mL}$ increase; DWI-MRI OR $=0.87$ (95\% CI 0.81 to 0.94 ) per $10 \mathrm{~mL}$ increase.

However, there was no significant modification of treatment effect by infarct volume. In the small subgroup of patients with $>70 \mathrm{~mL}$ infarct core volume on CTP $(\mathrm{n}=50$, median $100 \mathrm{~mL}$, IQR $82-144 \mathrm{~mL}$ ), two (8\%) of 25 patients treated with MT and none of 25 control patients achieved functional independence. The unadjusted common OR for better functional outcome associated with MT was 3.1 (95\% CI 1.0 to 9.4) in this subgroup, but the sample size did not allow meaningful adjustment on potential confounders. The number needed to treat (NNT) remained stable across the spectrum of core volumes (NNT $<10$ for functional independence).

The two RCTs randomizing patients exclusively beyond 6 hours had stringent inclusion criteria for infarct volume (table 3). DAWN used a stratification by age and NIHSS score, leading to differing maximum infarct core cut-off volumes measured by imaging software in an automated fashion ( $>80$ years core cut-off volume up to $20 \mathrm{~mL},<80$ years, and NIHSS score 10-19 core volume up to $30 \mathrm{~mL},<80$ years and NIHSS score $\geq 20$ core volume up to $50 \mathrm{~mL}) .^{9}$ DEFUSE-3 allowed a core volume up to $70 \mathrm{~mL}$, but required the presence of a perfusion mismatch. ${ }^{10}$ The median infarct core volumes were 8 (75thcentile: $20 \mathrm{~mL}$ ) and $10 \mathrm{~mL}$ (75thcentile: $25 \mathrm{~mL}$ ) in DAWN and DEFUSE-3, respectively. There was no evidence of a modification of treatment effect by infarct core volume in DEFUSE-3 $\left(\mathrm{p}_{\text {interaction }}=0.47\right)$.

\section{Recommendations}

- In the 0-6hour time window, we recommend mechanical thrombectomy plus best medical management (including intravenous thrombolysis whenever indicated) over best medical management alone in patients with large vessel occlusion-related anterior circulation stroke without evidence of extensive infarct core (eg, ASPECTS $\geq 6$ on non-contrast CT scan or infarct core volume $\leq 70 \mathrm{~mL}$ ).

Quality of evidence: High $\oplus \bigoplus \bigoplus \oplus$; strength of recommendation: Strong $\uparrow \uparrow$

- In the 6-24hour time window, we recommend mechanical thrombectomy plus best medical management (including intravenous thrombolysis whenever indicated) over best medical management alone in patients with large vessel occlusion-related anterior circulation stroke fulfilling the selection criteria of DEFUSE-3* or DAWN** including estimated volume of infarct core.

Quality of evidence: Moderate $\oplus \bigoplus \bigoplus$; strength of recommendation: Strong $\uparrow \uparrow$

- We recommend that patients with anterior circulation stroke with extensive infarct core (eg, ASPECTS $<6$ on non-contrast CT scan or core volume $>70 \mathrm{~mL}$ or $>100 \mathrm{~mL}$ ) be included in randomized controlled trials comparing mechanical thrombectomy plus best medical management with best medical management alone.

Quality of evidence: Very low $\oplus$; strength of recommendation: -

*6-16 hours since time last known well:

- Age $\leq 90$ years and NIHSS $\geq 6$ : infarct core volume $<70 \mathrm{~mL}$ and penumbra volume $>15 \mathrm{~mL}$ and penumbra volume/core vol $>1.8$.

**6-24 hours since time last known well:

- Age $<80$ years: infarct core $\leq 30 \mathrm{~mL}$ if NIHSS score $\geq 10$; infarct core $\leq 51 \mathrm{~mL}$ if NIHSS score $\geq 20$.

- Age $\geq 80$ years: infarct core $\leq 20 \mathrm{~mL}$ and NIHSS score $\geq 10$.

See table 3 for details.

\section{Additional information}

Increased pretreatment infarct volume has been consistently shown to be an independent predictor of functional dependency (mRS score 3-6), worse functional outcome, and mortality in patients undergoing $\mathrm{MT} .{ }^{89-91}$ Randomized controlled trials enrolling patients with low CT-ASPECTS or large infarct core volume are under way (Efficacy and Safety of Thrombectomy in Stroke With Extended Lesion and Extended Time Window [TENSION]: NCT03094715; In Extremis/LASTE). 


\section{Expert opinion}

Expert opinion on thrombectomy in patients with low ASPECTS or large infarct volume

If inclusion of the patient in a dedicated randomized controlled trial is not possible, we suggest that treatment with mechanical thrombectomy may be reasonable on an individual basis in selected cases with ASPECTS $<6$ or core volume $>70 \mathrm{~mL}$ (11/11 experts agree). Patient selection criteria might include age, severity and type of neurological impairment, time since symptom onset, location of the ischemic lesion on plain CT scanner or MRI, and results of advanced imaging, notably perfusion-core mismatch.

\section{PICO 9: FOR ADULTS WITH LARGE VESSEL OCCLUSION- RELATED ACUTE ISCHEMIC STROKE, DOES SELECTION OF MECHANICAL THROMBECTOMY CANDIDATES BASED ON ADVANCED PERFUSION, CORE OR COLLATERAL IMAGING COMPARED WITH NO ADVANCED IMAGING: (A) IMPROVE IDENTIFICATION OF PATIENTS WITH A THERAPY EFFECT OF THROMBECTOMY ON FUNCTIONAL OUTCOME? (B) DECREASE THE RISK OF SYMPTOMATIC INTRACEREBRAL HEMORRHAGE?}

\section{Analysis of current evidence and evidence-based recommendation}

The literature search did not identify any RCT of modern devices that compared the effect of the selection of MT candidates with and without advanced imaging selection (ie, perfusion or core assessment on CTP or MRI, or collateral imaging on multiphase CTA). A higher therapeutic effect was observed in the RCTs randomizing patients in the 0-6hour time window with more extensive use of advanced imaging analysis (EXTEND IA, ${ }^{2}$ ESCAPE, ${ }^{3}$ and SWIFT PRIME ${ }^{4}$ compared with other trials ${ }^{1515-18}$ : the pooled unadjusted ORs for functional independence were 2.84 (95\% CI 2.02 to 4.01 ) and 1.75 (95\% CI 1.39 to 2.20) in trials with and without advanced imaging patient selection, respectively ( $\mathrm{p}=0.02$ for heterogeneity between the two groups; figures 7 and 8).

Importantly, MT plus BMM was clearly better than BMM alone also in trials in which only a plain CT scan and CTA were required before randomization, such as MR CLEAN. ${ }^{1}$

Advanced imaging selection with automated software was mandatory for both RCTs randomizing patients exclusively $>6$ hours after symptom onset or last known well. ${ }^{9}{ }^{10}$

\section{Recommendations}

- In adult patients with anterior circulation large vessel occlusion-related acute ischemic stroke presenting from 0 to 6 hours from time last known well, advanced imaging is not necessary for patient selection.

Quality of evidence: Moderate $\oplus \oplus \oplus$; strength of recommendation: Weak $\downarrow$ ?

- In adult patients with anterior circulation large vessel occlusion-related acute ischemic stroke presenting beyond 6 hours from time last known well, advanced imaging selection is necessary.

Quality of evidence: Moderate $\oplus \oplus \oplus$; strength of recommendation: Strong $\uparrow \uparrow$

\section{Additional information}

Three of the 0-6hour RCTs initially required confirmation of salvageable brain tissue (ESCAPE, ${ }^{3}$ EXTEND IA, ${ }^{2}$ and SWIFT PRIME $^{4}$ either by defining small ischemic cores in combination with the presence of salvageable brain tissue (SWIFT PRIME and EXTEND IA) and/or adequate collateral flow (ESCAPE). Within EXTEND IA and SWIFT PRIME, detection of salvageable tissue was attempted using automated perfusion postprocessing software in $100 \%$ and $81 \%$ of patients. SWIFT PRIME used the same software for the first 71 patients. After enrollment of the first 71 patients, the investigators added the alternate criterion of ASPECTS $\geq 6$ for sites which did not have automated CTP capability. In ESCAPE, multiphase CTA was used to select patients with moderate to good collateral circulation (filling of $\geq 50 \%$ pial arterial circulation visualized). ${ }^{92}$

In the HERMES collaboration individual patient data meta-analysis, there was no significant modification of treatment effect by collateral grade $\left(\mathrm{p}_{\text {interaction }}=0.30\right)$. The adjusted common OR for better functional outcome was 1.49 (95\% CI 0.86 to 2.55 ) in the subgroup of patients with poor collaterals (grade $0-1 ; n=211 / 1278$ ). ${ }^{23}$

Both RCTs exclusively enrolling patients beyond the 6-hour time window mandated the use of automated software processing of either CTP or MRI (table 3). ${ }^{910}$ The DAWN trial (0-24 hours)

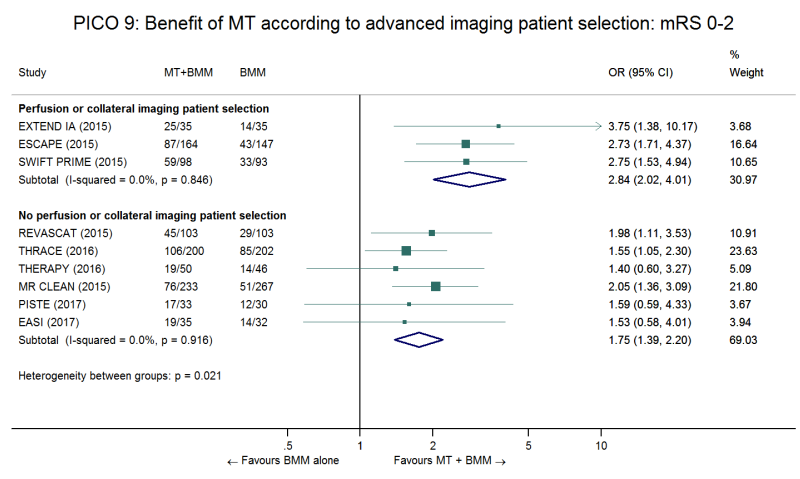

Figure 7 Therapy effect of MT plus BMM versus BMM alone on functional independence, according to advanced imaging patient selection. Unadjusted pooled odds ratios, fixed-effect meta-analysis. BMM, best medical management; mRS, modified Rankin Scale; MT, mechanical thrombectomy.

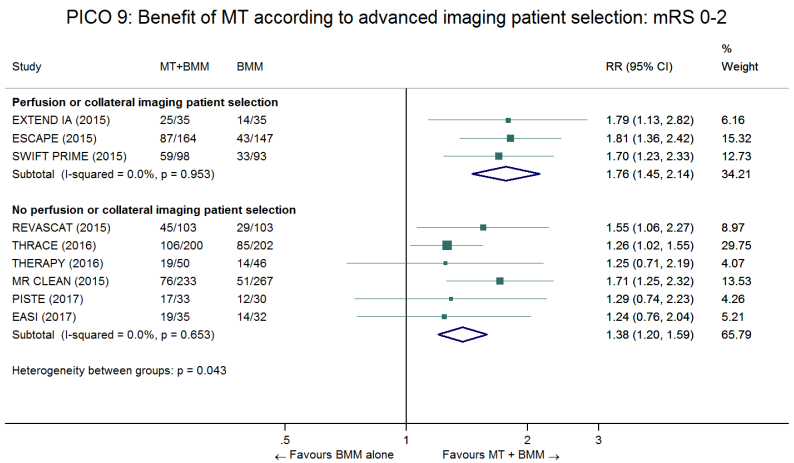

Figure 8 Therapy effect of MT plus BMM versus BMM alone on functional independence, according to advanced imaging patient selection. Unadjusted pooled risk ratios, fixed-effect metaanalysis. BMM, best medical management; mRS, modified Rankin Scale; MT, mechanical thrombectomy. 
used clinical imaging (core) mismatch as the inclusion criterion, whereas DEFUSE-3 (0-16 hours) used perfusion-core mismatch and maximum core size to select patients with LVO for enrollment. Both trials showed a significant improvement in functional outcome at 90 days with MT (see PICO question 2).

A subgroup analysis of CTP data from MR CLEAN suggested that this method could be useful for predicting functional outcome but not for reliable identification of patients who will not benefit from endovascular treatment. ${ }^{93}$

It has been consistently shown that advanced perfusion imaging can identify those patients with good clinical prognosis and high therapy effect. ${ }^{94-99}$

\section{Expert opinion}

Within the 0-6 hour time window, patient selection with perfusion or collateral imaging does modify the expected therapy effect. However, patient selection with advanced imaging may exclude a substantial proportion of patients who have the potential to respond favorably to reperfusion. The possible enhanced benefit of advanced perfusion or collateral image processing using new thresholds (ie, larger core infarction volumes) for patient selection may justify further study, especially in the 0-6 hour time window.

Within the 6-24hour time window, specific national and regional resources and their limitations need to be considered in choosing optimal imaging-based patient selection.
Consequently, regions with limited MT resources should apply the most advanced imaging capabilities available for strict patient selection.

\section{PICO 10: FOR ADULTS WITH LARGE VESSEL OCCLUSION-RELATED ACUTE ISCHEMIC STROKE, DOES MECHANICAL THROMBECTOMY PERFORMED IN A COMPREHENSIVE STROKE CENTER COMPARED WITH MECHANICAL THROMBECTOMY PERFORMED OUTSIDE OF A COMPREHENSIVE STROKE CENTER: (A) IMPROVE FUNCTIONAL OUTCOME? (B) REDUCE TIME TO REPERFUSION? (C) REDUCE THE RATE OF SYMPTOMATIC INTRACEREBRAL HAEMORRHAGE?}

Analysis of current evidence and evidence-based recommendation

The literature search did not identify RCTs of MT performed in a comprehensive stroke centre compared with MT performed outside of a comprehensive stroke centre. The RCTs that showed superiority of MT plus BMM over BMM alone had following common minimum characteristics for centres appropriate to conduct $\mathrm{MT}^{1-515}$ :

- An established organization to support rapidly instituted IV recombinant tissue plasminogen activator (rtPA) use.

- Team organization of a level sufficient to support clinical trial participation.

Table 8 Center requirements to participate in the main thrombectomy trials showing a benefit of MT plus BMM versus BMM alone

\begin{tabular}{|c|c|}
\hline Trial & Criteria \\
\hline MR CLEAN ${ }^{1}$ & $\begin{array}{l}\text { The intervention team should have ample experience with endovascular interventions for cerebrovascular disease, peripheral artery disease, or coronary } \\
\text { artery disease. At least one member of the intervention team should have sufficient experience with intra-arterial thrombolysis (IAT). } \\
\text {... At least one member of the intervention team should have sufficient experience with the particular device (defined as completion of at least five full } \\
\text { procedures with the particular device). Procedures that have been carried out by two team members (for example, in a training setting) count. Procedures } \\
\text { do not need to be successful, or uncomplicated. Procedures consisting of mechanical thrombectomy combined with IAT count for both. } \\
\text {... The possibility of treatment by an interventionalist with sufficient experience is listed as an inclusion criterion.' }\end{array}$ \\
\hline EXTEND IA ${ }^{2}$ & Sites were required to have an established intravenous rtPA program with multimodal CT or MRI as standard procedure. \\
\hline ESCAPE $^{3}$ & $\begin{array}{l}\text { Sites were required to employ CTA as standard of care for patients with acute stroke and have effective systems for identification of patients. } \\
\text { In addition, the protocol stated that 'the quality of intervention will be ensured by hand-selection of sites and only be approved by the executive committee after a } \\
\text { site visit. All sites must submit evidence within the } 2 \text { years prior to commencement of the trial that they can meet the } 90 \text { min target of CTA-to-recanalization time. A } \\
\text { key and critical component of the trial will be an ongoing quality assurance programme to ensure that sites can meet these targets for endovascular intervention. } \\
\text { Training will be undertaken at the sites and continued on a quarterly basis. Monitoring of interval times will be collated and provided to sites on a quarterly basis so } \\
\text { that regular feedback might induce appropriately fast treatment processes. Sites that fail to meet these objectives in the trial will be dropped from the trial.' }\end{array}$ \\
\hline REVASCAT $^{5}$ & $\begin{array}{l}\text { Conducted in the setting of a regional network of acute stroke care, covering a population of } 7.5 \text { million in a compact geographical region of Catalonia. No trial } \\
\text { specified the characteristics of a network, only of individual participating centres. }\end{array}$ \\
\hline SWIFT-PRIME ${ }^{4}$ & $\begin{array}{l}\text { In addition to general criteria related to GCP, other criteria were: } \\
\text { Previous experience with clinical research and mechanical thrombectomy procedures } \\
\text { Experience in conducting randomized, controlled, clinical studies } \\
\text { Currently treating subjects who meet the inclusion/exclusion criteria } \\
\text { Ability to enrol an adequate number of subjects } \\
\text { - Ability and willingness to randomize study subjects } \\
\text { - Ability to perform required clinical testing, including angiography, CT, and MRI }\end{array}$ \\
\hline THRACE ${ }^{15}$ & No mention of specific centre requirements. \\
\hline DAWN $^{9}$ & No mention of specific centre requirements. \\
\hline DEFUSE-3 $3^{10}$ & $\begin{array}{l}\text { No mention of specific centre requirements } \\
\text { Interventionalists had to meet to following requirements: } \\
\text { - Training: satisfactory completion of a 7-year ACGME approved neurosurgical residency OR Board certification (ABMS) Board in Neurology with } \\
\text { subspecialty certification from an ACGME-accredited Vascular/Stroke Neurology Fellowship OR Board certification (ABMS) Board (Radiology) with } \\
\text { subspecialty certification in neuroradiology AND interventionalist has completed a minimum of } 12 \text { months of continuous training as a fellow in a } \\
\text { dedicated neuroendovascular fellowship } \\
\text { - Experience: interventionalist has performed a minimum of } 200 \text { cerebral angiograms AND has performed at least } 20 \text { stroke thrombectomy cases with } \\
\text { stent retrievers and/or suction thrombectomy devices as a primary operator. (When a prospective interventionalist had extensive experience performing } \\
\text { endovascular thrombectomies, but did not fully meet the training requirements, they could be approved by unanimous vote of the four-member } \\
\text { DEFUSE-3 endovascular committee.) }\end{array}$ \\
\hline
\end{tabular}


- Experience with acute CT interpretation including ASPECT scoring.

- Experience with CTA in patients with acute stroke as a minimum additional imaging modality.

- A process for monitoring door to needle/groin puncture/ reperfusion, and procedural duration times, and a governance process to ensure that these are reviewed.

- Implementation of door-to-needle time minimization strategies as for IV rtPA use.

- Minimum institutional and individual experience of cerebrovascular procedures in general, of thrombectomy for acute stroke, and of the specific device.

The generalizability of the trial findings to centres or interventional teams that do not fulfil these criteria is not established by the literature.

Table 8 summarizes the center requirements to participate in each RCT showing a benefit of MT plus BMMversus BMM alone.

A recent study based on administrative data assessed mortality rates among 8533 patients admitted for MT in 118 US centers, showing a negative correlation between institutional procedural volume and mortality $(r=-0.24, p=0.007) .{ }^{100}$ Numeric cut-offs points for institutional procedural volumes that yielded the greatest differences in mortality index were $\leq 7$ procedures a year (low-volume thrombectomy centers) and $>35$ procedures a year (high-volume thrombectomy centers). A lower mortality rate among patients treated with MT who were transferred to high-volume centers compared with those directly admitted to low-volume centers was observed $(10.0 \%$ vs $20.4 \%$; $\mathrm{p}=0.005)$. The authors concluded that the benefit of greater institutional procedural experience may mitigate the delay in reperfusion associated with hospital transfer.

\section{Recommendation}

In adult patients with large vessel occlusion-related acute ischemic stroke, we recommend treatment in a comprehensive stroke center.

Quality of evidence: Very low $\oplus$; strength of recommendation: Strong $\uparrow \uparrow$

In the above recommendation, 'comprehensive stroke center' refers to centers meeting the definition of 'ESO Stroke Center' according to the ESO recommendations. ${ }^{101}$

\section{Expert opinion}

The same organizational components that have been shown to achieve rapid door-to-needle times for intravenous thrombolysis will be required also for provision of MT. ${ }^{102}$ Process improvements have been documented in a number of publications and guidelines, which have been shown to improve treatment times when translated into a different healthcare environment. ${ }^{103}$ The additional components required for implementation of MT should include early notification of the interventional team, and neuroradiology workflow that minimizes acquisition, processing, and interpretation of additional imaging to select patients for MT. ${ }^{78}$

A group of international multidisciplinary societies involved in MT for acute ischemic stroke, have put forth training guidelines. Formal neuroscience training, stringent peer review, and quality assurance processes are critical to ensuring the best possible patient outcomes. ${ }^{104}$ The key specifications are:

- The operator must have a training in radiology, neurology, or neurosurgery, which should include documented training in the diagnosis and management of acute stroke, the interpretation of cerebral arteriography and neuroimaging under the supervision of a neuroradiologist, neurologist or neurosurgeon with subsequent eligibility or certification. Those physicians who do not have adequate training during their residencies must spend an additional period (at least 1 year) training in clinical neurosciences and neuroimaging.AND:

- Dedicated training in interventional neuroradiology (also termed endovascular neurosurgery or interventional neurology) under the direction of a neurointerventionalist (with neuroradiology, neurology, or neurosurgical training background), at a high-volume centre. It is preferred that this is a dedicated time (minimum of 1 year), which occurs after graduating (ie, a fellowship).

\section{PICO 11: FOR ADULTS WITH LARGE VESSEL OCCLUSION- RELATED ACUTE ISCHEMIC STROKE, DOES REPERFUSION TICI GRADE 3 COMPARED WITH REPERFUSION TICI GRADE 2B IMPROVE FUNCTIONAL OUTCOME? \\ Analysis of current evidence and evidence-based recommendation}

The TICI grading system was described in 2003 as tool for grading the response of thrombolytic therapy for ischemic stroke from grade 0: no perfusion, to grade 3: complete perfusion. ${ }^{105}{ }^{106}$ In neurointerventions, it is the standard for patients after endovascular revascularization. Successful reperfusion is defined as a TICI score of $2 \mathrm{~b}$ or $3 .^{107}$

The literature search did not identify RCTs comparing the effect of attempting a reperfusion result of TICI grade 3 versus TICI grade $2 \mathrm{~b}$. A dedicated systematic review and study-level meta-analysis included 14 studies with available follow-up. ${ }^{108}$ Eleven of the 14 studies were retrospective observational studies, while one currently unpublished study examined different degrees of successful reperfusion in the HERMES collaboration of recent endovascular trials. ${ }^{109}$ TICI 3 and $2 \mathrm{~b}$ were achieved in 1131 and 1248 patients, respectively.

In the meta-analysis, TICI 3 reperfusion was associated with higher rates of functional independence ( $\mathrm{mRS}$ score $\leq 2$ : $\mathrm{OR}=1.74,95 \% \mathrm{CI} 1.44$ to 2.10 ), also after including adjusted estimates. Owing to the observational design of available studies, the quality of evidence for the present recommendations was considered to be low (table 9).

Table 9 Summary of findings for PICO 11

\begin{tabular}{|c|c|c|c|c|c|c|c|c|c|c|c|c|}
\hline \multicolumn{7}{|c|}{ Certainty assessment } & \multicolumn{2}{|c|}{ No of patients } & \multicolumn{2}{|l|}{ Effect } & \multirow[b]{2}{*}{$\begin{array}{l}\text { Quality of } \\
\text { evidence }\end{array}$} & \multirow[b]{2}{*}{ Importance } \\
\hline $\begin{array}{l}\text { No of } \\
\text { studies }\end{array}$ & Study design & Risk of bias & Inconsistency & Indirectness & Imprecision & $\begin{array}{l}\text { Other } \\
\text { considerations }\end{array}$ & $\mathrm{TICl} 3$ & $\mathrm{TICl} 2 \mathrm{~b}$ & $\begin{array}{l}\text { Relative } \\
(95 \% \mathrm{Cl})\end{array}$ & $\begin{array}{l}\text { Absolute } \\
(95 \% \mathrm{Cl})\end{array}$ & & \\
\hline \multicolumn{13}{|c|}{ mRS score 0-2 } \\
\hline 14 & $\begin{array}{l}\text { Observational } \\
\text { studies }\end{array}$ & Not serious & Not serious & Not serious & Not serious & None & $-/ 1131$ & $-/ 1248$ & $\begin{array}{l}\mathrm{OR}=1.74 \\
(1.44 \text { to } 2.10)\end{array}$ & & $\begin{array}{l}\oplus \oplus \bigcirc \bigcirc \\
\text { LOW }\end{array}$ & CRITICAL \\
\hline
\end{tabular}

$\mathrm{Cl}$, confidence interval; OR, odds ratio; $\mathrm{TICl}$, Thrombolysis in Cerebral Infarction. 


\section{Recommendation}

For adults with large vessel occlusion-related acute ischemic stroke, we recommend that interventionalists should attempt a $\mathrm{TICl}$ grade 3 reperfusion, if achievable with reasonable safety.

Quality of evidence: Low $\oplus \bigoplus$; strength of recommendation: Strong $\uparrow \uparrow$

\section{Additional information}

This effect superiority of TICI 3 over TICI $2 \mathrm{~b}$ seems to be independent of time and collaterals. ${ }^{108}$ The safety profile of patients with TICI 3 was superior, as demonstrated by lower rates of mortality (OR $=0.59,95 \% \mathrm{CI} 0.37$ to 0.92$)$ and $\mathrm{sICH}(\mathrm{OR}=0.42$, $95 \%$ CI 0.25 to 0.71$).^{108}$

A low number of thrombectomy attempts leading to TICI 3 is additionally associated with better outcome. A recent analysis suggested a higher rate of functional independence with first pass effect (single pass, TICI 3, no rescue therapy) when compared with final TICI 3 with more than one pass, any TICI $2 b$, or TICI $2 b$ from the first pass $(61.3 \%$ vs $45 \%[p=0.07]$, $44.3 \%[\mathrm{p}=0.02]$, and $52.4 \%[\mathrm{p}=0.35]) .^{110}$

Generally, new scoring systems do not seem to be better than the traditional TICI. ${ }^{111}$ A modified TICI scoring system has been suggested (mTICI) that includes an additional TICI score category (TICI 2c) comprising a near complete reperfusion except for slow flow or distal emboli in a few distal cortical vessels. ${ }^{112}$ Another group recently suggested the oTICI 2c scale, which subdivides grade $2 \mathrm{~b}$ into $2 \mathrm{~b}$ with $50-66 \%$ reperfusion and $2 \mathrm{~b}$ with $67-90 \%$ reperfusion. Here, reperfusion of $90-99 \%$ is referred to as grade $2 c^{113}$

\section{Expert opinion}

There is consensus that TICI 3 reperfusion is associated with a better outcome and better safety profile than TICI $2 \mathrm{~b}$ reperfusion. As reperfusion quality is the most important modifiable predictor of patients' outcome, a more conservative definition of reperfusion success and further evaluation of treatment approaches geared towards achieving TICI 3 reperfusion are desirable. ${ }^{108} 114$

The key practical question is when to stop a procedure after incomplete reperfusion and when to pursue further reperfusion attempts that might increase the risk of complications A dedicated study could randomize these approaches after a predefined number of reperfusion attempts.

The key research question is which method is associated with the highest rate of TICI 3 with the lowest number of passes-for example, the highest first pass effect. The methods to be investigated include the access material, reperfusion devices, and combinations thereof.

\section{PICO 12: FOR ADULTS WITH LARGE VESSEL OCCLUSION- RELATED ACUTE ISCHEMIC STROKE, DOES MECHANICAL THROMBECTOMY USING DIRECT ASPIRATION COMPARED WITH A STENT RETRIEVER (A) IMPROVE FUNCTIONAL OUTCOME? (B) INCREASE THE RATE OF COMPLETE RECANALIZATION? \\ Analysis of current evidence and evidence-based recommendation}

Stent retrievers were the preferred devices in the pivotal trials demonstrating the benefits of MTplus BMM over BMM alone. ${ }^{1-5}$ Therefore, MT using stent retrievers should be considered as the current standard of care.
THERAPY was a RCT of non-ADAPT (a direct aspiration first pass technique) aspiration thrombectomy after IVT compared with IVT alone in patients with large vessel ischemic stroke because of a thrombus length of $\geq 8 \mathrm{~mm} .{ }^{16}$ The primary efficacy end point was the rate of functional independence at 90 days (mRS score $\leq 2$; intention-to-treat analysis). Enrollment was halted after 108 patients (of 692 planned) because of external evidence of the added benefit of MT plus IVT rather than IVT alone. THERAPY did not achieve its primary end point in this underpowered sample. The Intention-to-treat common OR for better functional outcome was 1.76 (95\% CI 0.86 to $3.59, \mathrm{p}=0.12$ ) in favour of aspiration thrombectomy.

No RCT compared direct aspiration alone with a stent retriever alone in LVO-related strokes. However, two RCTs (ASTER $^{115}$ and COMPASS ${ }^{116}$ ) compared direct aspiration with a stent retriever as first-line therapeutic strategy, with the possibility of switching to another endovascular therapy (rescue treatment).

The ASTER trial compared direct contact aspiration (ADAPT) with stent retriever thrombectomy as first-line therapeutic strategy, with the aim of successful reperfusion (mTICI $\geq 2 \mathrm{~b}$ ) in 381 patients with LVO-related acute ischemic stroke. ${ }^{115}$ Operators were required to perform at least three attempts at reperfusion using the assigned endovascular technique before switching to another endovascular therapy. At the end of all endovascular procedures, the rate of successful recanalization was $85 \%$ in the first-line ADAPT group versus $83 \%$ in the first-line stent retriever group $(p=0.53)$ and the rates of functional independence were not statistically different (90-day mRS score $\leq 2: 45 \%$ vs $50 \%$, $\mathrm{p}=0.38$ ). Successful reperfusion after first-line strategy alone was observed in $63 \%$ versus $68 \%$ of patients in the ADAPT and stent retriever groups, respectively $(\mathrm{p}=0.34)$. After firstline treatment with a stent retriever mTICI 3 was achieved in $35.4 \%$ versus $28.6 \%$ with aspiration. The ASTER trial was designed to show the superiority of contact aspiration versus a stent retriever, and in this regard the trial was unsuccessful. The authors concluded that the ASTER trial was not designed or adequately powered to demonstrate the non-inferiority of ADAPT over stent retriever thrombectomy.

The COMPASS trial, recently presented at the International Stroke Conference 2018, was a prospective, randomized, multicentre non-inferiority trial of first-line aspiration thrombectomy (ADAPT) versus first-line stent retriever thrombectomy. ${ }^{116} 117$ The primary efficacy end point was functional independence at 90 days (mRS score $\leq 2$ ) with secondary end points of mTICI $2 \mathrm{c}-3$ within $45 \mathrm{~min}$ of groin puncture and time to mTICI $2 \mathrm{~b}$ or greater. There was no statistically significant difference in clot location between the two groups. Using the primary modality, TICI $\geq 2 \mathrm{~b}$ was achieved in $83.2 \%$ of patients in the aspiration group versus $81.3 \%$ of the stent retriever group $(p=0.75)$. Functional independence at 90 days was seen in $52 \%$ of patients in the first-line aspiration group versus $49 \%$ of patients in the first-line stent retriever group ( $\mathrm{p}=0.001$ for non-inferiority).

Despite the results of the ASTER and COMPASS trials (figures 9-13 and table 10), we believe that no evidence-based recommendation can be currently provided for the first-line contact aspiration versus first-line stent retriever approaches. Indeed, the COMPASS trial has not been published yet and we feel that more detailed results are needed to make an evidencebased recommendation. 


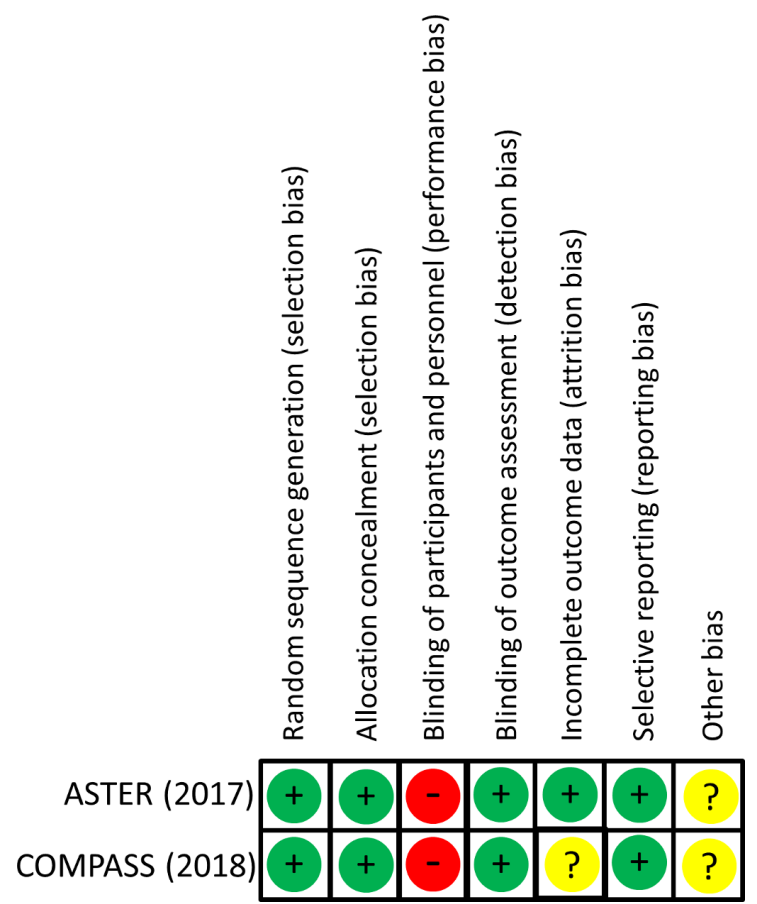

Figure 9 Risk of bias in each trial.

PICO 12: First-line ADAPT vs. First-line stentriever: mRS 0-2

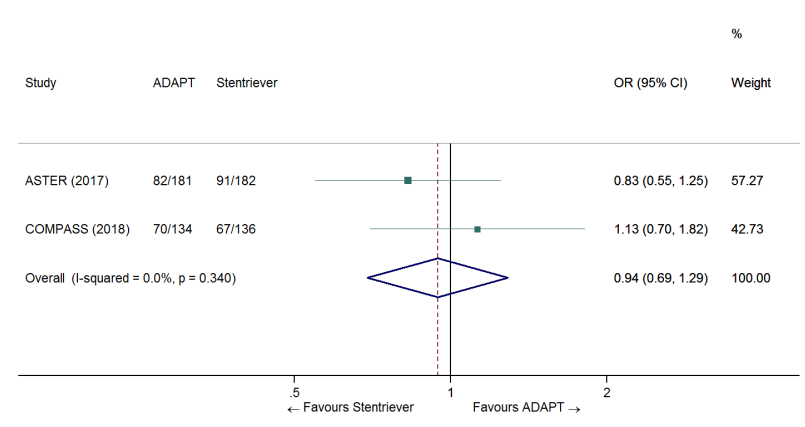

Figure 10 Pooled OR for functional independence in patients treated with first-line ADAPT versus first-line stent retriever. Random-effects meta-analysis. ADAPT, a direct aspiration first pass technique; $\mathrm{mRS}$, modified Rankin Scale.

PICO 12: First-line ADAPT vs. First-line stentriever: mRS 0-2

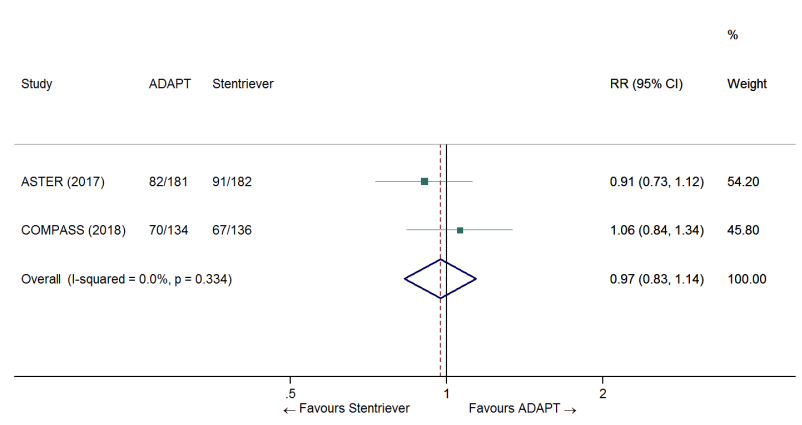

Figure 11 Pooled risk ratio for functional independence in patients treated with first-line ADAPT versus first-line stent retriever. Randomeffects meta-analysis. ADAPT, a direct aspiration first pass technique; mRS, modified Rankin Scale.
PICO 12: First-line ADAPT vs. First-line stentriever: $\mathrm{mTICI} 2 \mathrm{~b}$ or 3 at the end of all procedures

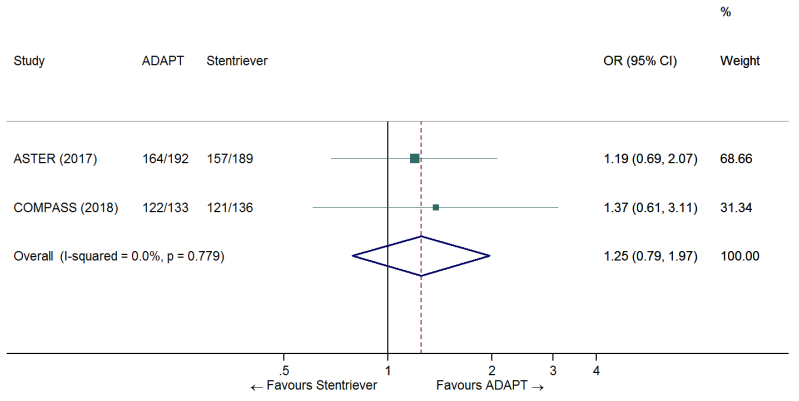

Figure 12 Pooled OR for successful reperfusion in patients treated with first-line ADAPT versus first-line stent retriever. Random-effects meta-analysis. ADAPT, a direct aspiration first-pass technique, $\mathrm{mTICl}$, modified Thrombolysis in Cerebral Infarction.

\section{Recommendations}

There is no evidence that contact aspiration alone improves functional outcome compared with best medical management in patients undergoing mechanical thrombectomy.

- There is no evidence that contact aspiration alone increases the rate of reperfusion over thrombectomy using a stent retriever.

- Therefore, we suggest the use of a stent retriever over contact aspiration alone for mechanical thrombectomy in patients with acute ischemic stroke.

Quality of evidence: Very low $\bigoplus$; strength of recommendation:

Weak $\uparrow$ ?

See expert opinion below for first-line aspiration versus firstline stent retriever, which have been specifically assessed in ASTER and COMPASS.

\section{Additional Information}

In the ASTER trial, there was an uneven distribution of clots between the groups with a higher percentage of M2 occlusions in the aspiration group $(27.6 \%$ vs $17.6 \%)$ and fewer terminal internal carotid artery occlusions $(12.6 \%$ vs $18.7 \%) .{ }^{115}$ In a subgroup analysis of M2 occlusions, the rate of mTICI 3 recanalization when stent retrievers were used as first-line devices was $38.7 \%$, compared with $29.2 \%$ for first-line aspiration $(p=0.33$

PICO 12: First-line ADAPT vs. First-line stentriever: $\mathrm{mTICI} 2 \mathrm{~b}$ or 3 at the end of all procedures

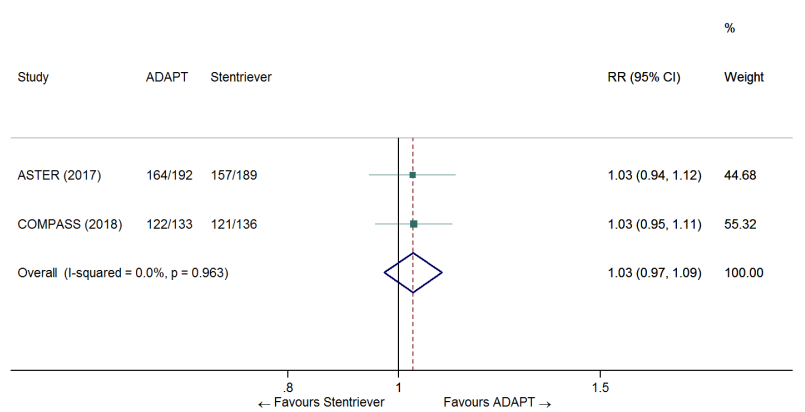

Figure 13 Pooled risk ratio for successful reperfusion in patients treated with first-line ADAPT versus first-line stent retriever. Randomeffects meta-analysis. ADAPT, a direct aspiration first pass technique; $\mathrm{mTICl}$, modified Thrombolysis in Cerbral Infarction. 


\begin{tabular}{|c|c|c|c|c|c|c|c|c|c|c|c|c|}
\hline \multicolumn{7}{|c|}{ Certainty assessment } & \multicolumn{2}{|c|}{ No of patients } & \multicolumn{2}{|l|}{ Effect } & \multirow[b]{2}{*}{$\begin{array}{l}\text { Quality of } \\
\text { evidence }\end{array}$} & \multirow[b]{2}{*}{ Importance } \\
\hline $\begin{array}{l}\text { No of } \\
\text { studies }\end{array}$ & $\begin{array}{l}\text { Study } \\
\text { design }\end{array}$ & $\begin{array}{l}\text { Risk of } \\
\text { bias }\end{array}$ & Inconsistency & Indirectness & Imprecision & $\begin{array}{l}\text { Other } \\
\text { considerations }\end{array}$ & $\begin{array}{l}\text { First-line } \\
\text { ADAPT }\end{array}$ & $\begin{array}{l}\text { First-line } \\
\text { stent retriever }\end{array}$ & $\begin{array}{l}\text { Relative } \\
(95 \% \mathrm{Cl})\end{array}$ & $\begin{array}{l}\text { Absolute } \\
(95 \% \mathrm{Cl})\end{array}$ & & \\
\hline \multicolumn{13}{|c|}{$\mathrm{mRS}$ score $0-2$} \\
\hline 2 & $\begin{array}{l}\text { Randomized } \\
\text { trials }\end{array}$ & Serious* & Not serious & Serioust & Not serious & None & $\begin{array}{l}152 / 315 \\
(48.3 \%)\end{array}$ & $\begin{array}{l}158 / 318 \\
(49.7 \%)\end{array}$ & $\begin{array}{l}\mathrm{RR}=0.97 \\
(0.83 \text { to } 1.14) \\
\mathrm{OR}=0.94 \\
\text { (0.69 to } 1.29)\end{array}$ & $\begin{array}{l}15 \text { fewer per } \\
1000 \\
\text { (from } 70 \text { more } \\
\text { to } 84 \text { fewer) }\end{array}$ & $\begin{array}{l}\oplus \oplus \bigcirc \bigcirc \\
\text { LOW }\end{array}$ & CRITICAL \\
\hline \multicolumn{13}{|c|}{$\mathrm{mTICI} 2 \mathrm{~b}-3$} \\
\hline 2 & $\begin{array}{l}\text { Randomized } \\
\text { trials }\end{array}$ & Serious* & Not serious & Serious & Not serious & None & $\begin{array}{l}286 / 325 \\
(88.0 \%)\end{array}$ & $\begin{array}{l}278 / 325 \\
(85.5 \%)\end{array}$ & $\begin{array}{l}R R=1.03 \\
(0.97 \text { to } 1.09) \\
O R=1.25 \\
\text { (0.79 to } 1.97)\end{array}$ & $\begin{array}{l}26 \text { more per } \\
1000 \\
\text { (from } 26 \text { fewer } \\
\text { to } 77 \text { more) }\end{array}$ & $\begin{array}{l}\oplus \oplus \bigcirc \bigcirc \\
\text { LOW }\end{array}$ & CRITICAL \\
\hline
\end{tabular}

${ }^{*}$ ASTER was not designed or powered to demonstrate non-inferiority.

tRescue therapy with another type of device was allowed in both trials.

ADAPT, a direct aspiration first pass technique; $\mathrm{Cl}$, confidence interval; mRS, modified Rankin Scale; RR, risk ratio; mTICl, modified Thrombolysis in Cerebral Infarction.

for comparison). ${ }^{118}$ Furthermore, in this subgroup analysis the 24-hour change in NIHSS score showed a trend towards better outcomes with stent retriever treatment as did the change in ASPECTS at 24 hours. Similarly, there was a numerically higher mortality rate at 90 days in the aspiration group (19.6\% vs $3.3 \%$, $\mathrm{p}=0.078$ ) and a non-significantly higher rate of procedure-related adverse events in the aspiration group $(14.6 \%$ vs $9.7 \%, \mathrm{p}=0.73)$.

The proportion of patients in the aspiration group who required rescue therapy with a stent retriever in the ASTER and COMPASS trials were $32.8 \%$ and $20.9 \%$, respectively. ${ }^{115} 116$ Retrospective studies have reported the need for rescue treatment with stent retrievers to be as high as $40 \% .{ }^{119}$ A difficulty in interpretation therefore arises since the results of these trials are presented as pooled data. Ideally, the results of patients requiring rescue treatment should be presented separately or a subgroup analysis should be performed similar to the results of the M2 subgroup analysis detailed above.

\section{Balloon guide catheters}

Many have advocated the use of balloon guide catheters (BGCs). However, no RCT has compared the outcomes of patients treated with MT in conjunction with a BGC and those without. Observational studies have suggested that BGCs are associated with higher recanalization rates and improved rates of good neurological outcome. ${ }^{120121}$

A systematic review and meta-analysis on the use of BGCs during MT was recently conducted. ${ }^{122}$ The authors identified five non-randomized studies of 2022 patients (1083 BGC group and 939 non-BGC group), all of whom were treated with stent retrievers. Patients treated with a BGC had higher rates of functional independence ( $\mathrm{mRS}$ score $\leq 2$ ): 59.7\% compared with $43.8 \%$ for non-BGC-treated patients $(\mathrm{OR}=1.84$, 95\% CI 1.52 to $2.22, \mathrm{p}<0.01)$. Mortality rates were significantly lower in the BGC-treated patients $(13.7 \%)$ than in non-BGC treated patients $(24.8 \%)(\mathrm{OR}=0.52,95 \% \mathrm{CI} 0.37$ to $0.73, \mathrm{p}<0.01)$. Similarly, the overall first pass recanalization rate for the BGC group was $63.1 \%$ compared with $45.2 \%$ for the non-BGC group $(\mathrm{OR}=2.05,95 \% \mathrm{CI} 1.65$ to $2.55, \mathrm{p}<0.01)$. The TICI 3 rate was also higher in the BGC group (57.9\%) than in the non-BGC group $(38.2 \%)(\mathrm{OR}=2.13,95 \% \mathrm{CI} 1.43$ to $3.17, \mathrm{p}<0.01)$ with higher rates of TICI $2 \mathrm{~b}-3$ also seen $(78.9 \%$ vs $67.0 \%, \mathrm{OR}=1.54$, $95 \%$ CI 1.21 to $1.97, \mathrm{p}<0.001)$. The mean number of passes was lower for BGC patients $(1.7$ vs $2, \mathrm{p}<0.01)$ and the mean procedure time was shorter $(70.5 \mathrm{~min}$ vs $90.9 \mathrm{~min}, \mathrm{p}<0.01)$
Optimizing mechanical thrombectomy

Several advanced MT techniques have been described in the literature and these include:

- Solumbra: complete retraction of stent retriever into distal aspiration catheter under aspiration. ${ }^{123}$

- ARTS (aspiration retriever technique for stroke): stent retriever locked and removed under continuous aspiration with additional flow arrest. ${ }^{124}$

- SAVE (stent retriever assisted vacuum locked extraction): removal of stent retriever with aspiration catheter as a vacuum locked unit. ${ }^{125}$

- CAPTIVE (continuous aspiration prior to intracranial vascular embolectomy): local aspiration catheter connected to the continuous aspiration pump before deployment of the stent retriever. $^{126}$

Details on reperfusion rates using these techniques is provided in the Supplementary appendix (online supplemental table 2).

\section{Expert opinion}

Expert opinion on aspiration, stent retriever, and proximal balloon guide catheter

Experts (9/11) believe that ADAPT may be used as standard first-line treatment, followed by stent retriever thrombectomy as rescue therapy if needed.

Additionally,

- We did not reach a majority vote on the proposal that distal aspiration should be used only in combination with a stent retriever (3/11 experts).

- 8/11 experts believe that any mechanical thrombectomy procedure should preferably be performed in conjunction with a proximal balloon guide catheter.

\section{PICO 13: FOR ADULTS WITH LARGE VESSEL OCCLUSION- RELATED ACUTE ISCHEMIC STROKE UNDERGOING MECHANICAL THROMBECTOMY, DOES CONSCIOUS SEDATION COMPARED WITH GENERAL ANESTHESIA IMPROVE FUNCTIONAL OUTCOME? \\ Analysis of current evidence and evidence-based recommendation}

Three randomized trials of conscious sedation (CS) versus general anesthesia (GA) in patients receiving MT for acute stroke were identified: SIESTA, ${ }^{127}$ AnSTROKE, ${ }^{128}$ and GOLIATH. ${ }^{129}$ The trials recruited 128,90 , and 150 patients $(n=368$ in total), 
respectively. Of these, 185 patients received CS and 183 patients GA. The risk of bias in each trial was considered low (figure 14). There was no blinding of patients or staff for treatment arm but the end point of interest for the present meta-analysis (mRS score at 90 days, figure 15) was assessed in a blinded fashion. There was a statistically non-significant trend in favor of GA with a RR for an independent outcome (mRS score $\leq 2)$ of $0.74(95 \%$ CI 0.54 to $1.01, \mathrm{p}=0.056 ; \mathrm{I}^{2}=37 \%$, figure 15 ) and a significant OR of 0.55 (95\% CI 0.34 to $0.89, p=0.01 ; \mathrm{I}^{2}=15 \%$, figure 16 ), with both analyses showing low heterogeneity.

Using the risk ratio as summary measure, the absolute effect was 91 fewer (from 4 more to 162 fewer) patients being dependent or dead for 1000 patients treated. Despite the randomized design of these single-center trials, the overall quality of evidence was downgraded to low, owing to serious indirectness and imprecision (table 11).

The HERMES collaboration performed a pooled analysis of individual patient data from seven RCTs of $\mathrm{MT}^{130}$ in which the use of GA was either discouraged $\left(\mathrm{ESCAPE}^{3}\right.$ and REVASCAT trials) or left at the discretion of the investigators. ${ }^{12415} 17$ Two hundred and thirty-six (30\%) of 797 patients who had MT procedures were treated under GA. The protocol for GA or CS was left at the discretion of each investigator. Three-month functional outcome, evaluated in a blinded fashion, was significantly better for patients who did not receive GA than for those who received GA (adjusted common OR for better outcome: 1.53, $95 \%$ CI 1.14 to 2.04 ). The proportion of patients with functional independence was also higher in patients treated without GA $(50 \%$ vs $40 \%$, adjusted $\mathrm{OR}=1.65$, 95\% CI 1.14 to 2.38$)$. Still both outcomes were significantly better for patients treated with MT and GA versus patients in the BMM control arms. ${ }^{130}$ We consider that this analysis represents the best available observational evidence for the present PICO question, because highquality data were prospectively collected and monitored in large multicenter trials, allowing adjustment for several confounders.

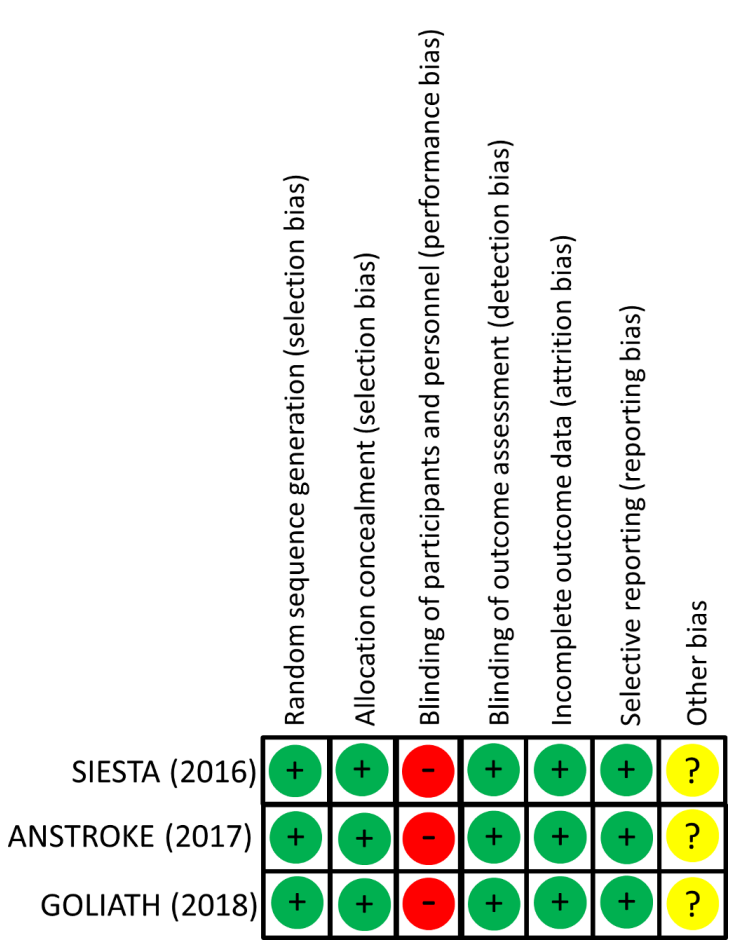

Figure 14 Risk of bias in each randomized trial.
PICO 13: Conscious sedation vs. General anesthesia: mRS 0-2

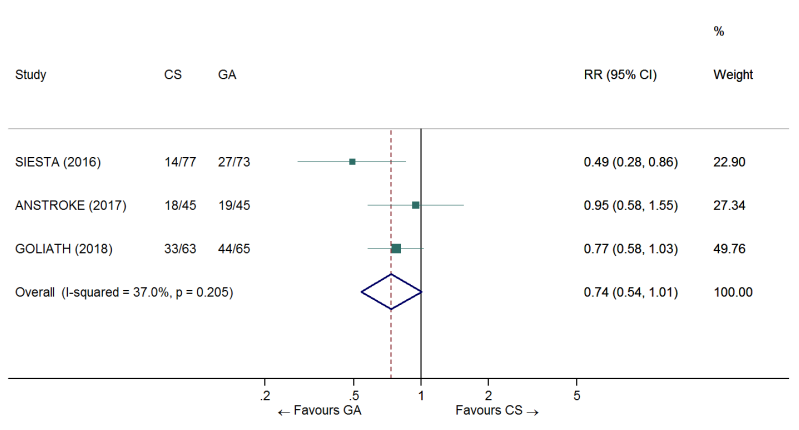

Figure 15 Pooled risk ratio for functional independence in patients undergoing conscious sedation (CS) versus general anesthesia (GA) for mechanical thrombectomy. Random-effects meta-analysis restricted to randomized controlled trials. mRS, modified Rankin Scale.

However, a major limitation of the HERMES data is the high likelihood of confounding by indication. It is likely that patients who underwent GA had more frequently a medically required GA rather than an 'elective' GA. The quality of evidence for the HERMES collaboration analysis was therefore considered very low (table 11). Unfortunately, no information on the indication for GA is available in the HERMES database.

\section{Recommendation}

We cannot provide recommendations to use general anesthesia or conscious sedation in patients undergoing mechanical thrombectomy, due to a low quality of evidence and conflicting results between three small single-center randomized clinical trials and the best available observational evidence. Therefore, we recommend the enrollment of patients in multicenter randomized controlled trials addressing this question.

Quality of evidence: Very low $\oplus$; strength of recommendation: -

\section{Additional information}

Several ongoing RCTs are comparing conscious sedation or local anesthesia versus general anesthesia (SEdation Versus General Anesthesia for Endovascular Therapy in Acute Ischemic

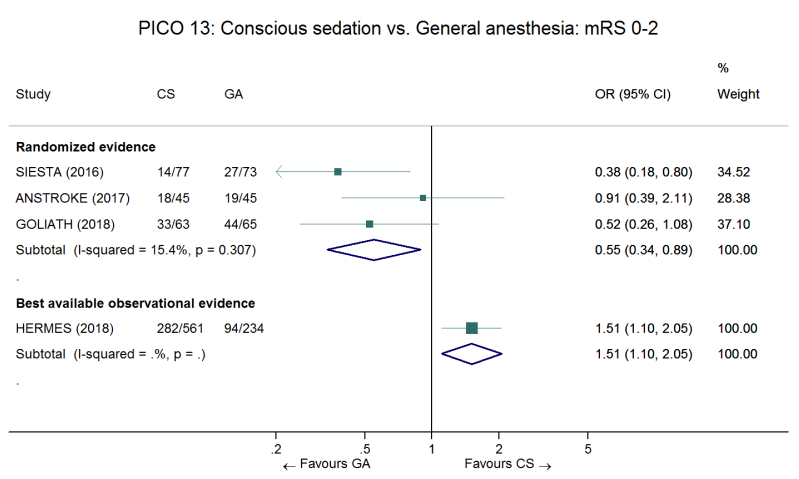

Figure 16 Unadjusted OR for functional independence in patients undergoing conscious sedation (CS) versus general anesthesia (GA) for mechanical thrombectomy. Random-effects meta-analysis. mRS, modified Rankin Scale. 


\begin{tabular}{|c|c|c|c|c|c|c|c|c|c|c|c|c|}
\hline \multicolumn{7}{|c|}{ Certainty assessment } & \multicolumn{2}{|c|}{ No of patients } & \multicolumn{2}{|l|}{ Effect } & \multirow[b]{2}{*}{$\begin{array}{l}\text { Quality of } \\
\text { evidence }\end{array}$} & \multirow[b]{2}{*}{ Importance } \\
\hline $\begin{array}{l}\text { No of } \\
\text { studies }\end{array}$ & Study design & $\begin{array}{l}\text { Risk of } \\
\text { bias }\end{array}$ & Inconsistency & Indirectness & Imprecision & $\begin{array}{l}\text { Other } \\
\text { considerations }\end{array}$ & GA & CS & $\begin{array}{l}\text { Relative } \\
(95 \% \mathrm{Cl})\end{array}$ & $\begin{array}{l}\text { Absolute } \\
(95 \% \mathrm{Cl})\end{array}$ & & \\
\hline \multicolumn{13}{|c|}{ mRS score 0-2 (dedicated RCTs) } \\
\hline 3 & $\begin{array}{l}\text { Randomized } \\
\text { trials }\end{array}$ & Not serious & Not serious & Serious* & Serioust & None & $\begin{array}{l}90 / 183 \\
(49.2 \%)\end{array}$ & $\begin{array}{r}65 / 185 \\
(35.1 \%)\end{array}$ & $\begin{array}{l}\mathbf{R R}=0.74 \\
(0.54 \text { to } 1.01)\end{array}$ & $\begin{array}{l}91 \text { fewer per } \\
1000 \\
\text { (from } 4 \text { more to } 162 \\
\text { fewer) }\end{array}$ & $\begin{array}{l}\oplus \oplus \bigcirc \bigcirc \\
\text { LOW }\end{array}$ & Critical \\
\hline \multicolumn{13}{|c|}{ mRS score 0-2 (HERMES) } \\
\hline 7 & $\begin{array}{l}\text { Observational } \\
\text { studies }\end{array}$ & Seriousł & Not serious & Not serious & Not serious & None & $\begin{array}{l}94 / 234 \\
(40.2 \%)\end{array}$ & $\begin{array}{l}282 / 561 \\
(50.3 \%)\end{array}$ & $\begin{array}{l}\text { OR=1.65 } \\
\text { (1.14 to } 2.38)\end{array}$ & $\begin{array}{l}122 \text { more per } \\
1000 \\
\text { (from } 33 \text { more to } \\
204 \text { more) }\end{array}$ & $\begin{array}{l}\oplus \bigcirc \bigcirc \bigcirc \\
\text { VERY LOW }\end{array}$ & Critical \\
\hline
\end{tabular}

*We believe that the setting in which the interventions in the three RCTs were performed cannot easily be implemented with the same sophistication in daily practice in many centers.

tClinical action would differ if the upper versus the lower boundary of the $95 \% \mathrm{Cl}$ of the risk ratio represents the truth: GA would be recommended if the true RR is 0.54 ; GA would not be recommended if the true RR is 1.01 .

¥Probable indication bias (confounding by indication): it is likely that patients who underwent GA had more frequently a medically required GA rather than an 'elective' GA

$\mathrm{Cl}$, confidence interval; $\mathrm{CS}$, conscious sedation; $\mathrm{GA}$, general anesthesia; $\mathrm{OR}$, odds ratio; $\mathrm{RCTs}$, randomized controlled trials; RR, risk ratio.

Stroke [SEGA]: NCT03263117; General Anesthesia Versus Sedation During Intra-arterial Treatment for Stroke [GASS]: NCT02822144; Anesthesia Management in Endovascular Therapy for Ischemic Stroke [AMETIS]: NCT03229148; Impact of Anesthesia Type on Outcome in Patients With Acute Ischemic Stroke Undergoing Endovascular Treatment [CANVAS]: NCT02677415). The conflicting results of the three RCTs and the HERMES analysis are partially counterintuitive, although partially explained by a strictly standardized anesthesia protocol in the RCTs versus standard of care procedures in patients recruited into the trials analysed in the HERMES collaboration.

\section{Expert opinion}

Expert opinion on anesthesia modalities for mechanical thrombectomy

We suggest that further randomized multicentric data with less bias should be generated. However, if inclusion of the patient in a randomized controlled trial is not possible, 11/11 experts suggest that local anesthesia or conscious sedation may be favored over general anesthesia, if the patient is able to undergo mechanical thrombectomy without general anesthesia. On the other hand, general anesthesia does not need to be avoided if indicated. The decision for or against general anesthesia should be made rapidly and delays to induction of general anesthesia should be minimized. We suggest, that according to the three randomized controlled trials, a specialized neuroanesthesiological or neurocritical care team should perform the general anesthesia procedure, whenever possible. Excessive blood pressure drops should be avoided (see PICO question 14). ${ }^{134}$ Adequate monitoring of vital parameters also of patients under conscious sedation or local anesthesia is advised.

\section{PICO 14: FOR ADULTS WITH LARGE VESSEL OCCLUSION- RELATED ACUTE ISCHEMIC STROKE UNDERGOING MECHANICAL THROMBECTOMY, DOES MAINTAINING BLOOD PRESSURE TO A PARTICULAR TARGET COMPARED WITH AN ALTERNATIVE TARGET IMPROVE FUNCTIONAL OUTCOME?}

\section{Analysis of current evidence and evidence-based} recommendation

Blood pressure (BP) targets, for patients with LVO-related acute ischemic stroke undergoing MT, were not specifically evaluated in RCTs. Post hoc analyses from MR CLEAN indicated a U-shaped correlation between baseline systolic blood pressure (SBP) and functional outcome. ${ }^{131}$ Both low and high baseline SBPs were associated with a 3-month poor functional outcome, whereas higher SBP levels were associated with sICH (adjusted $\mathrm{OR}=1.25$ for every $10 \mathrm{mmHg}$ increment in SBP, 95\% CI 1.09 to 1.44 ). Retrospective studies suggest also an association between baseline SBP and mortality, following a similar U-shaped correlation. During the first 24 hours after MT, each $10 \mathrm{mmHg}$ increment in SBP is associated with increased 3-month poor functional outcome $(\mathrm{OR}=0.70,95 \% \mathrm{CI} 0.56$ to 0.87$)$ and mortality $(\mathrm{OR}=1.49 ; 95 \% \mathrm{CI}, 1.18$ to 1.88$) .{ }^{132}$ Retrospective data also support the proposal that achieving a BP goal below $160 / 90 \mathrm{mmHg}$ is associated with decreased 3-month mortality rates $(\mathrm{OR}=0.08,95 \% \mathrm{CI} 0.01$ to 0.54$) .{ }^{133}$ Additionally, mean arterial BP falls during MT procedures, as low as $10 \%$, were reported to be a risk factor for poor outcome in patients eligible for MT. ${ }^{134}$ Interpretation of these pieces of evidence should be done keeping in mind that studied populations are often heterogeneous, mixing patients with different recanalization statuses (ie, complete versus incomplete or no recanalization), and medical histories (eg, with or without history of hypertension). Indeed, the impact of BP reduction may be different for different patient characteristics. There is no strong evidence to support the use of a specific BP-lowering drug in the setting of MT.

According to the GRADE methodology, the quality of evidence of these recommendations based on observational data was downgraded from low to very low due to indirectness.

\section{Recommendations}

We suggest keeping blood pressure below 180/105 mmHg during, and 24 hours after, mechanical thrombectomy. No specific blood pressure-lowering drug can be recommended. Quality of evidence: Very low $\bigoplus$; strength of recommendation: Weak $\uparrow$ ?

- During mechanical thrombectomy systolic blood pressure drops should be avoided.

Quality of evidence: Very low $\oplus$ strength of recommendation: Strong $\downarrow \downarrow$

\section{Expert opinion}

The quality of available studies does not allow the guidelines writing group to provide evidence-based recommendations for a different BP target in patients with versus without successful 
reperfusion. There is evidence from observational studies that patients with successful reperfusion (TICI $2 \mathrm{~b}$ or 3 ) after MT are at risk of reperfusion hemorrhage and may therefore warrant a tight BP control, such as a target below $160 / 90 \mathrm{mmHg}{ }^{133} 135$ Conversely, some authors advocated permissive hypertension in patients with incomplete reperfusion because it may help to optimize collateral blood flow and maintain brain perfusion pressure. ${ }^{136} 137$ In one observational study, $\mathrm{sICH}$ was observed at lower mean values of maximum SBP in patients with successful reperfusion compared with patients without $(170 \pm 9.1 \mathrm{mmHg}$ vs $196 \pm 8.1 \mathrm{mmHg}, \mathrm{p}=0.05) .{ }^{135}$

Expert opinion on blood pressure targets after

mechanical thrombectomy

$11 / 11$ experts think that the degree of reperfusion should be taken into account in the choice of a blood pressure target after mechanical thrombectomy, with a lower blood pressure target in cases of complete reperfusion.

This was also a common viewpoint in a recent U.S. survey. ${ }^{138}$ However, further prospective and randomized data are needed to further inform clinical decision-making.

\section{PICO 15: FOR ADULTS WITH LARGE VESSEL OCCLUSION- RELATED ACUTE ISCHEMIC STROKE AND HIGH-GRADE IPSILATERAL EXTRACRANIAL CAROTID STENOSIS, DOES CERVICAL STENTING IN ADDITION TO MECHANICAL THROMBECTOMY COMPARED WITH MECHANICAL THROMBECTOMY ALONE IMPROVE FUNCTIONAL OUTCOME?}

\section{Analysis of current evidence and evidence-based recommendation}

The only trial in which patients with LVO-related acute stroke underwent randomization for the treatment of an associated cervical carotid stenosis or occlusion was the EASI care trial. ${ }^{18}$ However, that study was not primarily designed nor powered to answer that question, but rather to evaluate MT plus BMM versus BMM alone. The very small numbers of patients simultaneously randomized to treatment or no treatment of a cervical carotid stenosis or occlusion $(n=8)$ does not allow any conclusion to be drawn on the potential benefits of cervical stenting.

Four of the pivotal RCTs of MT allowed the inclusion of patients with extracranial cervical carotid stenosis or occlusion: MR CLEAN, ${ }^{1}$ EXTEND IA, ${ }^{2}$ ESCAPE, ${ }^{3}$ and REVASCAT. ${ }^{5}$ In SWIFT-PRIME, carotid occlusion requiring stenting was an exclusion criterion but angioplasty could be performed. ${ }^{4}$ In all trials, the treatment of a tandem lesion was left to the discretion of the interventionalist, with a wide panel of available endovascular approaches-namely, no treatment of the cervical lesion, angioplasty, stenting, angioplasty plus stenting. It was also left to the discretion of the interventionalist whether the cervical lesion or the intracranial occlusion should be treated first. Hence, those trials do not allow any conclusion to be drawn about the best strategy for treating extracranial stenosis or occlusion.

Importantly, benefit from MT was observed for patients with or without extracranial cervical carotid stenosis or occlusion: in an individual patient data meta-analysis of the first five RCTs conducted by the HERMES collaboration, common ORs for a better functional outcome were 2.95 (95\% CI 1.38 to 6.32) and 2.35 (95\% CI 1.68 to 3.28$)$ in patients with and without tandem lesion, respectively ( $\mathrm{p}$ value for interaction $=0.17$ ). ${ }^{6}$
Recommendation

- No recommendation can be provided regarding which treatment modality should be favored in patients with large vessel occlusion-related acute ischemic stroke and associated extracranial carotid artery stenosis or occlusion. We recommend the inclusion of such patients in dedicated randomized controlled trials.

Quality of evidence: Very low $\oplus$; strength of recommendation:-

\section{Additional information}

A recently published systematic review and meta-analysis aimed to compare the following therapeutic approaches in adults with LVO-related acute ischaemic stroke and extracranial carotid occlusion (ie, tandem occlusion): (a) stenting versus angioplasty alone for the extracranial lesion and (b) treatment of the intracranial versus extracranial lesion first. ${ }^{139}$ However, the number of patients in each study was very small and most importantly only indirect comparisons could be performed, without adjustment for potential confounding factors. A total of 13 studies provided data in patients undergoing extracranial stenting, with a pooled rate of functional independence (mRS score $\leq 2)$ of $49 \%$ (95\% CI $42 \%$ to $56 \%, \mathrm{I}^{2}=54 \%$ ), while three studies provided data in patients solely treated with angioplasty, with a pooled rate of functional independence of $49 \%$ (95\% CI $33 \%$ to $\left.65 \%, I^{2}=50 \%\right)$. There was no significant heterogeneity between the two groups $(p=0.39)$. There was also no evidence of significant heterogeneity in the pooled rates of functional independence in patients treated with the 'intracranial first' (seven studies; $49 \%, 95 \% \mathrm{CI} 39 \%$ to $60 \%, \mathrm{I}^{2}=31 \%$ ) or 'extracranial first' (eight studies; $53 \%, 95 \%$ CI $44 \%$ to $61 \%, \mathrm{I}^{2}=11 \%$ ) therapeutic approaches $(\mathrm{p}=0.58$ for heterogeneity between the two groups).

Another recent systematic review and meta-analysis, including predominantly retrospective multicenter studies, reported that stenting for extracranial cervical carotid stenosis or occlusion was associated with a pooled rate of functional independence of $53 \%(95 \%$ CI $43 \%$ to $62 \%)$, a mTICI $\geq 2$ b rate of $80 \%(95 \%$ CI $73 \%$ to $87 \%)$, a 90 -day mortality rate of $14 \%(95 \%$ CI $9 \%$ to $19 \%)$, and a symptomatic intracranial hemorrhagic rate of $7 \%$ $(95 \%$ CI $4 \%$ to $12 \%) .{ }^{140}$

\section{Expert opinion}

Overall, the above-mentioned results are comparable to those of patients without extracranial cervical carotid stenosis who undergo MT. Emergency stenting in patients undergoing thrombectomy also seemed to be reasonably safe without an increase of sICH, especially if glycoprotein IIb/IIIa inhibitors are avoided. ${ }^{141}$

Expert opinion on carotid artery stenting in mechanical thrombectomy patients with high-grade cervical stenosis or occlusion

9/11 experts suggest that if inclusion in a dedicated randomized controlled trial is not possible, patients with high-grade stenosis or occlusion may be treated with intraprocedural stenting if unavoidably needed.

Restoration to normal caliber (100\%) of the carotid stenosis should probably be avoided in the acute stage as it might increase the risk of reperfusion injury and intracerebral haemorrhage. 


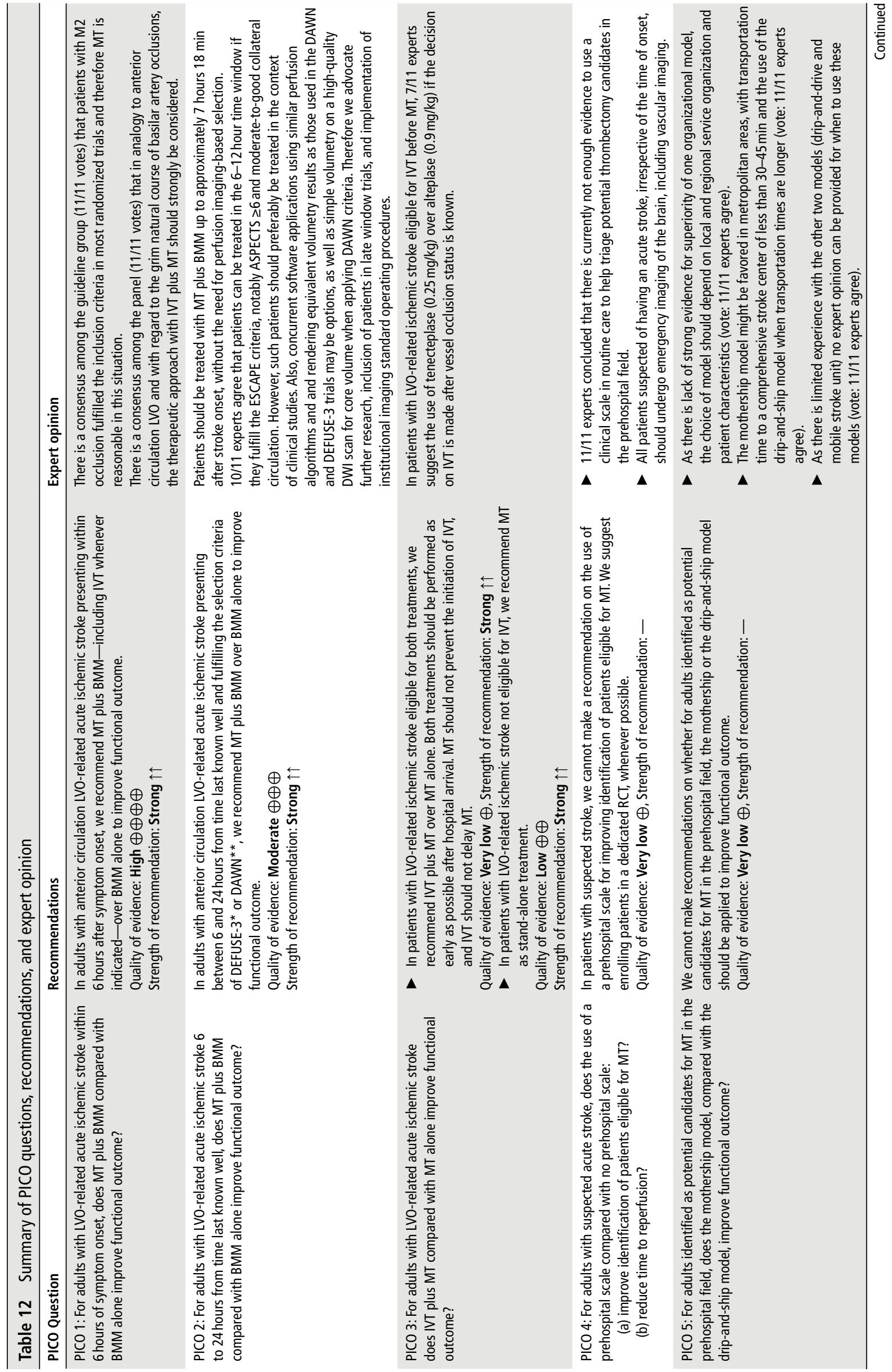




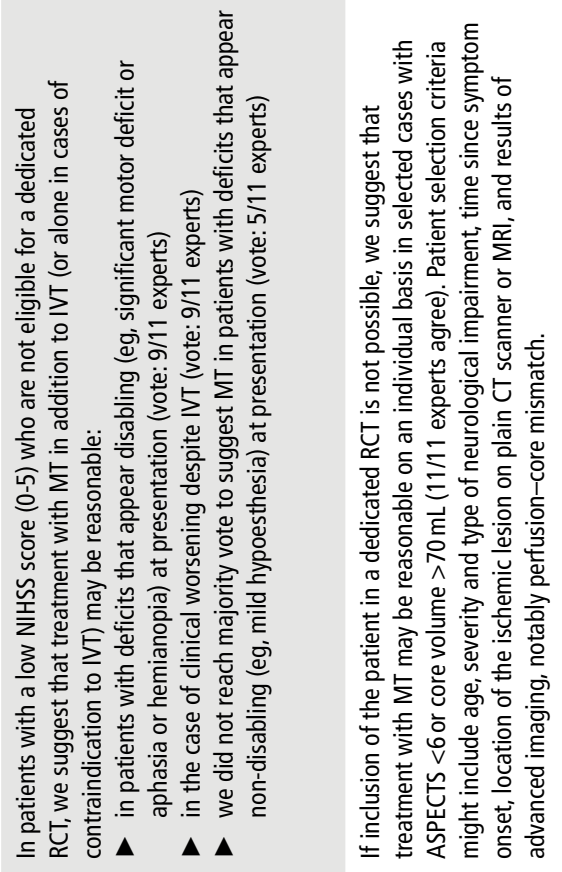

竞点

$\frac{5}{9}$

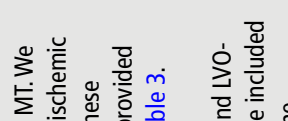

童总

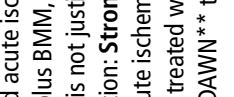

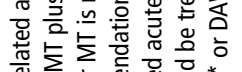

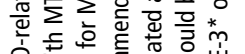

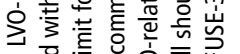

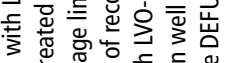

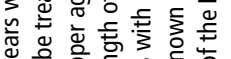

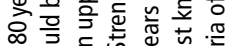

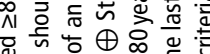

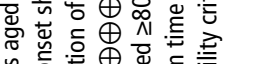

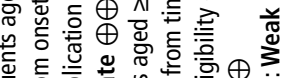

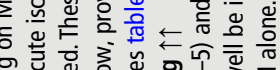

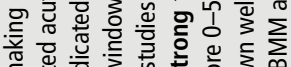

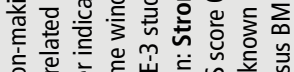

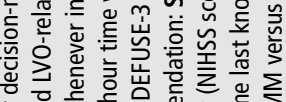

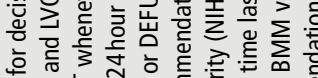

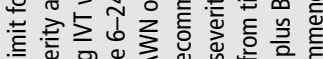

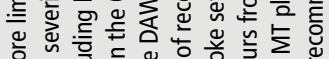

은

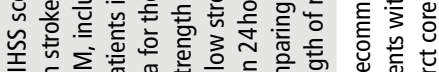

总总

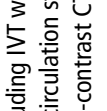

른

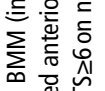

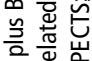

象定

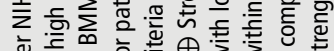

空

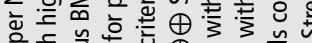

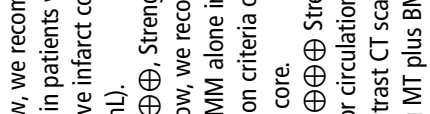

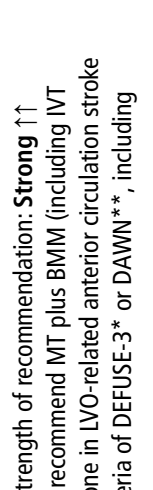

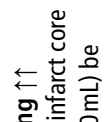

空

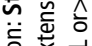

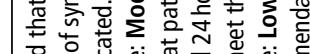

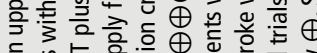

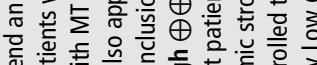

3.

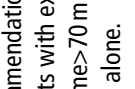

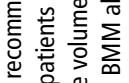

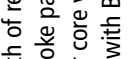

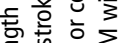

등 댕

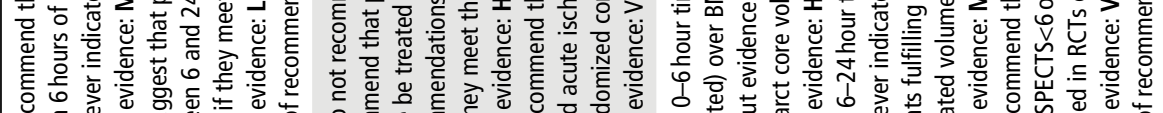

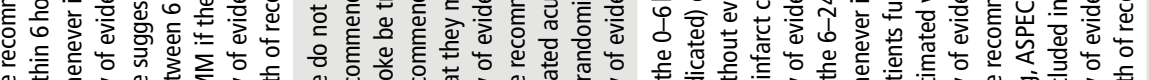

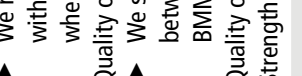

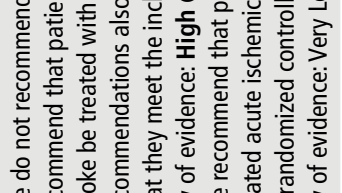

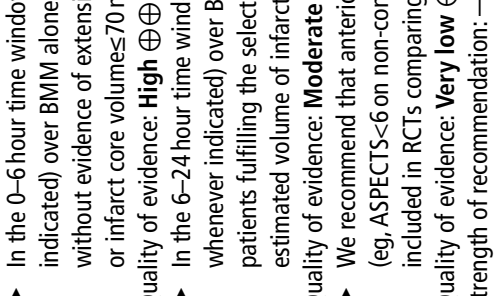

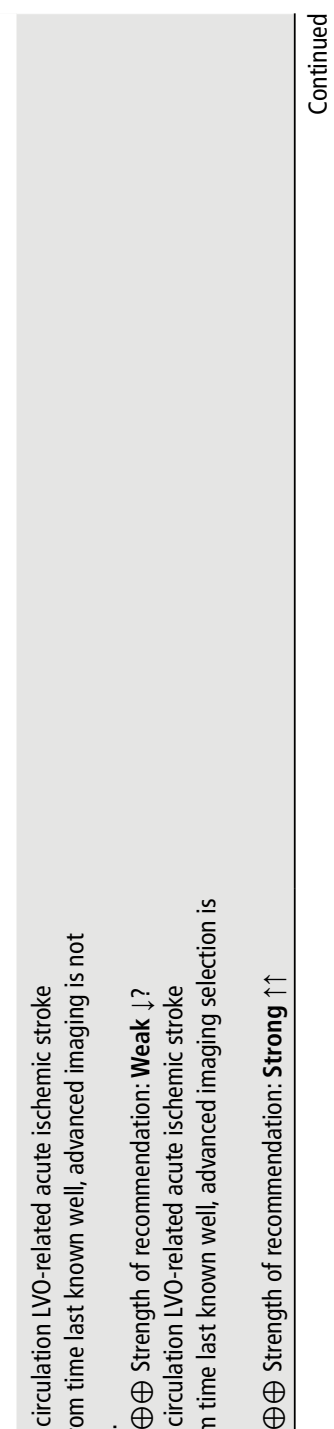

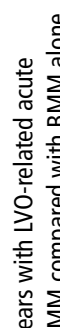

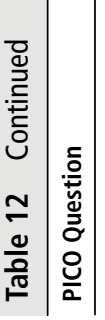

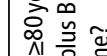

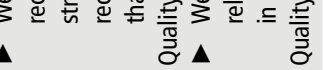

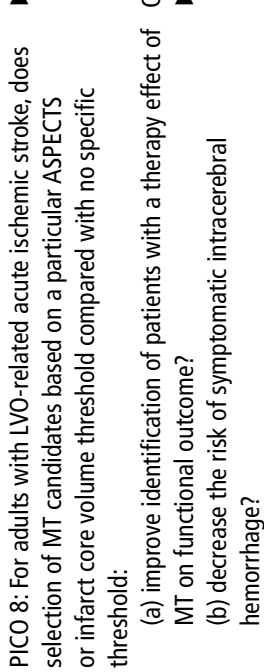

흐 흔

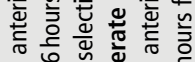

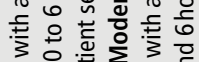

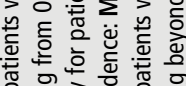

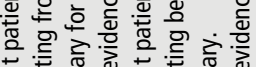

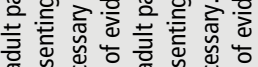

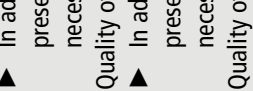

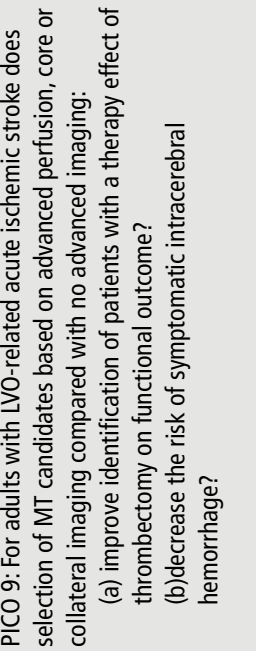




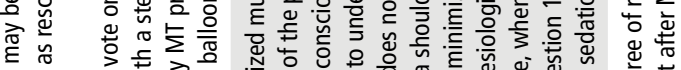

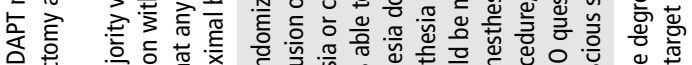

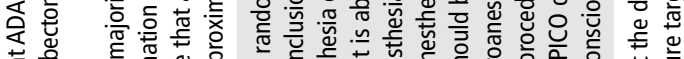

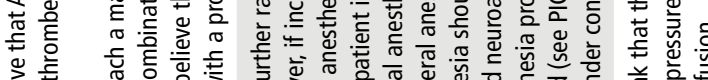

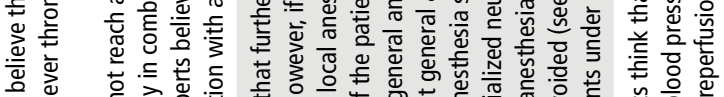

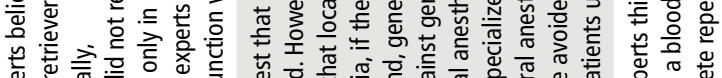

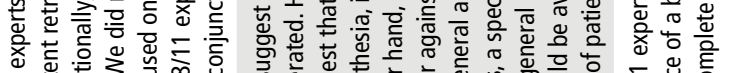

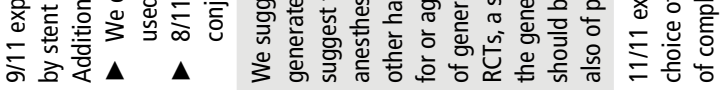

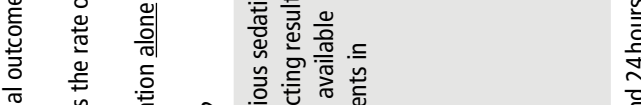
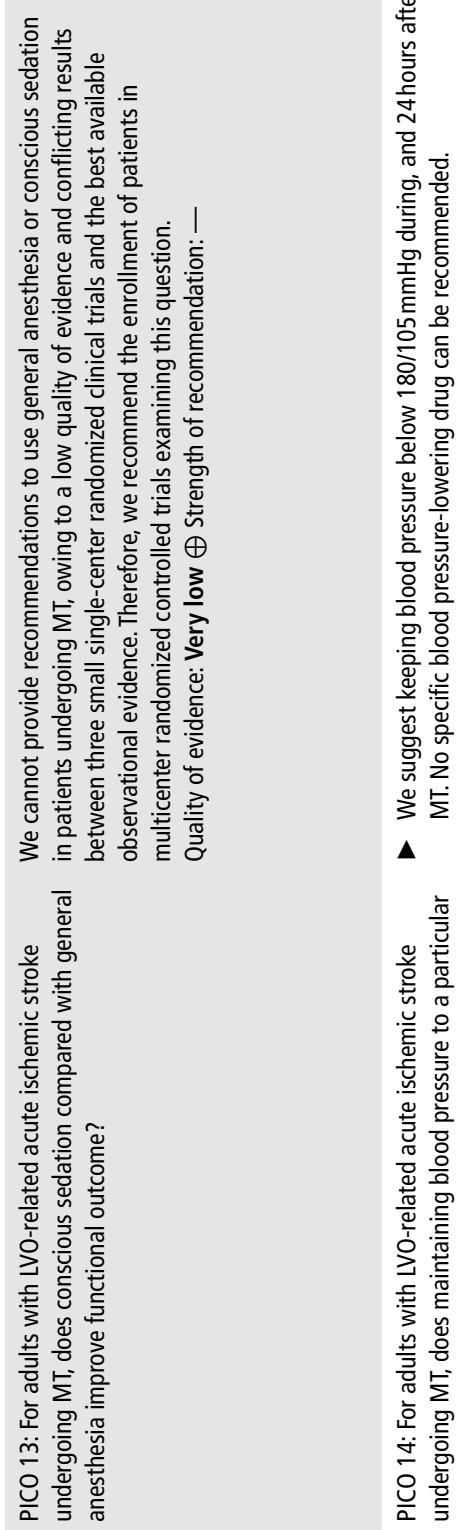

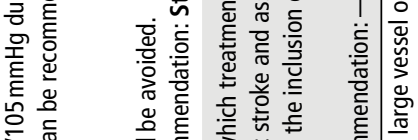

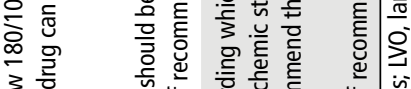

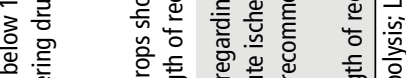

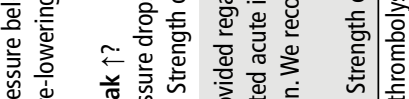

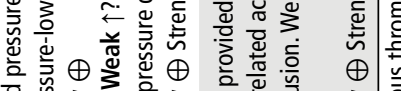

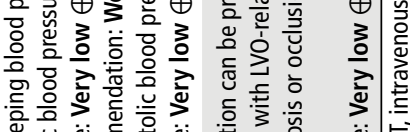

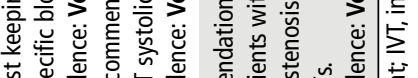

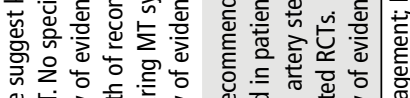

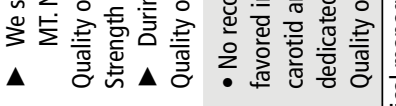

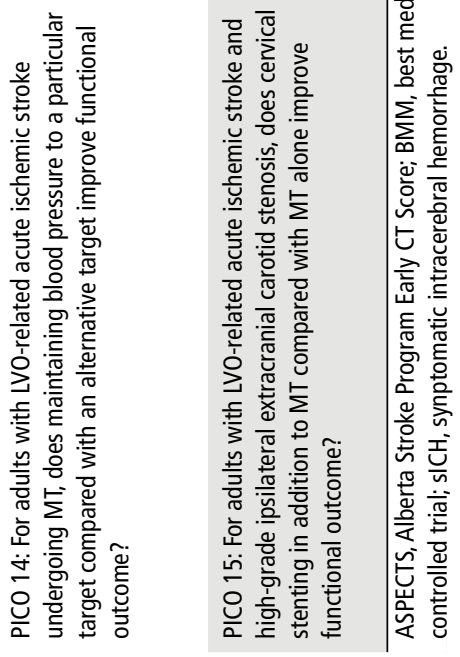




\section{DISCUSSION}

This guideline document was developed following the GRADE process and aims to assist physicians in decision-making in patients with large vessel occlusions and potential MT therapy. ${ }^{11} 12$ It includes new scientific evidence from the past twoyears and supersedes the previously published EROICAS recommendations. ${ }^{8}$ All recommendations and expert opinions are summarized in table 12 .

Although the number of studies with highest scientific quality in the field has increased impressively over the past few years, 14 out of 22 recommendations are based on low or very low quality of evidence. Still, much of the evidence was derived from observational studies, and the influence of bias from such studies on efficacy is well known. ${ }^{142}$ For ethical and practical reasons, not all open questions in medical science can be answered by randomized trials, specifically in surgical innovations and in the field of medical devices. ${ }^{143} 144$ Other multicenter academic collaboration is a key element to improving our knowledge on MT. Registries, observational studies and treatment trials contribute valuable online supplementary information. ${ }^{145}$

To support physicians in their practical decision-making, expert opinions are given in a dedicated paragraph. Whenever appropriate, these opinions were systematically collected as polls. About half of these polls led to a good agreement of 9-11 of the 11 experts. In the remaining questions, the experts' opinions varied considerably. The recommendations with very low evidence and poor agreement among experts were on the subjects of 'intravenous thrombolysis plus MT compared with MT alone' (PICO 3) and 'direct aspiration compared with a stent retriever' (PICO 12). Fortunately, trials are under way to increase the scientific evidence to better answer these questions.

Enrolling patients in a dedicated RCT, whenever possible, was specifically recommended for PICO 4 (prehospital scales), PICO 8 (extensive infarct core), PICO 13 (type of anesthesia), and PICO 15 (acute carotid stenting). Several trials on these and other subjects are under way. Trials studying topics such as type of anesthesia compete with studies on new therapies and devices, some of them with generous industry support. National and international societies are starting to get involved. All these trials will increase the experience and knowledge of interventionalists in conducting trials in the neurointerventional field. These developments are very positive for the progress of science and the welfare of patients. The authors of this guideline are convinced that several current gaps in our knowledge about MT will be closed by high-quality studies during the next few years.

There is a large gap between the state of the art as described in these guidelines and the reality of care in many European countries, leaving many patients untreated. ${ }^{146}$ ESO and ESMINT will help to support governments, healthcare providers, and European politicians to develop strategies to implement MT to further reduce stroke-related mortality and morbidity in Europe. ${ }^{147}$ This guideline document will hopefully play a central role in this process.

\section{Plain language summary}

The ESO-ESMINT guidelines on mechanical thrombectomy (MT) strongly recommend MT plus best medical treatment, including intravenous thrombolysis in patients with a stroke with the occlusion of a large brain-supplying artery (large vessel occlusion [LVO]). Based on the quality of the scientific evidence, the committee was able to make weak or strong recommendations for different patient groups and different therapy approaches. There is a high-quality of evidence and strong recommendation for MT in combination with best medical treatment within the 6 hours after stroke symptom onset and a moderate quality of evidence up to 24 hours. With moderate to low quality of evidence this applies also to patients aged $>80$ years for the early and the late time window, respectively. There is no evidence for an upper stroke severity limit. However, patients with an LVO with low severity (NIHSS scores $<6$ ) should be included in clinical trials whenever possible. If imaging before therapy shows a very large infarct already, then participation in a clinical study is recommended.

Whether MT alone is not inferior to combined IVT/MT is a matter of debate and ongoing trials. With a low level of evidence it is strongly recommended that both treatments are performed whenever indicated without the one or the other causing treatment delays for either one.

Complete reperfusion of the entire brain tissue is related to improved outcomes compared with incomplete reperfusion and, if safely achievable, should be the treatment goal. While the recommendation has low quality of evidence, this recommendation is strong.

Furthermore there is no evidence that contact aspiration of the blood clot alone improves reperfusion rates or good outcomes over MT with a stent retriever; however, the initial use of this aspiration technique followed by MT with a stent retriever is deemed appropriate. There is no evidence to provide a recommendation for or against stenting of the brain supplying artery of the neck (carotid artery) if occluded on the way up to the brain. Intraprocedural stenting may be performed if unavoidable for successful MT. There is no evidence for any recommendation for general anesthesia versus conscious sedation or local anesthesia for the MT procedure. General anesthesia should neither be favored if not needed nor be avoided, if necessary, trying to prevent severe drops in blood pressure. Of the general recommendation to keep blood pressure below $180 / 105 \mathrm{~mm} \mathrm{Hg}$ within the first 24 hours, there is no evidence or recommendation for a specific target blood pressure.

It is not recommended to select patients for MT based on advanced imaging methods within 6 hours after symptom onset. At later times from symptom onset, MT requires advanced imaging showing small brain lesion volume or a clinical/imaging based mismatch with a neurological deficit exceeding the small lesion volume.

There is no evidence for the benefit of a prehospital method to identify patients eligible for MT by clinical judgment alone. Also there is no evidence-based recommendation for the preferred organizational model of how to get the patient to the MT; the most typical two of these are known as drip-and-ship or mothership. Generally speaking, as there is lack of strong evidence for superiority of one organizational model, the choice of model should depend on local and regional service organization and patient characteristics. Both these questions are matter for debate and also clinical trials. Although the quality of evidence is very low, the guidelines strongly recommend that MT is performed in a comprehensive stroke center table 12 .

\section{Author affiliations}

'Department of Neurology, Sainte-Anne Hospital, Paris, France

2Université Paris Descartes, Paris, France

${ }^{3}$ DHU NeuroVasc, Paris, France

${ }^{4}$ U1266, INSERM, Paris, France

${ }^{5}$ The Royal London Hospital, London, UK

${ }^{6}$ Department of Neurology, Inselspital, University Hospital Bern and University of Bern, Bern, Switzerland

${ }^{7}$ Department of Neurology, University of Cincinnati, Cincinnati, Ohio, USA

${ }^{8}$ Imperial College Healthcare NHS Trust, Charing Cross Hospital, London, UK

${ }^{9}$ INSERM U1148, Sorbonne Paris Cité Université Paris Diderot, Paris, France

${ }^{10}$ Department of Interventional Neuroradiology, Rothschild Foundation Hospital, 
Paris, France

${ }^{11}$ Stroke Unit Lariboisière Hospital, Paris, France

${ }^{12}$ Department of Neurology and Neurogeriatry, Johannes Wesling Medical Center Minden, University Hospitals of the Ruhr-University of Bochum, Bochum, Germany

${ }^{13}$ Department of Human Neurosciences, Hospital Policlinico Umberto I, Sapienza University of Rome, Rome, Italy

${ }^{14}$ Departmentof Neurosurgery, Radboudumc University Nijmegen, Nijmegen, The Netherlands

${ }^{15}$ Institute of Neuroscience (Stroke Research Group), Newcastle University, Newcastle Upon Tyne, UK

${ }^{16}$ Klinik und Poliklinik für Neuroradiologische Diagnostik und Intervention,

Universitätsklinikum Hamburg-Eppendorf, Hamburg, Germany

Contributors All authors contributed to the research and drafting of the manuscript.

Funding The authors have not declared a specific grant for this research from any funding agency in the public, commercial or not-for-profit sectors.

Competing interests Competing interests for the authors can be found in the file entitled ESO-ESMINT Thrombectomy Guidelines Suppl appendix.

Patient consent Not required.

Provenance and peer review Commissioned; internally peer reviewed.

\section{REFERENCES}

1 Berkhemer OA, Fransen PS, Beumer D, et al. A randomized trial of intraarterial treatment for acute ischemic stroke. N Engl J Med 2015;372:11-20.

2 Campbell BC, Mitchell PJ, Kleinig TJ, et al. Endovascular therapy for ischemic stroke with perfusion-imaging selection. N Engl J Med 2015;372:1009-18.

3 Goyal M, Demchuk AM, Menon BK, et al. Randomized assessment of rapid endovascular treatment of ischemic stroke. N Eng/ J Med 2015;372:1019-30.

4 Saver JL, Goyal M, Bonafe A, et al. Stent-retriever thrombectomy after intravenous t-PA vs. t-PA alone in stroke. N Engl J Med 2015;372:2285-95.

5 Jovin TG, Chamorro A, Cobo E, et al. Thrombectomy within 8 hours after symptom onset in ischemic stroke. N Engl J Med 2015;372:2296-306.

6 Goyal M, Menon BK, van Zwam WH, et al. Endovascular thrombectomy after large-vessel ischaemic stroke: a meta-analysis of individual patient data from five randomised trials. Lancet 2016;387:1723-31.

7 Wahlgren N, Moreira T, Michel P, et al. Mechanical thrombectomy in acute ischemic stroke: consensus statement by ESO-Karolinska stroke update 2014/2015, supported by ESO, ESMINT, ESNR and EAN. Int I Stroke 2016;11:134-47.

8 Fiehler J, Cognard C, Gallitelli M, et al. European Recommendations on Organisation of Interventional Care in Acute Stroke (EROICAS). Int I Stroke 2016:11:701-16.

9 Nogueira RG, Jadhav AP, Haussen DC, et al. Thrombectomy 6 to 24 hours after stroke with a mismatch between deficit and infarct. N Engl J Med 2018;378:11-21.

10 Albers GW, Marks MP, Kemp S, et al. Thrombectomy for stroke at 6 to 16 hours with selection by perfusion imaging. N Eng/ J Med 2018;378:708-18.

11 Guyatt GH, Oxman AD, Schünemann HJ, et al. GRADE guidelines: a new series of articles in the Journal of Clinical Epidemiology. J Clin Epidemiol 2011;64:380-2.

12 Ntaios G, Bornstein NM, Caso V, et al. The European Stroke Organisation Guidelines: a standard operating procedure. Int I Stroke 2015;10:128-35.

13 Higgins JP, Altman DG, Gøtzsche PC, et al. The Cochrane Collaboration's tool for assessing risk of bias in randomised trials. BMJ 2011;343:d5928.

14 Higgins JPT, Green S. Cochrane handbook for systematic reviews of interventions version 5.1.0 [updated march 2011] The Cochrane Collaboration. 2011 http:// handbook.Cochrane.Org

15 Bracard S, Ducrocq X, Mas JL, et al. Mechanical thrombectomy after intravenous alteplase versus alteplase alone after stroke (THRACE): a randomised controlled trial. Lancet Neurol 2016:15:1138-47.

16 Mocco J, Zaidat 00, von Kummer R, et al. Aspiration thrombectomy after intravenous alteplase versus intravenous alteplase alone. Stroke 2016;47:2331-8

17 Muir KW, Ford GA, Messow C-M, et al. Endovascular therapy for acute ischaemic stroke: the pragmatic ischaemic stroke thrombectomy evaluation (piste) randomised, controlled trial. J Neurol, Neurosurg Psychiatry. 2017;88:38-44.

18 Khoury NN, Darsaut TE, Ghostine J, et al. Endovascular thrombectomy and medical therapy versus medical therapy alone in acute stroke: a randomized care trial. $J$ Neuroradio/ 2017:44:198-202

19 Broderick JP, Palesch YY, Demchuk AM, et al. Endovascular therapy after intravenous t-PA versus t-PA alone for stroke. N Engl J Med 2013:368:893-903.

20 Ciccone A, Valvassori L, Nichelatti M, et al. Endovascular treatment for acute ischemic stroke. N Engl J Med 2013;368:904-13.

21 Kidwell CS, Jahan R, Gornbein J, et al. A trial of imaging selection and endovascular treatment for ischemic stroke. N Engl J Med 2013;368:914-23.

22 Bassler D, Montori VM, Briel M, et al. Reflections on meta-analyses involving trials stopped early for benefit: is there a problem and if so, what is it? Stat Methods Med Res 2013:22:159-68.
23 Román LS, Menon BK, Blasco J, et al. Imaging features and safety and efficacy of endovascular stroke treatment: a meta-analysis of individual patient-level data. Lancet Neurol 2018;17:895-904

24 Goyal M, Menon BK, Krings T, et al. What constitutes the M1 segment of the middle cerebral artery? J Neurointerv Surg 2016.

25 Schonewille WJ, Wijman CA, Michel P, et al. Treatment and outcomes of acute basilar artery occlusion in the basilar artery international cooperation study (BASICS): a prospective registry study. Lancet Neuro/ 2009;8:724-30.

26 van der Hoeven EJ, Schonewille WJ, Vos JA, et al. The Basilar Artery International Cooperation study (basics): study protocol for a randomised controlled trial. Trials 2013;14:200.

27 Powers WJ, Rabinstein AA, Ackerson T, et al. Guidelines for the early management of patients with acute ischemic stroke: a guideline for healthcare professionals from the American Heart Association/American Stroke Association. Stroke 2018:2018:e46-110.

28 Thomalla G, Simonsen CZ, Boutitie F, et al. MRI-guided thrombolysis for stroke with unknown time of onset. N Engl J Med 2018;379.

29 Jadhav AP, Desai SM, Kenmuir CL, et al. Eligibility for endovascular trial enrollment in the 6- to 24-hour time window: analysis of a single comprehensive stroke center. Stroke 2018;49:1015-7.

30 Saver JL, Goyal M, van der Lugt A, et al. Time to treatment with endovascular thrombectomy and outcomes from ischemic stroke: a meta-analysis. JAMA 2016:316:1279-88.

31 Mistry EA, Mistry AM, Nakawah MO, et al. Mechanical thrombectomy outcomes with and without intravenous thrombolysis in stroke patients: a meta-analysis. Stroke 2017:48:2450-6

32 Kaesmacher J, Mordasini P, Arnold M, et al. Direct mechanical thrombectomy in tPA-ineligible and -eligible patients versus the bridging approach: a meta-analysis. J Neurointerv Surg 2019;11.

33 Campbell BCV, Mitchell PJ, Churilov L, et al. Tenecteplase versus alteplase before thrombectomy for ischemic stroke. N Engl J Med 2018;378:1573-82.

34 Logallo N, Novotny V, Assmus J, et al. Tenecteplase versus alteplase for management of acute ischaemic stroke (NOR-TEST): a phase 3, randomised, open-label, blinded endpoint trial. Lancet Neurol 2017:16:781-8.

35 Haley EC, Thompson JL, Grotta JC, et al. Phase IIB/III trial of tenecteplase in acute ischemic stroke: results of a prematurely terminated randomized clinical trial. Stroke 2010;41:707-11.

36 Huang X, Cheripelli BK, Lloyd SM, et al. Alteplase versus tenecteplase for thrombolysis after ischaemic stroke (ATTEST): a phase 2, randomised, open-label, blinded endpoint study. Lancet Neurol 2015;14:368-76.

37 Huang X, Maclsaac R, Thompson JL, et al. Tenecteplase versus alteplase in stroke thrombolysis: an individual patient data meta-analysis of randomized controlled trials. Int J Stroke 2016;11:534-43.

38 Parsons M, Spratt N, Bivard A, et al. A randomized trial of tenecteplase versus alteplase for acute ischemic stroke. N Engl J Med 2012;366:1099-107.

39 Saver JL, Fonarow GC, Smith EE, et al. Time to treatment with intravenous tissue plasminogen activator and outcome from acute ischemic stroke. JAMA 2013:309:2480-8

40 Zaidi SF, Shawver J, Espinosa Morales A, et al. Stroke care: initial data from a county-based bypass protocol for patients with acute stroke. J Neurointerv Surg 2017:9:631-5.

41 Pérez de la Ossa N, Carrera D, Gorchs M, et al. Design and validation of a prehospital stroke scale to predict large arterial occlusion: the rapid arterial occlusion evaluation scale. Stroke 2014;45:87-91.

42 Mohamad N, Hastrup S, Rasmussen M, et al. Bypassing primary stroke centre reduces delay and improves outcomes for patients with large vessel occlusion. Eur Stroke J 2016:1:85-92.

43 Kobayashi A, Czlonkowska A, Ford GA, et al. European Academy of Neurology and European Stroke Organization consensus statement and practical guidance for prehospital management of stroke. Eur J Neurol 2018;25:425-33.

44 Hastrup S, Damgaard D, Johnsen SP, et al. Prehospital acute stroke severity scale to predict large artery occlusion: design and comparison with other scales. Stroke 2016;47:1772-6.

45 Vidale $\mathrm{S}$, Agostoni E. Prehospital stroke scales and large vessel occlusion: a systematic review. Acta Neurol Scand 2018;138.

46 Lima FO, Silva GS, Furie KL, et al. Field assessment stroke triage for emergency destination: a simple and accurate prehospital scale to detect large vessel occlusion strokes. Stroke 2016:47:1997-2002.

47 Katz BS, McMullan JT, Sucharew H, et al. Design and validation of a prehospital scale to predict stroke severity: Cincinnati Prehospital Stroke Severity Scale. Stroke 2015:46:1508-12.

48 Scheitz JF, Abdul-Rahim AH, Maclsaac RL, et al. Clinical selection strategies to identify ischemic stroke patients with large anterior vessel occlusion: results from SITS-ISTR (safe implementation of thrombolysis in stroke international stroke thrombolysis registry). Stroke 2017;48:290-7

49 Smith EE, Kent DM, Bulsara KR, et al. Accuracy of prediction instruments for diagnosing large vessel occlusion in individuals with suspected stroke: a systematic 
review for the 2018 guidelines for the early management of patients with acute ischemic stroke. Stroke 2018;49:e111-22.

50 McMullan JT, Katz B, Broderick J, et al. Prospective prehospital evaluation of the Cincinnati Stroke Triage Assessment Tool. Prehosp Emerg Care 2017;21:481-8.

51 Kim JT, Chung PW, Starkman S, et al. Field validation of the Los Angeles motor scale as a tool for paramedic assessment of stroke severity. Stroke 2017;48:298-306.

52 Zhao H, Pesavento L, Coote S, et al. Ambulance clinical triage for acute stroke treatment: paramedic triage algorithm for large vessel occlusion. Stroke 2018;49:945-51.

53 Teleb MS, Ver Hage A, Carter J, et al. Stroke vision, aphasia, neglect (VAN) assessment-a novel emergent large vessel occlusion screening tool: pilot study and comparison with current clinical severity indices. J Neurointerv Surg 2017:9:122-6

54 Nazliel B, Starkman S, Liebeskind DS, et al. A brief prehospital stroke severity scale identifies ischemic stroke patients harboring persisting large arterial occlusions. Stroke 2008;39:2264-7.

55 Vanacker $\mathrm{P}$, Heldner MR, Amiguet M, et al. Prediction of large vessel occlusions in acute stroke: National Institute of Health Stroke Scale is hard to beat. Crit Care Med 2016:44:e336-43.

56 Gropen T, Boehme A, Martin-Schild S, et al. Comparison of large vessel occlusion prediction scores. Stroke 2016:47.

57 Kothari R, Hall K, Brott T, et al. Early stroke recognition: developing an out-ofhospital NIH Stroke Scale. Acad Emerg Med 1997;4:986-90.

58 Singer OC, Dvorak F, du Mesnil de Rochemont R, et al. A simple 3-item stroke scale: comparison with the National Institutes of Health Stroke Scale and prediction of middle cerebral artery occlusion. Stroke 2005:36:773-6.

59 Turc G, Maïer B, Naggara 0 , et al. Clinical scales do not reliably identify acute ischemic stroke patients with large-artery occlusion. Stroke 2016:47:1466-72.

60 Heldner MR, Zubler C, Mattle HP, et al. National Institutes of Health Stroke Scale score and vessel occlusion in 2152 patients with acute ischemic stroke. Stroke 2013:44:1153-7.

61 Heldner MR, Hsieh K, Broeg-Morvay A, et al. Clinical prediction of large vessel occlusion in anterior circulation stroke: mission impossible? I Neurol 2016;263:1633-40.

62 Pfaff J, Herweh C, Pham M, et al. Mechanical thrombectomy in patients with acute ischemic stroke and lower NIHSS scores: recanalization rates, periprocedural complications, and clinical outcome. AJNR Am J Neuroradiol 2016:37:2066-71.

63 Bhogal P, Bücke P, Ganslandt O, et al. Mechanical thrombectomy in patients with M1 occlusion and NIHSS score $\leq 5$ : a single-centre experience. Stroke Vasc Neurol 2016;1:165-71.

64 Alqahtani SA, Stemer AB, McCullough MF, et al. Endovascular management of stroke patients with large vessel occlusion and minor stroke symptoms. Cureus 2017:9:e1355.

65 Dargazanli C, Arquizan C, Gory B, et al. Mechanical thrombectomy for minor and mild stroke patients harboring large vessel occlusion in the anterior circulation: a multicenter cohort study. Stroke 2017:48:3274-81.

66 Milne MS, Hill MD, Nygren A, et al. Drip 'n ship vs. Mothership for endovascular treatment: modeling the best transportation options for optimal outcomes in California and Alberta. Stroke 2017:48.

67 Adamczyk C, Heidger W, Huettemann K, et al. Drip-and-ship, a comprehensive view. Analysis of patients transferred for endovascular treatment within a stroke-network. Eur Stroke J 2017:2:158.

68 Froehler MT, Saver JL, Zaidat 00, et al. Interhospital transfer before thrombectomy is associated with delayed treatment and worse outcome in the stratis registry (systematic evaluation of patients treated with neurothrombectomy devices for acute ischemic stroke). Circulation 2017;136:2311-21.

69 Gerschenfeld G, Muresan IP, Blanc R, et al. Two paradigms for endovascular thrombectomy after intravenous thrombolysis for acute ischemic stroke. JAMA Neurol 2017;74:549-56.

70 Pérez de la Ossa N, Abilleira S, Dorado L, et al. Access to endovascular treatment in remote areas: analysis of the reperfusion treatment registry of catalonia. Stroke 2016:47:1381-4

71 Weber R, Reimann G, Weimar C, et al. Outcome and periprocedural time management in referred versus directly admitted stroke patients treated with thrombectomy. Ther Adv Neurol Disord 2016;9:79-84.

72 Hiyama N, Yoshimura S, Shirakawa M, et al. Safety and effectiveness of drip, ship, and retrieve paradigm for acute ischemic stroke: a single center experience. Neurol Med Chir 2016;56:731-6.

73 Park MS, Yoon W, Kim JT, et al. Drip, ship, and on-demand endovascular therapy for acute ischemic stroke. PLoS One 2016;11:e0150668.

74 Park MS, Lee JS, Park TH, et al. Characteristics of the drip-and-ship paradigm for patients with acute ischemic stroke in South Korea. I Stroke Cerebrovasc Dis 2016;25:2678-87.

75 Rinaldo L, Brinjikji W, McCutcheon BA, et al. Hospital transfer associated with increased mortality after endovascular revascularization for acute ischemic stroke. J Neurointerv Surg 2017;9:1166-72.
76 Brekenfeld C, Goebell E, Schmidt H, et al. 'Drip-and-drive': shipping the neurointerventionalist to provide mechanical thrombectomy in primary stroke centers. J Neurointerv Surg 2018;10.

77 Ebinger $\mathrm{M}$, Winter $\mathrm{B}$, Wendt $\mathrm{M}$, et al. Effect of the use of ambulance-based thrombolysis on time to thrombolysis in acute ischemic stroke: a randomized clinical trial. JAMA 2014:311:1622-31.

78 Fassbender K, Grotta JC, Walter S, et al. Mobile stroke units for prehospital thrombolysis, triage, and beyond: benefits and challenges. Lancet Neurol 2017; 16:227-37.

79 Wei D, Oxley TJ, Nistal DA, et al. Mobile interventional stroke teams lead to faster treatment times for thrombectomy in large vessel occlusion. Stroke 2017:48:3295-300.

80 Audebert H, Fassbender K, Hussain MS, et al. The PRE-hospital stroke treatment organization. Int I Stroke 2017;12:932-40.

81 Emberson J, Lees KR, Lyden P, et al. Effect of treatment delay, age, and stroke severity on the effects of intravenous thrombolysis with alteplase for acute ischaemic stroke: a meta-analysis of individual patient data from randomised trials. Lancet 2014;384:1929-35.

82 Haussen DC, Bouslama M, Grossberg JA, et al. Too good to intervene? Thrombectomy for large vessel occlusion strokes with minimal symptoms: an intention-to-treat analysis. J Neurointerv Surg 2017;9:917-21.

83 Dargazanli C, Consoli A, Gory B, et al. Is reperfusion useful in ischaemic stroke patients presenting with a low National Institutes of Health Stroke Scale and a proximal large vessel occlusion of the anterior circulation? Cerebrovasc Dis 2017:43:305-12.

84 Kaschner MG, Caspers J, Rubbert C, et al. Mechanical thrombectomy in MCAmainstem occlusion in patients with low NIHSS scores. Interv Neuroradiol 2018;24.

85 Xiong YJ, Gong JM, Zhang YC, et al. Endovascular thrombectomy versus medical treatment for large vessel occlusion stroke with mild symptoms: a meta-analysis. PLoS One 2018;13:e0203066.

86 Farzin B, Fahed R, Guilbert F, et al. Early CT changes in patients admitted for thrombectomy: Intrarater and interrater agreement. Neurology 2016;87:249-56

87 Nezu T, Koga M, Nakagawara J, et al. Early ischemic change on CT versus diffusionweighted imaging for patients with stroke receiving intravenous recombinant tissue-type plasminogen activator therapy: stroke acute management with urgent risk-factor assessment and improvement (SAMURAI) rt-PA registry. Stroke 2011:42:2196-200.

88 Campbell BCV, Majoie C, Albers GW, et al. Penumbral imaging and functional outcome in patients with anterior circulation ischaemic stroke treated with endovascular thrombectomy versus medical therapy: a meta-analysis of individual patient-level data. Lancet Neurol 2019;18.

89 Xie Y, Oppenheim C, Guillemin F, et al. Pretreatment lesional volume impacts clinical outcome and thrombectomy efficacy. Ann Neurol 2018;83:178-85.

90 Ryu CW, Shin HS, Park S, et al. Alberta Stroke Program Early CT Score in the prognostication after endovascular treatment for ischemic stroke: a meta-analysis. Neurointervention 2017;12:20-30.

91 Campbell BC, Majoie CB, Menon BK, et al. The association between baseline ischemic core volume and benefit of endovascular thrombectomy in pooled data from six randomized trials. Stroke 2017:48:A31.

92 Menon BK, d'Esterre CD, Qazi EM, et al. Multiphase CT angiography: a new tool for the imaging triage of patients with acute ischemic stroke. Radiology 2015;275:510-20.

93 Borst J, Berkhemer OA, Roos YB, et al. Value of computed tomographic perfusionbased patient selection for intra-arterial acute ischemic stroke treatment. Stroke 2015;46:3375-82.

94 Albers GW, Goyal M, Jahan R, et al. Relationships between imaging assessments and outcomes in solitaire with the intention for thrombectomy as primary endovascular treatment for acute ischemic stroke. Stroke 2015;46:2786-94.

95 Albers GW, Goyal M, Jahan R, et al. Ischemic core and hypoperfusion volumes predict infarct size in SWIFT PRIME. Ann Neurol 2016;79:76-89.

96 Barlinn K, Seibt J, Engellandt K, et al. Multimodal computed tomography based definition of cerebral imaging profiles for acute stroke reperfusion therapy (CT-define): results of a prospective observational study. Clin Neuroradiol 2015;25:403-10.

97 Bivard A, Levi C, Krishnamurthy V, et al. Perfusion computed tomography to assist decision making for stroke thrombolysis. Brain 2015;138:1919-31.

98 Inoue M, Mlynash M, Straka M, et al. Clinical outcomes strongly associated with the degree of reperfusion achieved in target mismatch patients: pooled data from the diffusion and perfusion imaging evaluation for understanding stroke evolution studies. Stroke 2013;44:1885-90.

99 Marks MP, Lansberg MG, Mlynash M, et al. Effect of collateral blood flow on patients undergoing endovascular therapy for acute ischemic stroke. Stroke 2014;45:1035-9.

100 Rinaldo L, Brinjikji W, Rabinstein AA. Transfer to high-volume centers associated with reduced mortality after endovascular treatment of acute stroke. Stroke 2017:48:1316-21 
101 Ringelstein EB, Chamorro A, Kaste M, et al. European Stroke Organization recommendations to establish a stroke unit and stroke center. Stroke 2013;44:828-40.

102 Meretoja A, Strbian D, Mustanoja S, et al. Reducing in-hospital delay to 20 minutes in stroke thrombolysis. Neurology 2012;79:306-13.

103 Meretoja A, Weir L, Ugalde M, et al. Helsinki model cut stroke thrombolysis delays to 25 minutes in Melbourne in only 4 months. Neurology 2013;81:1071-6.

104 Lavine SD, Cockroft K, Hoh B, et al. Training guidelines for endovascular ischemic stroke intervention: an international multi-society consensus document. AJNR Am J Neuroradio/ 2016:37:E31-4

105 Higashida R, Furlan A, Roberts $H$, et al. Trial design and reporting standards for intraarterial cerebral thrombolysis for acute ischemic stroke. J Vasc Interv Radiol 2003:14:E1-4

106 Technology Assesssment Committees of the American Society of Interventional and Therapeutic Neuroradiology; Society of Interventional Radiology. Trial design and reporting standards for intraarterial cerebral thrombolysis for acute ischemic stroke. 2003. J Vasc Interv Radiol 2003;14:945-6.

107 Yoo AJ, Simonsen CZ, Prabhakaran S, et al. Refining angiographic biomarkers of revascularization: improving outcome prediction after intra-arterial therapy. Stroke 2013;44:2509-12.

108 Kaesmacher J, Dobrocky T, Heldner MR, et al. Systematic review and meta-analysis on outcome differences among patients with $\mathrm{TICl} 2 \mathrm{~b}$ versus $\mathrm{TICl} 3$ reperfusions: success revisited. J Neurol Neurosurg Psychiatry 2018;89:910-7.

109 Liebeskind DS, Bracard S, Guillemin F, et al. eTICI reperfusion: defining success in endovascular stroke therapy. J Neurointerv Surg 2018;48:neurintsurg-2018-014127.

110 Zaidat 00, Castonguay AC, Linfante I, et al. First pass effect: a new measure for stroke thrombectomy devices. Stroke 2018;49:660-6.

111 Cimflova $\mathrm{P}$, Volny 0, Szeder V, et al. Tici, hici, aici-is there a better score for perfusion assessment? European Stroke Journal 2017;2:273-4.

112 Almekhlafi MA, Mishra S, Desai JA, et al. Not all "successful" angiographic reperfusion patients are an equal validation of a modified $\mathrm{TICI}$ scoring system. Interv Neuroradiol 2014;20:21-7.

113 Tung EL, McTaggart RA, Baird GL, et al. Rethinking thrombolysis in cerebral infarction $2 \mathrm{~b}$ : which thrombolysis in cerebral infarction scales best define near complete recanalization in the modern thrombectomy era? Stroke 2017;48:2488-93.

114 Chamorro Á, Blasco J, López A, et al. Complete reperfusion is required for maximal benefits of mechanical thrombectomy in stroke patients. Sci Rep 2017;7:11636.

115 Lapergue B, Blanc R, Gory B, et al. Effect of endovascular contact aspiration vs stent retriever on revascularization in patients with acute ischemic stroke and large vessel occlusion: the Aster randomized clinical trial. JAMA 2017;318:443-52.

116 Mocco J, Siddiqui A, Turk AS. A comparison of direct aspiration vs. stent retriever as a first approach (" compass"): a randomized trial. International Stroke Conference 2018.

117 Turk AS, Siddiqui AH, Mocco J. A comparison of direct aspiration versus stent retriever as a first approach ('compass'): Protocol. J Neurointerv Surg 2018.

118 Gory B, Lapergue B, Blanc R, et al. Contact aspiration versus stent retriever in patients with acute ischemic stroke with $\mathrm{M} 2$ occlusion in the Aster randomized trial (contact aspiration versus stent retriever for successful revascularization). Stroke 2018:49:461-4

119 Blanc R, Redjem H, Ciccio G, et al. Predictors of the aspiration component success of a direct aspiration first pass technique (ADAPT) for the endovascular treatment of stroke reperfusion strategy in anterior circulation acute stroke. Stroke 2017:48:1588-93.

120 Velasco A, Buerke B, Stracke CP, et al. Comparison of a balloon guide catheter and a non-balloon guide catheter for mechanical thrombectomy. Radiology 2016;280:169-76

121 Nguyen TN, Malisch T, Castonguay AC, et al. Balloon guide catheter improves revascularization and clinical outcomes with the Solitaire device: analysis of the North American Solitaire Acute Stroke Registry. Stroke 2014;45:141-5.

122 Brinjikji W, Starke RM, Murad MH, et al. Impact of balloon guide catheter on technical and clinical outcomes: a systematic review and meta-analysis. $J$ Neurointerv Surg 2018;10:335-9.

123 Delgado Almandoz JE, Kayan Y, Young ML, et al. Comparison of clinical outcomes in patients with acute ischemic strokes treated with mechanical thrombectomy using either Solumbra or ADAPT techniques. J Neurointerv Surg 2016;8:1123-8.

124 Massari F, Henninger N, Lozano JD, et al. ARTS (Aspiration-Retriever Technique for Stroke): Initial clinical experience. Interv Neuroradiol 2016;22:325-32.

125 Maus V, Behme D, Kabbasch C, et al. Maximizing first-pass complete reperfusion with save. Clin Neuroradiol 2018;28.

126 McTaggart RA, Tung EL, Yaghi S, et al. Continuous aspiration prior to intracranial vascular embolectomy (CAPTIVE): a technique which improves outcomes. $J$ Neurointerv Surg 2017;9:1154-9.
127 Schönenberger S, Uhlmann L, Hacke W, et al. Effect of conscious sedation vs general anesthesia on early neurological improvement among patients with ischemic stroke undergoing endovascular thrombectomy: a randomized clinical trial. JAMA 2016:316:1986-96.

128 Löwhagen Hendén P, Rentzos A, Karlsson JE, et al. General anesthesia versus conscious sedation for endovascular treatment of acute ischemic stroke: the anstroke trial (anesthesia during stroke). Stroke 2017;48:1601-7.

129 Simonsen CZ, Yoo AJ, Sørensen LH, et al. Effect of general anesthesia and conscious sedation during endovascular therapy on infarct growth and clinical outcomes in acute ischemic stroke: a randomized clinical trial. JAMA Neurol 2018;75:470-7.

130 Campbell BCV, van Zwam WH, Goyal M, et al. Effect of general anaesthesia on functional outcome in patients with anterior circulation ischaemic stroke having endovascular thrombectomy versus standard care: a meta-analysis of individual patient data. Lancet Neurol 2018;17:47-53.

131 Mulder M, Ergezen S, Lingsma HF, et al. Baseline blood pressure effect on the benefit and safety of intra-arterial treatment in MR CLEAN (multicenter randomized clinical trial of endovascular treatment of acute ischemic stroke in the Netherlands). Stroke 2017:48:1869-76

132 Maier B, Gory B, Taylor G, et al. Mortality and disability according to baseline blood pressure in acute ischemic stroke patients treated by thrombectomy: a collaborative pooled analysis. J Am Heart Assoc 2017:6.

133 Goyal N, Tsivgoulis G, Pandhi A, et al. Blood pressure levels post mechanical thrombectomy and outcomes in large vessel occlusion strokes. Neurology 2017:89:540-7.

134 Whalin MK, Halenda KM, Haussen DC, et al. Even small decreases in blood pressure during conscious sedation affect clinical outcome after stroke thrombectomy: an analysis of hemodynamic thresholds. AJNR Am J Neuroradio/ 2017;38:294-8.

135 Mistry EA, Mistry AM, Nakawah MO, et al. Systolic blood pressure within 24 hours after thrombectomy for acute ischemic stroke correlates with outcome. J Am Heart Assoc 2017;6:6

136 Tarlov N, Nien YL, Zaidat 00, et al. Periprocedural management of acute ischemic stroke intervention. Neurology 2012;79:S182-91.

137 Goyal N, Tsivgoulis G, Pandhi A, et al. Blood pressure levels post mechanical thrombectomy and outcomes in non-recanalized large vessel occlusion patients. J Neurointerv Surg 2018;10:925-31.

138 Mistry EA, Mayer SA, Khatri P. Blood pressure management after mechanical thrombectomy for acute ischemic stroke: a survey of the strokenet sites. J Stroke Cerebrovasc Dis 2018;27:2474-8.

139 Wilson MP, Murad MH, Krings T, et al. Management of tandem occlusions in acute ischemic stroke - intracranial versus extracranial first and extracranial stenting versus angioplasty alone: a systematic review and meta-analysis. J Neurointerv Surg 2018:10:721-8

140 Sadeh-Gonik U, Tau N, Friehmann T, et al. Thrombectomy outcomes for acute stroke patients with anterior circulation tandem lesions: a clinical registry and an update of a systematic review with meta-analysis. Eur J Neurol 2018;25:693-700.

141 Stampfl S, Ringleb PA, Möhlenbruch M, et al. Emergency cervical internal carotid artery stenting in combination with intracranial thrombectomy in acute stroke. AJNR Am J Neuroradiol 2014;35:741-6.

142 Lu CY. Observational studies: a review of study designs, challenges and strategies to reduce confounding. Int J Clin Pract 2009;63:691-7.

143 Broekman ML, Carrière ME, Bredenoord AL. Surgical innovation: the ethical agenda: a systematic review. Medicine (Baltimore) 2016;95:e3790.

144 Neugebauer EAM, Rath A, Antoine SL, et al. Specific barriers to the conduct of randomised clinical trials on medical devices. Trials 2017:18:427.

145 Nallamothu BK, Hayward RA, Bates ER. Beyond the randomized clinical trial: the role of effectiveness studies in evaluating cardiovascular therapies. Circulation 2008;118:1294-303.

146 Aguiar de Sousa D, von Martial R, Abilleira S, et al. Access to and delivery of acute ischaemic stroke treatments: a survey of national scientific societies and stroke experts in 44 European countries. Eur Stroke J 2018:23.

147 Action plan for stroke in Europe 2018 - 2030. Organised by ESO, in cooperation with SAFE. 2018 https://actionplan.eso-stroke.org/

148 Albers GW, Lansberg MG, Kemp S, et al. A multicenter randomized controlled trial of endovascular therapy following imaging evaluation for ischemic stroke (DEFUSE 3). Int J Stroke 2017:12:896-905.

149 Khatri P, Kleindorfer DO, Devlin T, et al. Effect of alteplase vs aspirin on functional outcome for patients with acute ischemic stroke and minor nondisabling neurologic deficits: the PRISMS randomized clinical trial. JAMA 2018;320:156-66.

150 Humphries W, Hoit D, Doss VT, et al. Distal aspiration with retrievable stent assisted thrombectomy for the treatment of acute ischemic stroke. J Neurointerv Surg 2015;7:90-4. 